\title{
A Twenty-First Century Cancer Epidemic Caused by Obesity: The Involvement of Insulin, Diabetes, and Insulin-Like Growth Factors
}

\author{
Rosalyne L. Westley and Felicity E. B. May \\ Northern Institute for Cancer Research, Faculty of Medical Sciences, University of Newcastle upon Tyne, Framlington Place, \\ Newcastle upon Tyne NE2 4HH, UK \\ Correspondence should be addressed to Felicity E. B. May; f.e.b.may@ncl.ac.uk
}

Received 6 July 2012; Accepted 25 March 2013

Academic Editor: Siamak Bidel

Copyright (C) 2013 R. L. Westley and F. E. B. May. This is an open access article distributed under the Creative Commons Attribution License, which permits unrestricted use, distribution, and reproduction in any medium, provided the original work is properly cited.

\begin{abstract}
Obesity has reached epidemic proportions in the developed world. The progression from obesity to diabetes mellitus type 2, via metabolic syndrome, is recognised, and the significant associated increase in the risk of major human cancers acknowledged. We review the molecular basis of the involvement of morbidly high concentrations of endogenous or therapeutic insulin and of insulinlike growth factors in the progression from obesity to diabetes and finally to cancer. Epidemiological and biochemical studies establish the role of insulin and hyperinsulinaemia in cancer risk and progression. Insulin-like growth factors, IGF-1 and IGF-2, secreted by visceral or mammary adipose tissue have significant paracrine and endocrine effects. These effects can be exacerbated by increased steroid hormone production. Structural studies elucidate how each of the three ligands, insulin, IGF-1, and IGF-2, interacts differently with isoforms A and B of the insulin receptor and with type I IGF receptor and explain how these protagonists contribute to diabetes-associated cancer. The above should inform appropriate treatment of cancers that arise in obese individuals and in those with diabetes mellitus type 2. Novel drugs that target the insulin and insulin-like growth factor signal transduction pathways are in clinical trial and should be effective if appropriate biomarker-informed patient stratification is implemented.
\end{abstract}

\section{Introduction}

The twentieth century was notable for the eradication of epidemics that had hitherto obliterated large numbers of mankind. This success was realised through widespread vaccination, the introduction of effective antibiotics, and improved nutrition as a result of the implementation of intensive farming.

Tragically, a new epidemic will guarantee the twenty-first century an ignominious place in the history of medicine. As the early twenty-first century has unfolded, obesity in the developed world has increased dramatically. While many are aware of the association between obesity and diabetes because it is reported widely and discussed in the media, few appreciate the associations between obesity-associated diabetes and cancer.

This review summarises the biochemistry behind the physiological response to increased calorie consumption in the absence of increased calorie expenditure and the pathological progression through metabolic syndrome to diabetes mellitus type 2 . We examine the evidence for the associated increase in malignancies and why and how these malignancies develop and progress. We focus in particular on the roles of insulin, insulin-like growth factors (IGFs), and the influence of steroid hormones. We conclude with a discussion of how knowledge of the biochemical basis of adiposity- and diabetes-induced cancers should inform the development and selection of effective drugs with which to treat cancer patients with a history of adiposity, metabolic syndrome, and diabetes.

\section{The Twenty First Century Epidemic}

2.1. Obesity. Our ancestors have roamed the earth for some four to six million years but obesity has become endemic only within the last thirty years [1]. The World Health Organisation estimates that at present one billion people are 
overweight worldwide and that at least 300 million are obese. The prevalence of obesity continues to rise at an alarming rate: $26.1 \%$ of adults in England are already obese and it is predicted that $60 \%$ of adult men, $50 \%$ of adult women, and $25 \%$ of children will be clinically obese by 2050 [2].

Obesity is defined most commonly using body mass index (BMI) which is calculated as an individual's weight in kilograms divided by their height in meters squared. BMI ranges from overweight (BMI $26-30 \mathrm{~kg} / \mathrm{m}^{2}$ ) through class I (BMI $30-35 \mathrm{~kg} / \mathrm{m}^{2}$ ), class II (BMI $35-40 \mathrm{~kg} / \mathrm{m}^{2}$ ) to class III (BMI $>40 \mathrm{~kg} / \mathrm{m}^{2}$ ) obesity. The merit of BMI as a measure of obesity is a matter of debate for several reasons but mainly because it takes no account of body fat distribution. In addition, BMI does not differentiate between the relative contributions to body mass from fat, muscle, or bone. The BMI measure overestimates fatness in individuals with a high muscle mass and underestimates fatness of those with a low muscle mass.

The cost of obesity in personal and socioeconomic terms is huge. Obesity increases the risk of a number of conditions including heart disease, stroke, osteoarthritis, sleep apnoea, and gout. Moreover, obesity is a powerful risk factor for diabetes mellitus type 2 ; it has been estimated that $80 \%$ of patients with diabetes mellitus type 2 are overweight or obese.

2.2. The Importance of Insulin. The pioneering work of Banting et al. [3] led to the discovery of insulin and identification of its pivotal role in glucose homeostasis and metabolism through stimulation of increased glucose uptake by cells and enhanced conversion of glucose into glycogen for storage.

Insulin has acute metabolic effects, the most important of which is to reduce blood sugar levels. Glucose levels increase following a meal, and these high postprandial blood sugar levels trigger release of insulin from the beta cells of the islets of Langerhans in the pancreas (Figure 1). In insulin-target tissues, insulin stimulates translocation of the high affinity GLUT4 glucose transporters from intracellular storage sites to the plasma membrane. GLUT4 then transports glucose into the muscle and liver cells which lowers blood sugar levels. Higher intracellular glucose concentrations stimulate increased glycolysis, glycogen synthesis and fatty acid synthesis, decreased gluconeogenesis, glycogenolysis, and fatty acid oxidation. In fasted individuals, the pancreas secretes glucagon which mobilises stored energy by stimulation of glycogenolysis in its target tissues and, in extreme situations, by neoglycogenesis from amino acids.

\subsection{Hyperinsulinaemia and the Metabolic Syndrome. Obesity} develops when energy intake exceeds energy expenditure for a prolonged time. In response, the body lays down triglycerides as an energy store in adipose tissue. Excess adipose tissue releases abundant quantities of nonesterified fatty acids which reach supraphysiological concentrations in the serum. The high serum concentrations of these fatty acids force liver, muscle, and other tissues to prioritise oxidation of fats for energy. As a result, the liver and muscle cells do not absorb, store, and metabolise glucose in response to insulin stimuli (Figure 1). Sustained calorie intake results in continuously high serum glucose concentrations, chronic hyperglycaemia, in the majority of obese individuals. Absence of a reaction to insulin secreted by the pancreas in response to the high blood glucose levels means that the obese individual manifests resistance to insulin. The development of this insulin resistance alongside obesity has been classified as metabolic syndrome (Figure 2). When the fat storage capacity of adipocytes is exceeded in obese individuals, skeletal muscle, liver and pancreatic $\beta$-cells are induced to absorb free fatty acids from serum and to store them as excess fat which drives further fatty acid oxidation in these cells $[4,5]$. Resultant intracellular metabolites of triglyceride metabolism in the skeletal muscle and liver cells cause additional insulin resistance.

The metabolic syndrome was identified first in 1988 by Reaven when he noticed that certain individuals had a collection of risk factors for cardiovascular disease, namely, dyslipidaemia, hypertension, and hyperglycaemia [6]. Reaven termed this collection of risk factors Syndrome X. Subsequently called metabolic syndrome, it was defined in 2001 by the Adult Treatment Panel III [7]. They advised that for a diagnosis of metabolic syndrome, an individual should have above a threshold level of three of the following five characteristics: waist circumference, serum triglyceride concentration, serum high-density lipoprotein (HDL) concentration, blood pressure, and fasting serum glucose level (Table 1).

\subsection{Diabetes Mellitus Type 2 Arises in Obese Individuals.} The metabolic syndrome is a biochemical state that is often present in the progression from obesity to diabetes. The combination of reduced glucose metabolism and insulinresistance leads to constant hyperglycaemia in the fasting as well as in the postprandial state. The pancreas secretes increasingly larger amounts of insulin in an attempt to reduce the high circulating levels of glucose which results in higher than normal serum levels of insulin, hyperinsulinaemia. With time, this excessive insulin production takes its toll on the pancreas and there is a gradual decline in insulin production (Figure 2). Hyperglycaemia in obesity with the resultant continuous insulin production induces metabolic stress in pancreatic $\beta$-cell mitochondria in the islets of Langerhans. This stress results in the production of reactive oxygen species, which damage the mitochondria. As a consequence, there is decreased $\beta$-cell mitochondrial ATP production and a reduction in the amount of insulin produced. As well as $\beta$-cell dysfunction, there is a loss in $\beta$-cell mass. Eventually, the failing mitochondria are no longer able to support the cell cycle, and apoptosis is induced [8]. Chronic hyperglycemia and hyperlipidemia harm directly pancreatic $\beta$-cells by two processes referred to as glucotoxicity and lipotoxicity, respectively. When the $\beta$-cells are exposed continuously to elevated levels of glucose and fatty acids, these processes lead to an inhibition of glucose-induced insulin secretion, impairment of insulin gene expression, and $\beta$-cell apoptosis $[9,10]$. Ectopic storage of triglycerides in pancreatic $\beta$-cells contributes also to their dysfunction and induces apoptosis $[4,5]$.

In the end stages of insulin resistance, when an individual has developed insulin insufficiency, their inability to control 


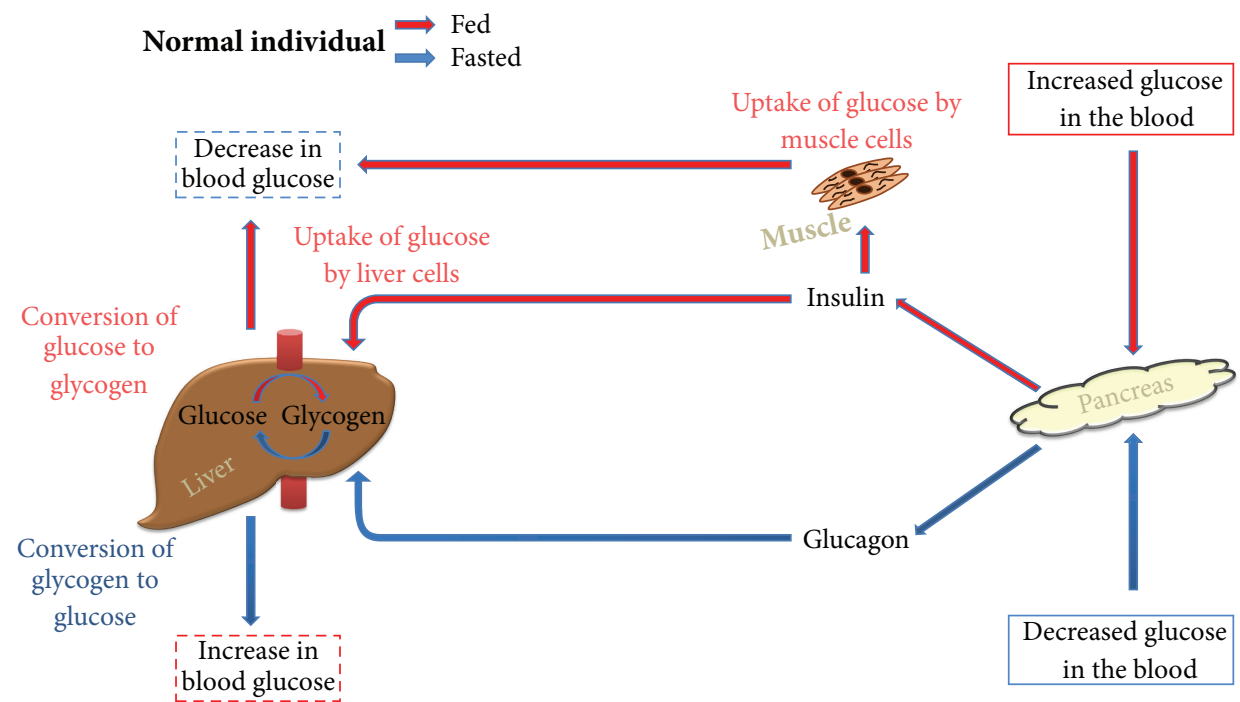

(a)

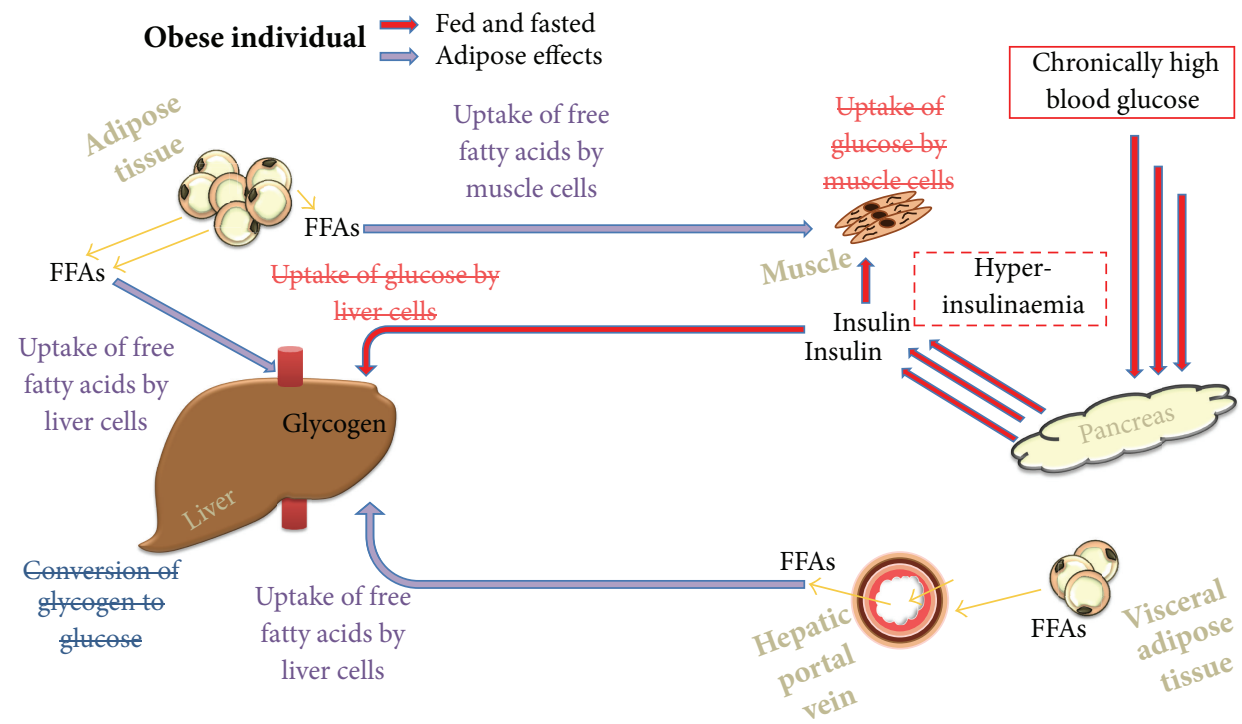

(b)

FiguRE 1: Insulin homeostasis in normal and obese individuals. In normal individuals, the postprandial increase in blood glucose concentration stimulates the beta cells in the Islets of Langerhans of the pancreas to release insulin (a). Insulin stimulates the uptake of glucose by liver and muscle cells and conversion of glucose to the energy store glycogen primarily in the liver and in skeletal muscle. The decrease in glucose levels in the blood of fasted individuals stimulates the alpha cells of the Islets of Langerhans in the pancreas to release glucagon. Glucagon stimulates the conversion of glycogen to glucose by glycogenolysis. In obese individuals, adipocytes in adipose tissue release nonesterified or free fatty acids (FFAs) energy into the circulation (b). The hepatic portal vein provides a direct conduit of free fatty acids from visceral adipose tissue to the liver. The high serum concentrations of nonesterified fatty acids force tissues to prioritise their oxidation as an energy source which prevents glucose uptake. Hence, the obese individual is resistant to the high levels of insulin secreted after a meal and blood glucose levels remain chronically high regardless of the fed state of the obese individual. The pancreas continues to secrete insulin in response to the high blood glucose levels. The obese individual manifests hyperglycaemia and hyperinsulinaemia.

normal biochemical glucose levels becomes irreversible. The obese individual has now developed chronic diabetes mellitus type 2 known formerly as noninsulin-dependent diabetes or adult-onset diabetes.

Diabetes means "to pass through" and refers to the symptoms of polydypsia and polyuria which are common symptoms in diabetic patients. More water is passed in the urine due to the high concentration of glucose in the urine. Patients become dehydrated and consequently drink more. The word mellitus means honey sweet and refers to the sweetness of the urine that results from the presence of glucose. Diabetes mellitus is a chronic disease of uncontrolled hyperglycaemia, which is secondary to defects in insulin secretion, the action of insulin, or both. For a diagnosis 


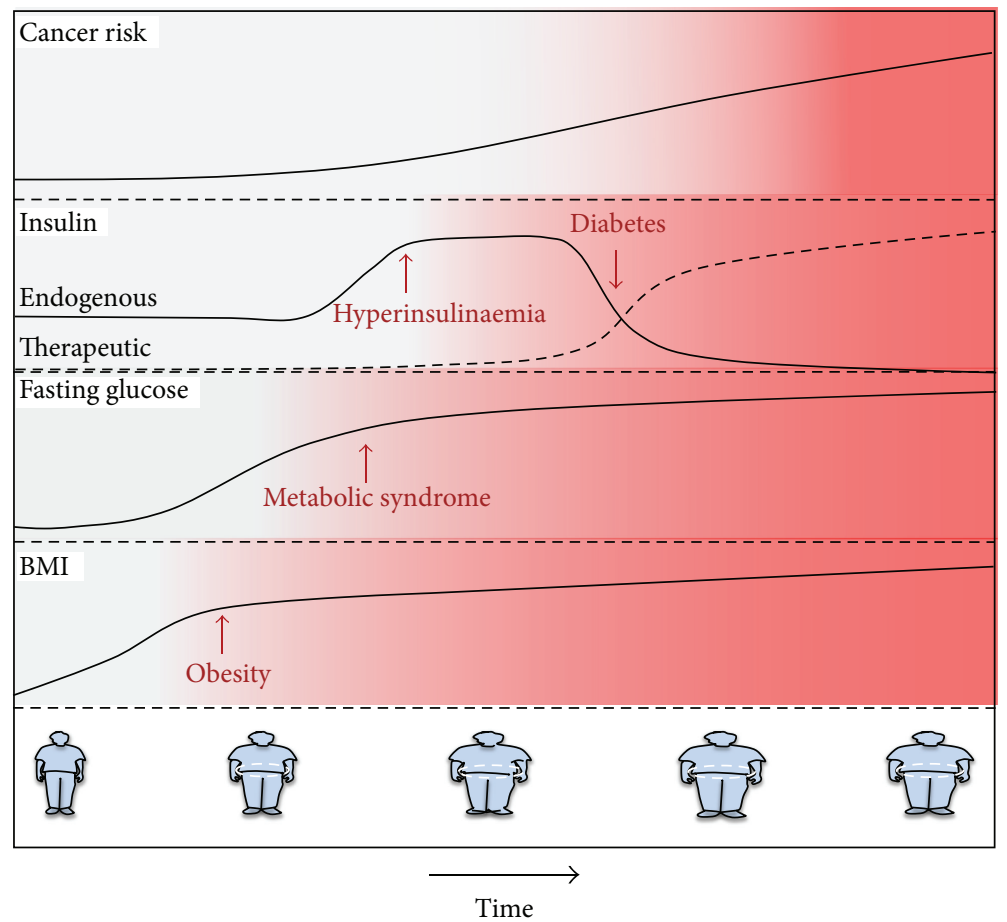

Figure 2: Progression from obesity through metabolic syndrome to diabetes and to increased cancer risk. As an individual's weight increases, they progress from having a normal weight to being overweight and with time become obese. There is a concomitant increase in high levels of circulating nonesterified fatty acids accompanied by high fasting serum glucose concentrations or hyperglycaemia. Many of these obese individuals exhibit a sufficient number of the defining symptoms to be classified as having metabolic syndrome. The high fasting serum glucose and development of insulin resistance induce chronic secretion of insulin from the pancreas, and the individual manifests hyperinsulinaemia. Eventually, the excessive demands on the pancreas lead to failure of insulin secretion, and diabetes is established. Diabetic therapies stimulate insulin secretion or administer exogenous insulin. Insulin concentrations must reach supraphysiological levels to be effective because of the chronic insulin resistance caused by the continued high concentrations of nonesterified fatty acids released from adipocytes. The combination of hyperinsulinaemia and endocrine or paracrine stimuli from adipose tissue increases the risk that these individuals will develop certain types of cancers.

TABLE 1: Threshold levels to define metabolic syndrome [100].

\begin{tabular}{lc}
\hline Characteristic & Threshold level \\
\hline Abdominal obesity & \\
$\quad$ Men & $>102 \mathrm{~cm}(40 \text { inches })^{\$}$ \\
Women & $>88 \mathrm{~cm}$ (35 inches) \\
Serum HDL & \\
$\quad$ Men & $>40 \mathrm{mg} / \mathrm{dL}$ \\
Women & $>50 \mathrm{mg} / \mathrm{dL}$ \\
Triglycerides & $\geq 150 \mathrm{mg} / \mathrm{dL}$ \\
Blood pressure & $\geq 130 / 85 \mathrm{~mm} \mathrm{Hg}$ \\
Fasting glucose & $\geq 110 \mathrm{mg} / \mathrm{dL}$ \\
\hline
\end{tabular}

\$Abdominal obesity is given as waist circumference.

of diabetes mellitus in a patient, confirmation of chronic hyperglycaemia is required [11, 12]. Diabetes mellitus can be classified into type 1, type 2, gestational, and other specific types. Diabetes mellitus type 1 develops as a result of autoimmune or idiopathic destruction of the beta cells of the pancreas. It is diagnosed most commonly in the young. Diabetes mellitus type 2 develops due to metabolic stress-induced beta cell dysfunction or apoptosis as described above. Gestational diabetes is a diagnosis of any glucose intolerance detected in pregnancy. The last rare category is caused by other diseases or specific mutations [12].

Diabetes mellitus type 2 is the most common cause of diabetes mellitus and accounts for $90 \%$ of cases. The incidence has risen and continues to rise at a rapid rate. It is estimated that there will be well over 430 million people with diabetes worldwide by 2030 compared with 30 million in 1985 and 285 million in 2010.

The World Health Organisation has reported that diabetes has become a global epidemic. This review focuses exclusively on diabetes mellitus type 2 , and this type of diabetes will be referred to simply as diabetes for most of the remainder of the review.

2.5. Treatment of Diabetes Mellitus Type 2. An unfortunate consequence of diabetes treatment, which results in part from the insulin resistance of patients, is chronic or transient hyperinsulinaemia (Figure 2). Treatment of diabetes is required to control symptoms and to prevent or slow progression and consequent organ damage. The overriding aim is to prevent or reduce hyperglycaemia. Diabetes treatments can be divided into those that increase endogenous 
insulin secretion, those that decrease insulin resistance, those that decrease glucose uptake from the intestine, and simple administration of exogenous insulin.

Secretagogues are a class of drugs which act to increase endogenous insulin production from the pancreatic beta cells. They include sulphonylureas and meglitinides. Patients treated with secretagogues are at risk of hypoglycaemia due to overproduction of insulin [13].

Biguanides and thiazolidinediones increase insulin sensitivity in peripheral cells. The exact mechanism of action of the thiazolidinediones is unknown but they increase insulin sensitivity through direct and indirect effects on muscle and adipose tissue [14]. Metformin is a biguanide and is the firstline therapy for the treatment of diabetes mellitus type 2 . The therapeutic effects of metformin are understood only partially. Metformin activates adenosine monophosphate(AMP-) activated protein kinase (AMPK), which leads to suppression of gluconeogenesis in the liver and increased peripheral uptake of glucose by skeletal and adipose tissues. It reduces glucose absorption from the intestine. In addition, metformin increases the affinity of insulin for the insulin receptor, which reduces insulin resistance [14].

Acarbose is an alpha glucosidase inhibitor which acts in the intestinal brush border to prevent the breakdown of complex carbohydrates to glucose and hence the uptake of glucose [13]. The incretins and the inhibitors of their inactivation are a newer group of antihyperglycemic drugs that slow gastric emptying, increase satiety, and decrease postprandial glucagon secretion [15].

When oral hyperglycaemic treatments are contraindicated or cease to be effective in patients with diabetes mellitus type 2, exogenous insulin is given by intramuscular injection. Relatively large doses of exogenous insulin are required to overcome the insulin resistance of the peripheral cells [16]. As a result, although diabetes in these patients was caused by insulin resistance and failure of insulin production as a direct result of hyperinsulinaemia, treatment with exogenous insulin causes necessarily hyperinsulinaemia [16].

2.6. Obesity- and Diabetes-Associated Cancer Risk. An estimated 17,294 cases, equivalent to $5.5 \%$ of new cancer cases, occurred in obese individuals in 2010 in the UK. The numbers are similar for the whole of Europe; 3.2\% of new cancers in men and $8.6 \%$ of new cancers in women are estimated to be attributed to obesity [2]. In the United States, $4 \%$ of new cancers in men, 34,000 cancers, and $7 \%$ of new cancers in women, 50,500 cancers, were due to obesity in 2007 (Figure 2) [17]. Direct evidence of the causative impact of obesity on cancer incidence derives from the demonstration that for obese individuals the risk is reduced by successful gastric bypass surgery [18].

The increased risk in the cancers most closely associated with obesity in men is 1.52 for every additional $5 \mathrm{~kg} / \mathrm{m}^{2}$ for oesophageal, 1.33 for thyroid, and 1.24 for colon and renal. For women, the increased risk for every additional $5 \mathrm{~kg} / \mathrm{m}^{2}$ is 1.59 for endometrial, 1.59 for gall bladder, 1.51 for oesophageal, and 1.34 for renal cancer (Table 2). Associations are found for a number of other cancers including pancreas and breast and colon cancer in women [19]. These cancer types account for $65 \%$ of all new cancers related to obesity $[2,20,21]$. The percentage of cases attributed to obesity is as high as $40 \%$ for oesophageal and endometrial cancers.

Diabetes is associated with increased risk of certain types of cancer [22-24] (Figure 2). The increased relative risk for diabetic individuals compared to nondiabetics is 2.5 -fold for liver, 2.22-fold for endometrial cancer, 1.5-2.0-fold for pancreatic cancer and non-Hodgkin's lymphoma, and 1.21.5-fold for biliary tract, renal, bladder, breast and bladder cancer, and oesophageal adenocarcinoma (Table 2). There is an increased risk in men with diabetes for oesophageal adenocarcinoma but a reduced risk for oesophageal squamous cell carcinoma [25]. There is no or inconclusive evidence for other cancers apart from prostate cancer for which there is a reduced risk [26].

Although the increased risks associated with obesity and diabetes may appear relatively small for some cancers, they translate into a significant number of new cancer cases. Across 30 European countries, obesity accounts for more than 124,000 new cancers per year [27], all of which are potentially avoidable.

\subsection{Obesity- and Diabetes-Associated Cancer Progression.} Intuitively, given its role as a risk factor and the putative mechanisms involved, obesity might be expected to be associated with worse prognosis in cancer patients. The evidence from the majority of studies that have addressed this issue is persuasive. In pancreatic cancer, it has been shown that increased intra-abdominal fat is associated with shorter survival [28].

For colon cancer, some studies have found no effect but others have found obesity to be an independent prognostic factor associated with a higher mortality, especially in men [29-31]. For endometrial cancer, $90 \%$ of women with the most common form of endometrial cancer, type I, are obese [32], and higher BMI is associated with increased mortality [33]. For epithelial ovarian cancer, a meta-analysis of observational studies concluded that obesity is associated with higher mortality [34].

The strongest evidence that obesity is associated with a poor prognosis is for breast cancer [35]. In a 2002 overview, the majority of studies found obesity was associated with increased risk of recurrence and death [36]. A recent large Danish study found that tumours in obese women were larger and were more likely to be of a high histological grade and to have metastasised to lymph nodes [37]. Obese women had a higher risk of distant metastases and death than nonobese women. There is some encouragement that prognosis can be improved by increased physical activity $[38,39]$.

2.8. Types and Roles of Adipose Tissue. The question arises, why do individuals who are obese and those who progress through metabolic syndrome to develop diabetes have an increased cancer incidence and worse prognosis? To answer this question, we must consider the biochemical consequences of obesity. The primary roles of adipose tissue have long been considered to be the storage of energy, thermal 
TABLE 2: Effects of obesity and diabetes mellitus type 2 on risk of different types of cancer.

\begin{tabular}{|c|c|c|c|}
\hline \multirow{2}{*}{ Type of cancer } & \multicolumn{2}{|c|}{ Obesity } & \multirow{2}{*}{$\begin{array}{c}\text { Diabetes mellitus type } 2 \\
\text { Men and women }\end{array}$} \\
\hline & Men & Women & \\
\hline Bladder & None & None & $1.37(1.04-1.8)[301]$ \\
\hline Breast & - & - & $1.2(1.11-1.3)[302]$ \\
\hline Premenopausal & - & $0.92(0.88-0.97)$ & Not available \\
\hline Postmenopausal & - & $1.12(1.08-1.16)$ & Not available \\
\hline Colorectal & - & - & $1.38(1.26-1.51)[303]$ \\
\hline Colon & $1.24(1.20-1.28)$ & $1.09(1.05-1.13)$ & Not available \\
\hline Rectum & $1.09(1.06-1.12)$ & None & Not available \\
\hline Endometrium & - & $1.59(1.50-1.68)$ & $2.22(1.80-2.74)[304]$ \\
\hline Gall bladder/biliary tract & None & $1.59(1.02-2.47)$ & $1.43(1.18-1.72)[305]$ \\
\hline Liver & None & None & $2.50(1.80-3.50)[306]$ \\
\hline Leukaemia & $1.08(1.02-1.14)$ & $1.17(1.04-1.32)$ & Not available \\
\hline Malignant melanoma & $1.17(1.05-1.30)$ & None & Not available \\
\hline Multiple myeloma & $1.11(1.05-1.18)$ & $1.11(1.07-1.15)$ & Not available \\
\hline Non-Hodgkin's lymphoma & $1.06(1.03-1.09)$ & $1.07(1.00-1.14)$ & $1.79(1.3-2.47)[307]$ \\
\hline Oesophageal adenocarcinoma & $1.52(1.33-1.74)$ & $1.51(1.31-1.74)$ & $1.3(1.12-1.50)[25]$ \\
\hline Pancreas & None & $1.12(1.02-1.22)$ & $1.94(1.5-2.4)[308]$ \\
\hline Renal & $1.24(1.15-1.34)$ & $1.34(1.25-1.43)$ & $1.42(1.06-1.91)$ [309] \\
\hline Thyroid & $1.33(1.04-1.70)$ & $1.14(1.06-1.23)$ & Not available \\
\hline
\end{tabular}

The increased relative risks and the $95 \%$ confidence limits, in brackets, are given. For obesity, the relative risk ratio is per $5 \mathrm{~kg} / \mathrm{m}^{2}$ increase in weight [19].

regulation, and mechanical protection. More recently, the role of adipose tissue as an endocrine or metabolic organ has been recognised. This section examines the different types of adipose tissue and their impacts on paracrine and endocrine levels of insulin, IGFs, and steroid hormones.

Adipose tissue is a specialized connective tissue made up of different cell types, including preadipocytes, adipocytes, fibroblasts, macrophages, and blood vessels [40], of which the majority are adipocytes. Approximately $15 \%$ of the body mass of a male of average weight, $70 \mathrm{~kg}$ or 11 stone, is adipose tissue. Adipose tissue is distributed throughout the body. Its percentage of body mass and pattern of distribution in the body are influenced by numerous factors including the sex, age, diet, physical activity level, and genotype of an individual [41]. In the body, lipids, commonly referred to as fat, are present usually in the form of triglycerides and make up $80 \%$ of adipose tissue. Although stored largely in adipose tissue, lipids are found in other tissues especially in pathological conditions [41]. Triglycerides are present also in the plasma. The body adapts to the accumulation of increased levels of triglycerides by hyperplasia and hypertrophy of its adipose tissue [42].

Adipose tissue can be defined by its biochemical role [41]. Brown adipose tissue is highly metabolic and utilises a large amount of glucose. Accordingly, the majority of the adipocyte cell volume is occupied by large spherical mitochondria [40], and it is this feature which gives rise to the brown colour. Brown adipose tissue produces heat through a specialised metabolic pathway which mobilises stored energy by breaking down triglycerides to generate heat energy. Brown adipose tissue is abundant in small animals and newborns and has been shown to have an important role in thermal homeostasis in adults.

White adipose tissue is a lipid-rich tissue that has been considered traditionally as an energy store of excess triglycerides that will be mobilised to release fatty acids when the body requires more fuel. The discovery of its ability to function as an endocrine and paracrine organ indicates that the metabolic role of white adipose tissue is more complex than appreciated previously [43]. Unlike brown adipocytes, white adipocytes are spherical cells that contain a single lipid droplet which accounts for $90 \%$ of the cell volume [40].

The mammary gland contains specialized adipose tissue that is important in epithelial cell growth and milk production while bone marrow adipose tissue is known to have a role in osteogenesis and haematopoiesis [41].

Alternatively, adipose tissue can be classified by its anatomical position which dichotomises it into subcutaneous and internal or visceral adipose tissues. Subcutaneous adipose tissue is the adipose tissue that accumulates beneath the skin. The term "viscera" refers to "organs in the cavity of the body" [41]. Internal or visceral adipose tissue encases these body organs.

2.9. Pathological Effects of Different Types of Adipose Tissue. There is increasing evidence that the anatomical position of adipose tissue determines the effects that the adipose tissue has on an individual and predicts the associated morbidity from cardiovascular disease and diabetes and eventually cancer [44]. This realisation has led to revised measures of obesity in addition to BMI. Preferred methods acknowledge 
the relative contributions in obese individuals of different anatomical types of adipose tissue.

Waist-to-hip ratio (WHR) is used widely to measure regional adipose tissue distribution because a relatively large waist measurement indicates that an individual has an excess of visceral adipose tissue. WHR has been shown to be a better predictor of subsequent cardiovascular disease and diabetes than BMI or skin fold thickness [45]. An increasing number of epidemiological studies use WHR or waist circumference as more useful measures of obesity [46]. It must be remembered that waist circumference will not be due exclusively to visceral adipose tissue but also to abdominal subcutaneous adipose tissue.

Visceral adipose tissue has been shown to have a greater influence on the development of hypertension and cardiovascular disease, and of insulin resistance and diabetes, than subcutaneous adipose tissue [44, 45]. A study on insulin sensitivity in obese adults showed that when the data was adjusted for BMI and visceral adipose tissue, subcutaneous adipose tissue was protective against development of insulin resistance. When the data was adjusted for BMI and subcutaneous adipose tissue, increased visceral adipose tissue was associated with an increase in insulin resistance. The implication is that visceral adipose tissue promotes insulin resistance but subcutaneous adipose tissue does not [47].

Multiple reasons have been postulated to explain the causal effects of visceral adipose tissue on the development of insulin resistance and cancer. When abdominal visceral adipose tissue, which is positioned around the liver, enters a hyperlipolytic state and releases free fatty acids, they travel through the portal vein to the liver (Figure 1(b)). The resultant high levels of free fatty acids in the liver impair hepatic metabolic function which leads to insulin resistance, hyperinsulinaemia, and hypertriglyceridaemia [48] which in turn contribute to the development of the metabolic syndrome. Molecules released by other adipose tissue do not travel directly to the liver. Inflammatory cells are present in abundance in visceral adipose tissue and the secretion of inflammatory mediators into the body creates a chronic inflammatory state which is thought to generate a protumourigenic environment [49].

The distribution of adipose tissue may explain partially the variance in the development of the metabolic syndrome and different types of cancer between men and women and between different age groups. Visceral adipose tissue increases with age and weight in both sexes but the progression is more complicated in females. Overall, females have a greater percentage body mass of adipose tissue than males but in premenopausal women, adipose tissue is predominantly subcutaneous; this is true in obese and in lean individuals [45]. In men, the majority of adipose tissue is abdominal visceral adipose tissue. This predominance of visceral adipose tissue increases with age in a linear fashion. Men have been shown to have $48 \%$ more adipose tissue around the waist than premenopausal women, of which the majority is visceral adipose tissue. There is evidence of this sexual dimorphism in fat patterning even in prepubertal children but the difference is most marked in young adolescents [50]. The distribution of adipose tissue changes in postmenopausal women, with an accumulation of abdominal adipose tissue. It has been found that postmenopausal women have $49 \%$ more visceral adipose tissue than premenopausal women [51].

2.10. Endocrine Role of Adipose Tissue. The role of adipose tissue as an endocrine tissue is relevant to the development of the metabolic syndrome, insulin resistance, diabetes, and cancer. Adipose tissue has been shown to produce adipokines, including leptin and adiponectin. Leptin is involved in the maintenance of normal body weight. Leptin binds the leptin receptor in the hypothalamus $[52,53]$ which results in appetite suppression and increased energy expenditure. Obese individuals become leptin resistant, and the increased production of leptin in response to raised food consumption does not stimulate reduced energy intake or increased energy expenditure [53,54]. Elevated levels of circulating leptin are associated with an increased risk of colorectal [55], endometrial [56], and in some studies, breast cancer [57]. Increased risk is thought to occur through direct activation of leptin receptors to induce cell proliferation and reduce apoptosis $[58,59]$. It has been reported that leptin can influence IGF signal transduction [60] which could modulate the effects of IGFs on cancer risk and progression that are described below.

Adiponectin acts to sensitive cells to insulin via interaction with the AdipoR1 and AdipoR2 receptors. Activation of the receptors has also anti-inflammatory effects and increases fatty acid oxidation which prevents insulin resistance [60]. Whilst the factors that control adiponectin levels are not defined clearly, levels are lower in obese individuals and higher levels can be achieved through weight loss [61]. Low levels of adiponectin are associated with an increased risk of breast, endometrial, prostate, colorectal, and renal carcinomas [62-65].

Adipose tissue produces also tumour necrosis factor- $\alpha$, interleukin-6, angiotensinogen, lipoprotein lipase, plasminogen activator inhibitor-1, monocytic chemoattractant protein, oestrogens, aromatase, IGFBP-3, IGF-1, and IGF-2 [45]. All of these molecules may have a role in the complex development of cancer in obesity. In this review, we concentrate on the production of IGF-1, IGF-2, IGFBP-3, oestrogens, $17 \beta$ hydroxysteroid dehydrogenase, and aromatase.

2.11. Adiposity and Insulin-Like Growth Factors. Numerous studies have shown that adipocytes produce IGF-1 and IGF-2 (Figure 3). This production was demonstrated first in animal studies. For instance, both IGF-1 and IGF-2 mRNAs are synthesised in rat and porcine adipose tissues [66, 67]. Plasma IGF-2, but not IGF-1 or IGFBP-3, was associated positively with back fat depth [68]. Free and total IGF-1 concentrations measured in serum by enzyme-linked immunosorbent assays were increased in patients with visceral obesity compared with nonobese individuals [69]. In vitro models in which human adipocytes were cultured in chemically defined culture conditions, demonstrated IGF-1 production from adipocytes and preadipocytes; production was tenfold higher from adipocytes than from preadipocytes. 


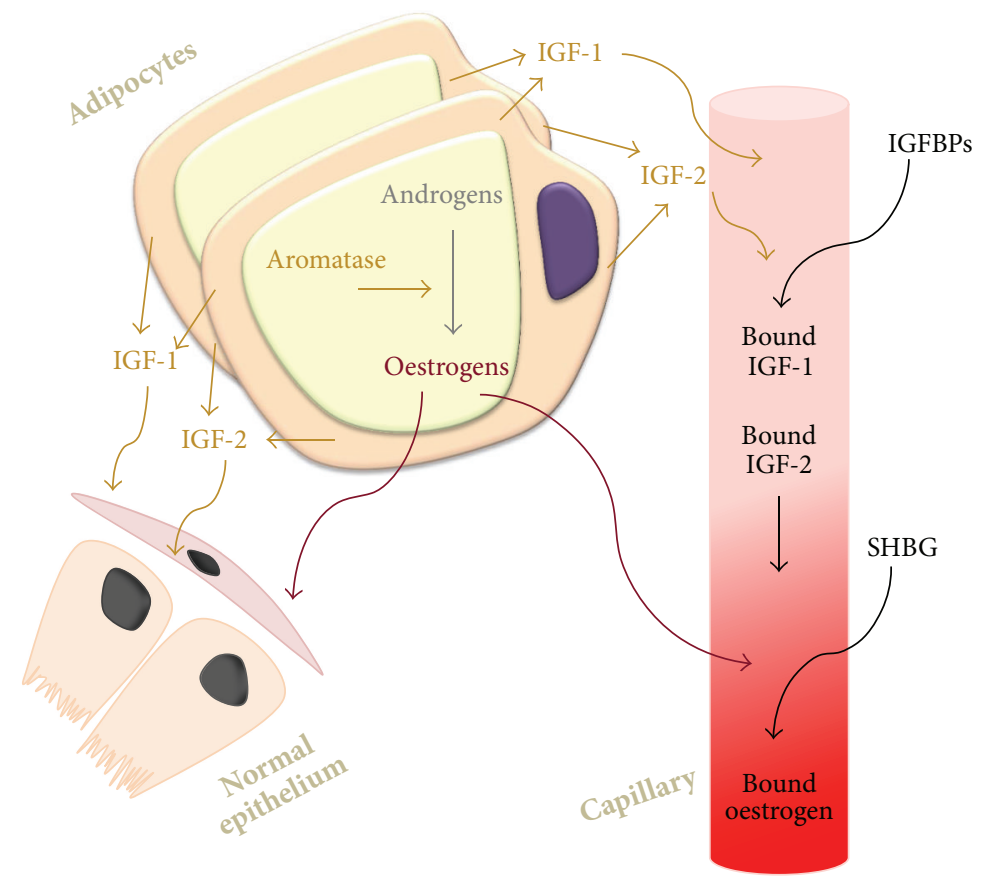

FIGURE 3: Adipose tissue as an endocrine organ. Adipocytes express enzymes involved in steroid metabolism, notably $17 \beta$-hydroxysteroid dehydrogenase and aromatase which converts androgens into oestrogens. There is a resultant increase in paracrine concentrations of oestrogens and a significant increase in the concentration of circulating oestrogens in obese men and in obese postmenopausal women compared to nonobese individuals. In the blood, oestrogen is complexed with sex hormone-binding globulin (SHBG). Adipocytes secrete several protein hormones including IGF-1 and IGF-2. IGF-1 and IGF-2 enter the blood stream where they can be bound by insulin-like binding proteins (IGFBPs). Local concentrations of IGF-1 and IGF-2 may be particularly high and are unlikely to be reduced by feedback mechanisms.

Some studies have shown that there are lower serum IGF-1 concentrations in obesity possibly due to the negative feedback that the initial rise in serum IGF-1 has on the production of growth hormone $(\mathrm{GH})$ by the pituitary gland [70]. A decrease in free $\mathrm{GH}$ would reduce stimulation of hepatocyte production of IGF-1. Although the total levels of circulating free IGF-1 in the body may be decreased, it is probable that IGF-1 levels in the adipose tissue remain higher than normal as a result of the increased production secondary to adipocyte hyperplasia and hypertrophy. These local concentrations of IGF-1 may exert significant effects on surrounding cells and adjacent tissues via paracrine effects rather than on distant tissue via endocrine mechanisms (Figure 3). Such local effects could contribute to the observed greater contribution of visceral adipose tissue to cancer risk than overall adipose tissue.

\subsection{Adiposity and Steroid Hormone Production. Adipose} tissue contains enzymes that are involved in steroid biosynthesis and is therefore a source of extragonadal oestrogens in men and women (Figure 3). Adipocytes express $17 \beta$ hydroxysteroid dehydrogenase that converts androstenedione to the more active androgen testosterone and converts oestrone to oestradiol (Figure 4). Aromatase, an enzyme of the cytochrome P450 family, is encoded by the CYP19 gene [71] and catalyses the final step of oestrogen synthesis by aromatisation of androgens to oestrogens, in particular androstenedione to oestrone and testosterone to oestradiol.
Increased adiposity leads therefore to higher local tissue concentrations of oestrone and oestradiol. There is some evidence that inflammation associated with adiposity increases aromatase activity [72].

In premenopausal women, aromatase is expressed in ovarian granulosa cells, placental syncytiotrophoblast cells, brain, breast cancer, skin fibroblasts, bone osteoblasts, chondrocytes, and adipose stromal fibroblasts [73]. Peripheral aromatisation is particularly relevant in postmenopausal women following cessation of androgen and oestrogen synthesis in the ovaries. In these women, circulating oestrogens are derived principally by peripheral aromatisation of androgens produced in the zona reticularis of the adrenal cortex.

A detailed study of the relationship between BMI and serum oestrogen levels in postmenopausal women showed an increase in all measures of oestrogen but a most marked increase in free oestrogen with increasing BMI. Serum concentrations of the most potent oestrogen, oestradiol, were twofold higher in the upper quartile compared to in the lower quartile, $57.9 \mathrm{pM}$ compared to $29.9 \mathrm{pM}$, and serum oestrone concentrations were 1.5 -fold higher, $133 \mathrm{pM}$ compared to $89 \mathrm{pM}$. The level of oestrogens increases in obese women due to the greater amount of adipose tissue and hence aromatase activity. Obesity causes also a reduction in sex hormonebinding globulins (Figure 3 ) and hence there is more free circulating oestrogen in obese individuals [74]. Free serum oestradiol was 2.5-fold higher in the upper quartile compared to in the lower quartile, $29 \mathrm{pM}$ compared to $12 \mathrm{pM}$. These free 


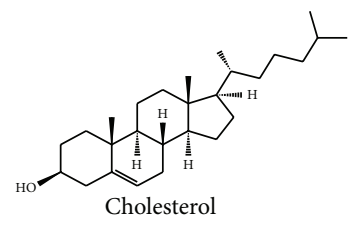

Cholesterol desmolase

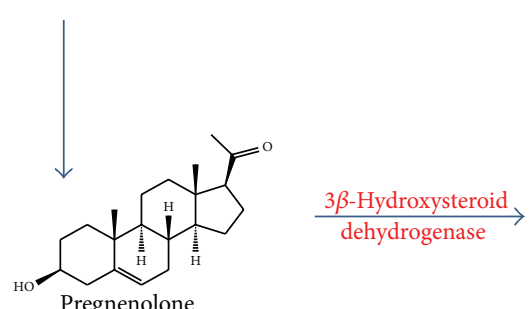

$17 \alpha$-Hydroxylase

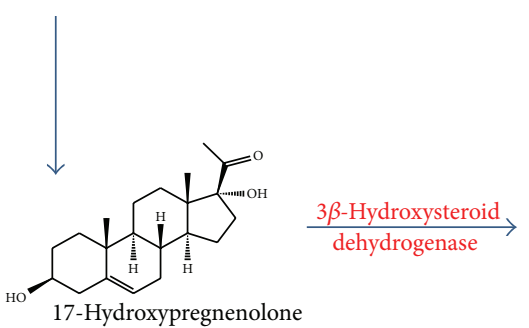

17,20-Lyase
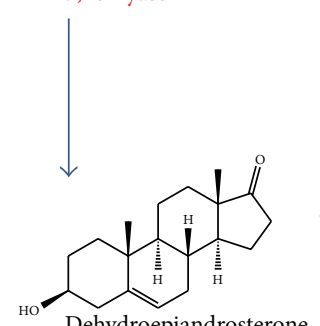

Dehydroepiandrosterone

$17 \beta$-Hydroxysteroid

dehydrogenase

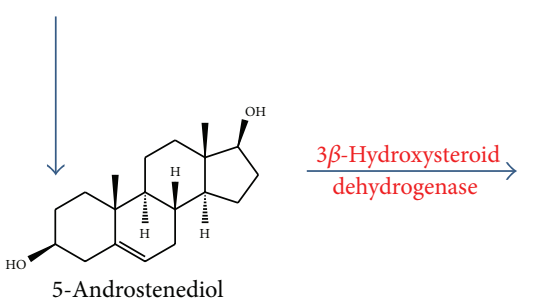

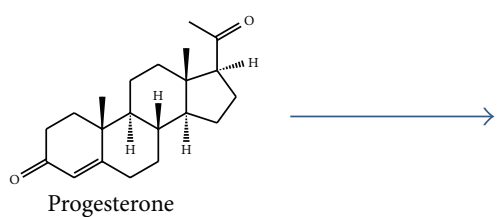

$17 \alpha$-Hydroxylase

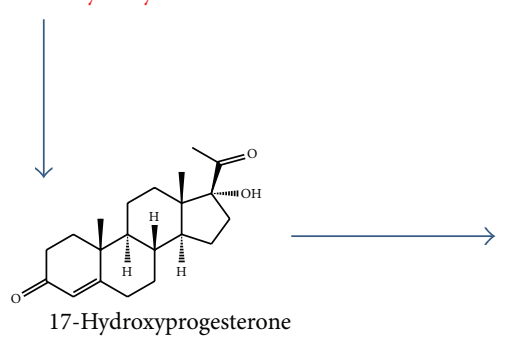

17,20-Lyase

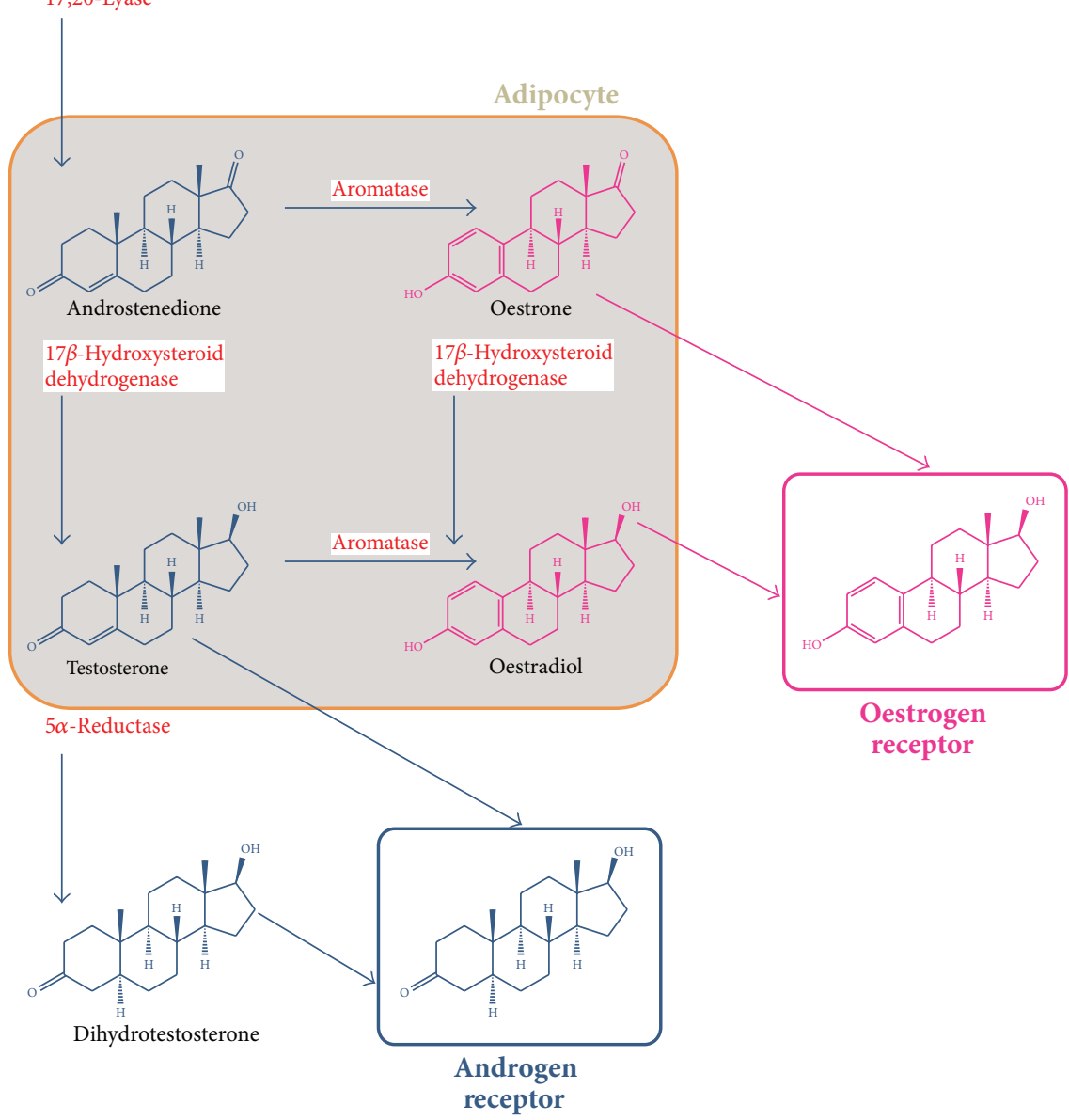

(a)

FIGURE 4: Continued. 


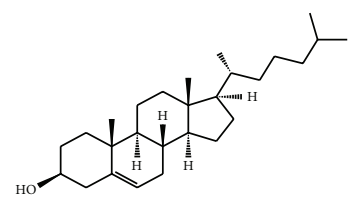

\section{Cholesterol}
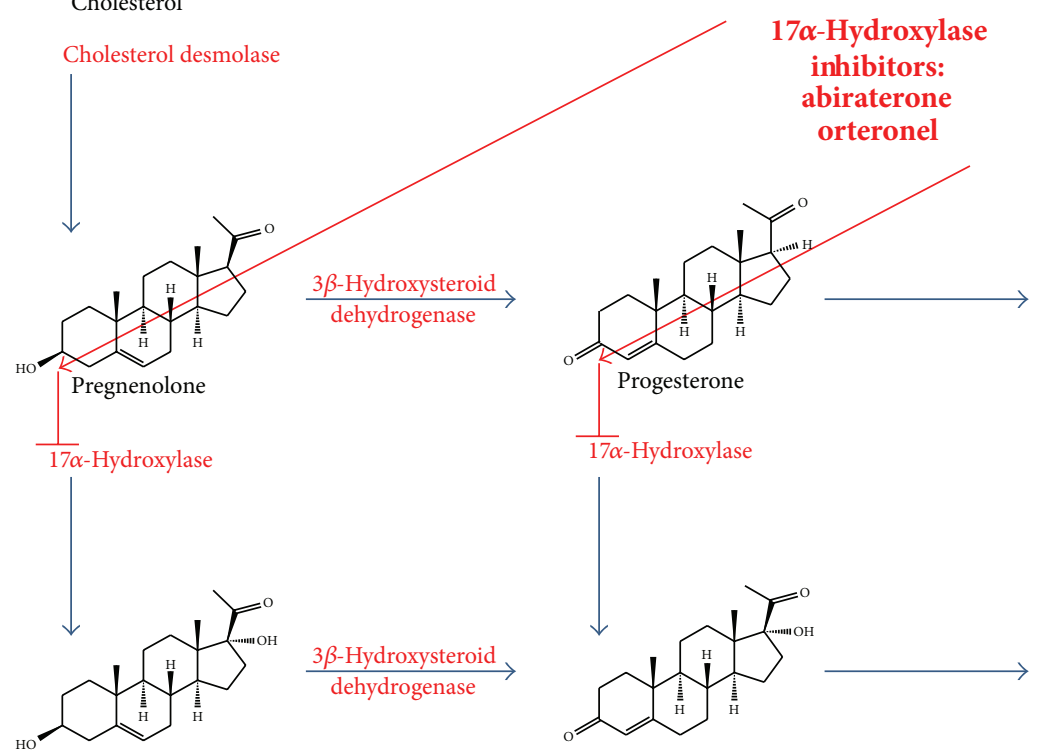

17-Hydroxypregnenolone

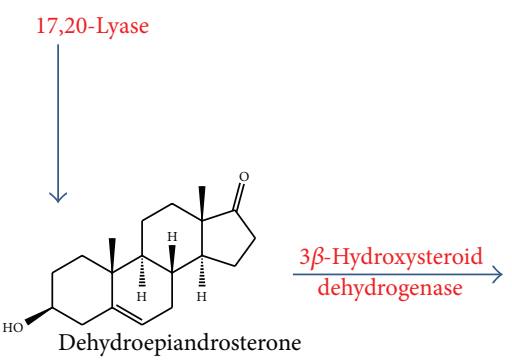

17 $\beta$-Hydroxysteroid dehydrogenase
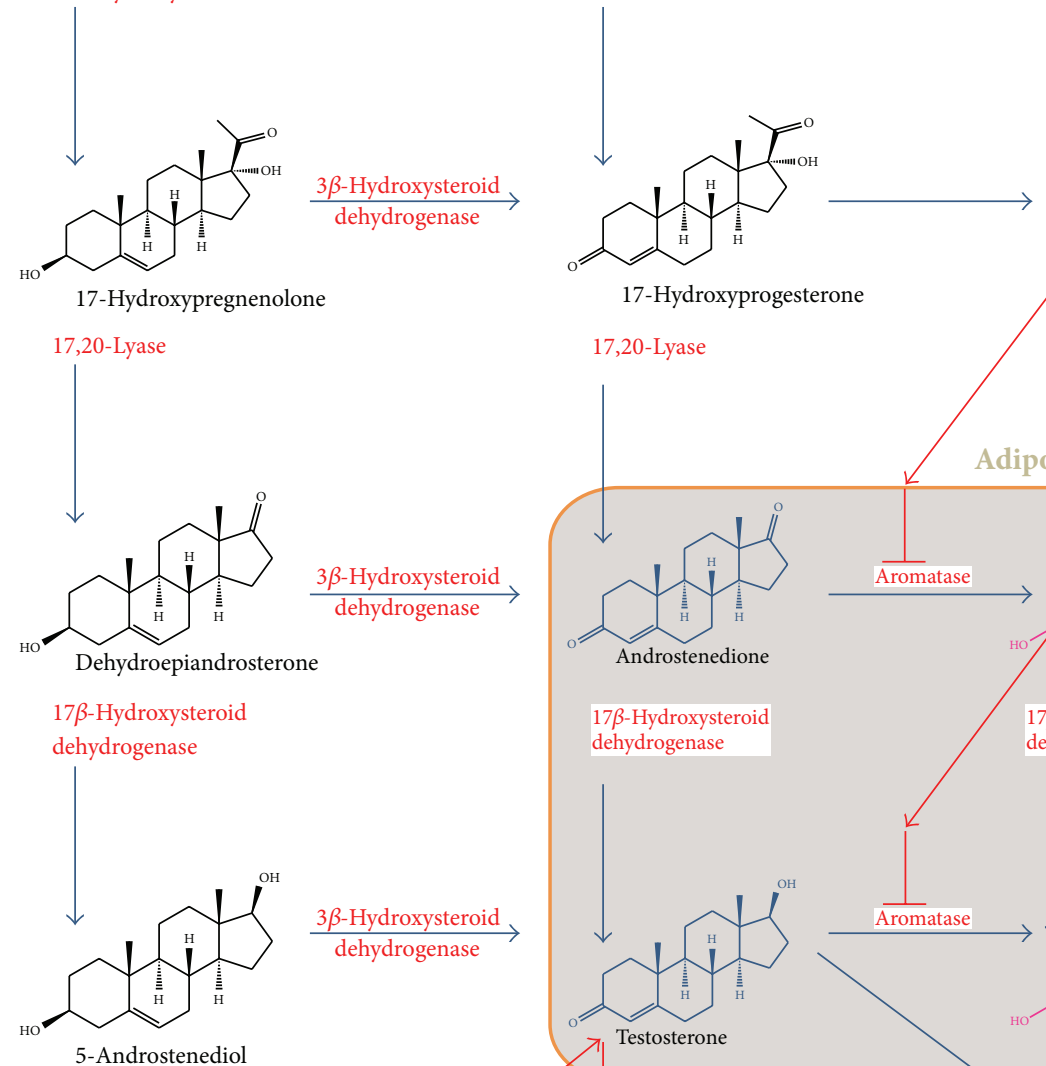

17-Hydroxyprogesterone

17,20-Lyase

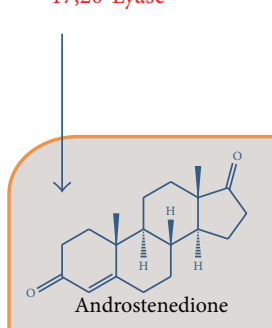

$$
\text { 17 } \beta \text {-Hydroxysteroid }
$$
dehydrogenase
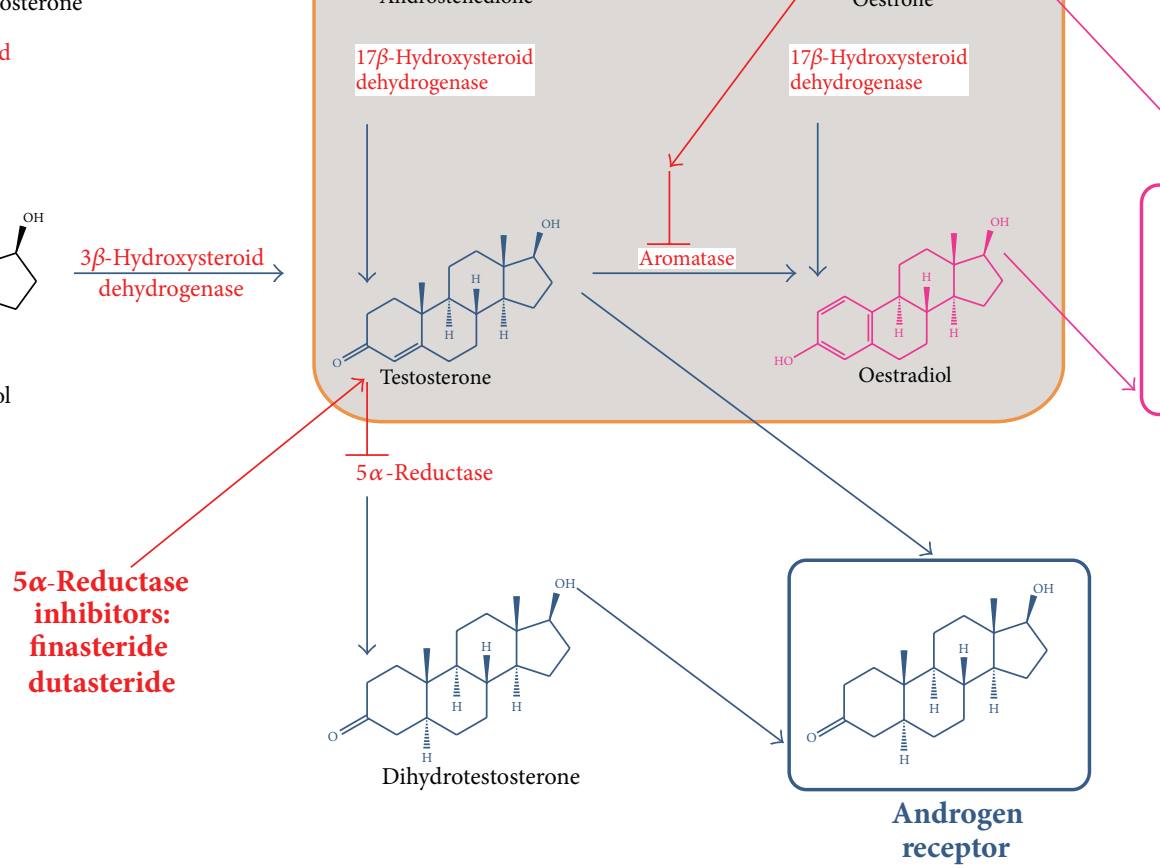

Aromatase

inhibitors:

anastrozole

exemestane

(b)

Figure 4: Continued. 

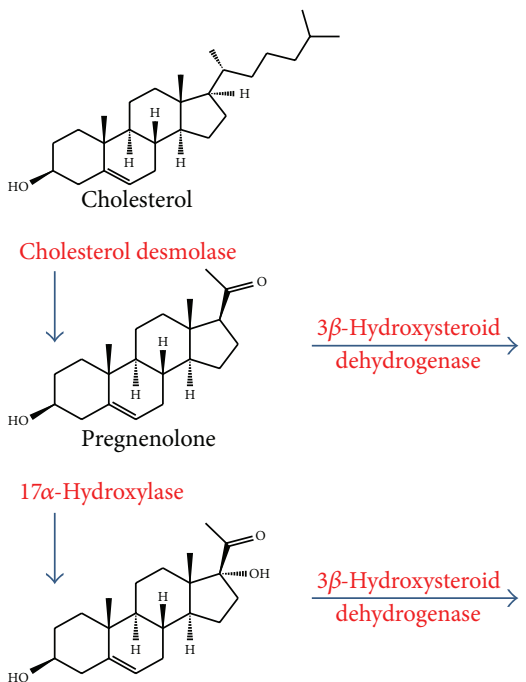

$\underset{\text { dehydrogenase }}{\stackrel{3 \beta \text {-Hydroxysteroid }}{\longrightarrow}}$

17-Hydroxypregnenolone
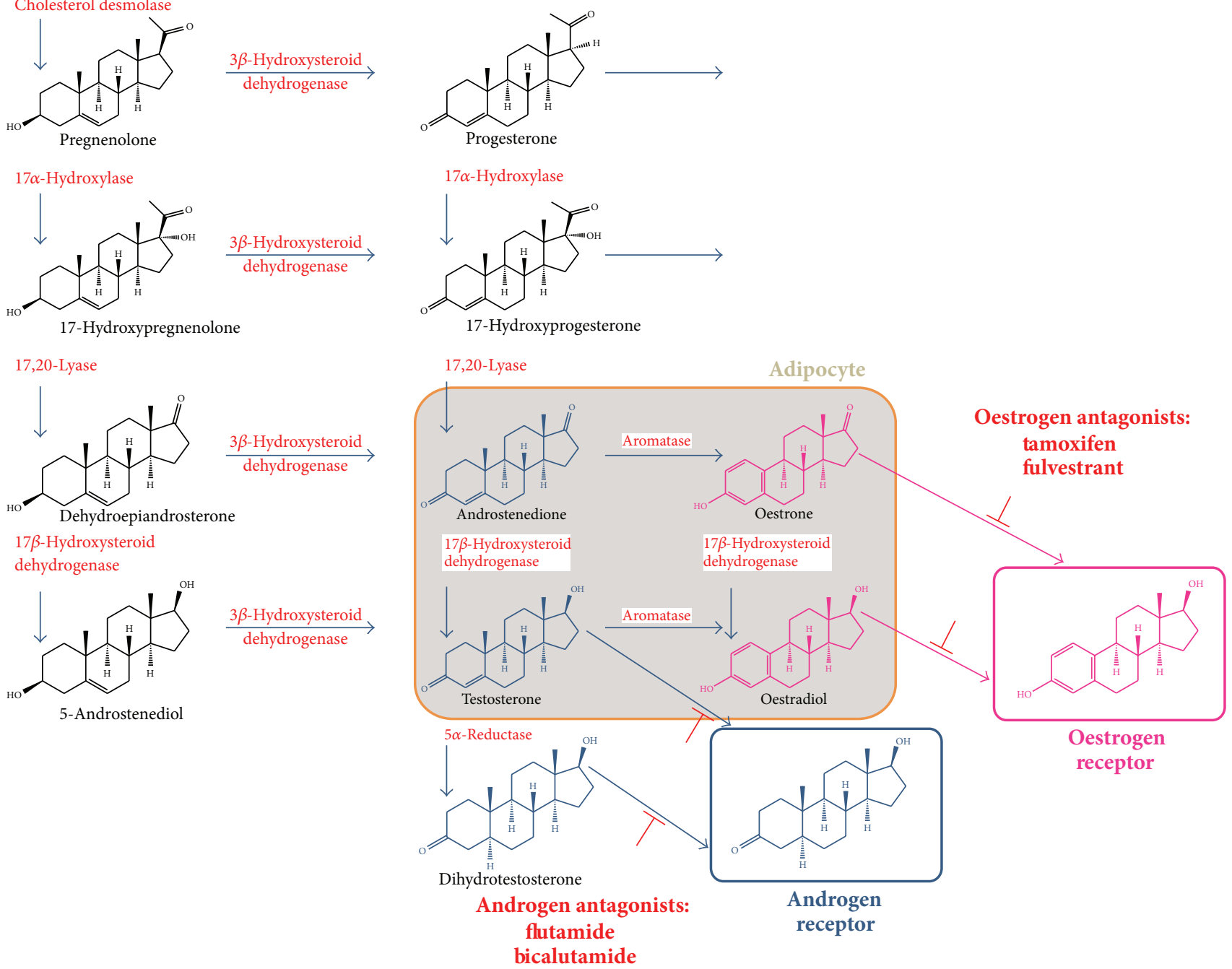

(c)

FIGURE 4: Steroid hormone biosynthesis and therapeutic prevention of steroid hormone action. The sterol cholesterol which contains 27 carbons and includes four interconnected cyclic hydrocarbons is the precursor of all steroid hormones (a). Removal of the cholesterol side chain yields the 21-carbon pregnenolone which is metabolised further to give active progestogens which are in turn converted into glucocorticoids and mineralocorticoids (not shown). Pregnenolone and progesterone may be converted also to $17 \alpha$-hydroxy pregnenolone and $17 \alpha$-hydroxy progesterone which are the precursors of the 19-carbon androgens. Metabolism of androgens by aromatisation of the first cyclic hydrocarbon and removal of carbon 19 produces the 18-carbon oestrogens. Two important enzymes in the end stages of androgen and oestrogen synthesis are expressed in adipocytes: $17 \beta$-hydrosteroid dehydrogenase converts androstenedione into the much more potent testosterone and oestrone into the more potent oestradiol. Aromatase converts the androgens androstenedione and testosterone into oestrone and oestradiol, respectively. All steroid hormones interact with and activate a cognate receptor which is a ligand-dependent transcription factor. For instance, all active androgens interact with the androgen receptor and all oestrogens interact with an oestrogen receptor. Systemic therapeutic intervention to inhibit androgen or oestrogen action involves inhibition of enzymes involved in their synthesis (b) or competitive inhibition of the interaction of the steroid ligands with their receptors (c). Recently, $17 \alpha$-hydroxylase inhibitors such as abiraterone and orteronel have been developed and are in clinical trial for the treatment of antiandrogen refractory prostate cancer. Inhibitors of $5 \alpha$ reductase such as finasteride and dutasteride are used in the treatment of benign prostatic hyperplasia and male pattern baldness. Aromatase inhibitors such as type I inhibitor anastrozole and type II steroid inhibitor exemestane are used widely in the treatment of postmenopausal women with breast cancer. Oestrogen antagonists include the partial antagonist tamoxifen which is a triphenylethylene derivative and the pure antioestrogen fulvestrant which is a steroid. Androgen antagonists include the nonsteroidal pure antiandrogens flutamide and bicalutamide which is the mainstay of systemic therapy in prostate cancer patients. 
serum oestradiol concentrations are high enough to occupy and activate the oestrogen receptor, and because the increase in oestradiol concentration observed in obese women is in the linear range of response to oestradiol, it would be predicted to increase significantly the induction of gene expression and cell proliferation in oestrogen-responsive malignant cells [75-78]. In breast cancer cells, induction of the expression of thirteen genes was half-maximal between 20 and $50 \mathrm{pM}$ oestradiol and the increase in oestradial-stimulated cell proliferation was half-maximal at $30 \mathrm{pM}$ oestradiol [77, 78]. Local tissue concentrations of oestradiol in obese individuals will exceed most probably those measured in serum (Figure 3).

\section{The Major Molecular Pathways Involved}

Several mechanisms have been postulated to explain the pathophysiology behind the obesity and diabetes-associated increased risk and progression of cancer. Insulin, IGFs and their receptors have all been suggested to play an important role. To understand how these different stimuli might influence cancer development and progression both individually and in concert, it is necessary to consider the biochemical basis of their activity.

3.1. Insulin. As described above, insulin is synthesised in and then secreted from beta cells of the pancreatic islets of Langerhans in response to plasma glucose. Insulin was the first protein to be sequenced and one of the first to have its structure solved using X-ray crystallography. Insulin is synthesised as a precursor protein, proinsulin, and is processed by the removal of a central $\mathrm{C}$ peptide which lies between the B and A polypeptide chains. Insulin comprises two polypeptide chains: an A chain of 21 amino acid residues that contains two regions of $\alpha$-helix and a B chain of 30 residues that contains a region of $\alpha$-helix towards the $\mathrm{N}$ terminus (Figure 5(a)). The two chains are linked together by two interchain disulphide bridges. There is a third disulphide bridge within the A chain between the sixth and eleventh residues.

3.2. Insulin-Like Growth Factors. The pioneering work of Salmon Jr. and Daughaday [79] led to the discovery of IGF-1 as the first known mediator of the effects of growth hormone. IGF-1 is synthesised by the liver under the control of growth hormone and stimulates bone growth because it increases the proliferation of cartilage cells in the epiphyseal plate of long bones. IGF-1 contains 70 amino acid residues in a single polypeptide chain and has three intramolecular disulphide bonds congruent to those found in insulin. It contains the $\alpha$ helix in the same location as that in the B chain of insulin but the 2 stretches of $\alpha$-helix in the equivalent of the A chain of insulin are less well defined (Figure 5(a)). It retains the equivalent of the $\mathrm{C}$ peptide of insulin and has an additional sequence, the $\mathrm{D}$ domain, at the carboxy-terminus. IGF-2 was discovered at about the same time as IGF-1 [80]. It is closely related to IGF-1 and is produced primarily by the liver, but its production is not controlled by growth hormone. IGF-2 expression is controlled by methylation of a differentially methylated region located upstream of the $I G F-2$ gene. IGF-2 is expressed normally from the paternal chromosome only as a result of maternal genetic imprinting [81]. Loss of imprinting leads to overexpression of IGF-2 and occurs frequently in human cancers $[82,83]$. IGF-2 contains 67 residues in a single polypeptide chain, retains a C- and Ddomain, and has a similar structure to those of insulin and IGF-1 with three congruent intramolecular disulphide bonds.

The boundaries between insulin and IGF signal transduction were thought originally to be quite distinct. It has become apparent that the structural similarities between insulin, IGF1 , and IGF-2 are sufficiently strong to allow them to interact with each other's receptors. Further, their cognate receptors are closely related and activate many common intracellular signal transduction molecules.

3.3. The Insulin Receptor. The cellular effects of insulin are mediated by the insulin receptor. The insulin receptor has a highest affinity for insulin and a lower affinity for the two related growth factors, IGF-1 and IGF-2 (Table 3). The insulin receptor is a cell surface tyrosine kinase receptor of $320 \mathrm{kDa}$. The receptor is present in its unbound form in the plasma membrane as a disulphide-linked heterotetramer which is referred to usually as the insulin receptor dimer.

After synthesis, the insulin receptor protein undergoes posttranslational proteolytic cleavage to generate an amino-terminal $\alpha$-chain and a carboxyl-terminal $\beta$-chain (Figure 6(a)). The two chains are then rejoined covalently by a disulphide bond between the $\alpha$ and $\beta$ chains of each monomer. The extracellular part of the insulin receptor dimer, called the ectodomain, contains both $\alpha$-chain and 194 residues of each $\beta$-chain. The two monomers in the insulin receptor dimer are bound covalently by four disulphide bonds between the two $\alpha$ chains.

The crystal structure of the ectodomain of the insulin receptor dimer has been solved [84, 85], and additional knowledge is available from molecular modelling, mutagenesis of both insulin and the insulin receptor, analysis of patients with defective insulin signaling, and thermodynamic and kinetic analyses of the binding reaction [86, 87]. Each insulin receptor monomer ectodomain comprises a leucinerich repeat domain (L1), a cysteine-rich region (CR), and a second leucine-rich repeat domain (L2) followed by three fibronectin type III domains: (FnIII-1, FnIII-2, and FnIII-3). FnIII-2 is interrupted by a $\sim 120$ amino acid residue insert domain (ID) that contains the furin proteolytic cleavage site that is cleaved by a protease to create the $\alpha$ and $\beta$ chains (Figure 6(a)). The segments of the ID that are in the $\alpha$ and $\beta$ chains are termed $\operatorname{ID} \alpha$ and $\operatorname{ID} \beta$, respectively. The single helix that spans the plasma membrane is C-terminal to the FnIII-3 domain and is followed by the intracellular domains comprising, a $\sim 40$ amino acid residue intracellular juxtamembrane region (JM), a tyrosine kinase (TK, dark 


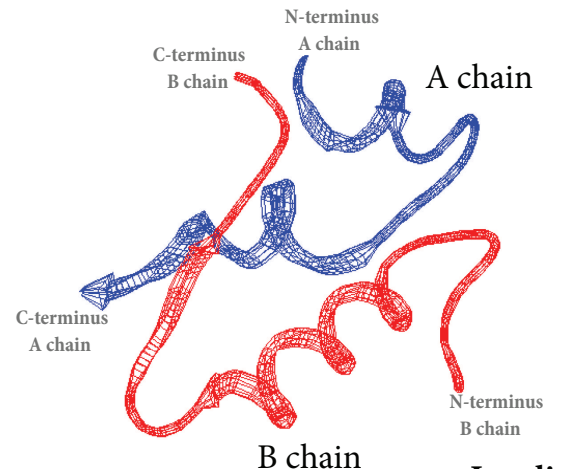

Insulin

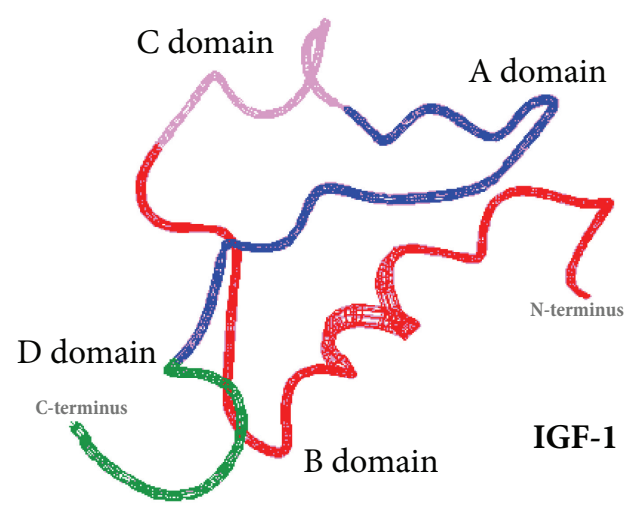

C domain

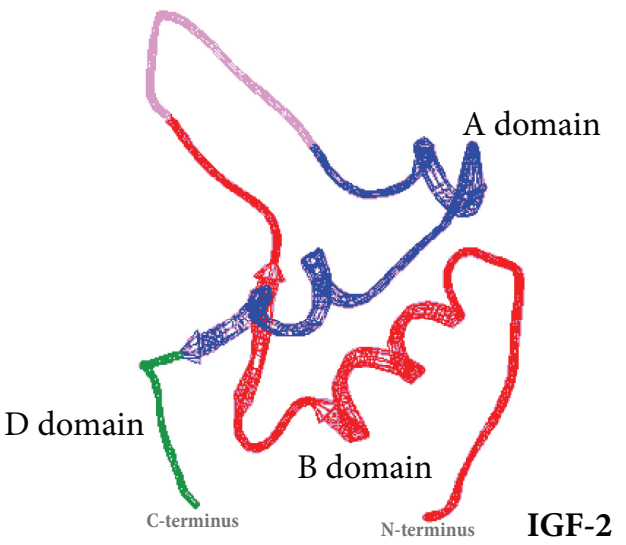

(a)

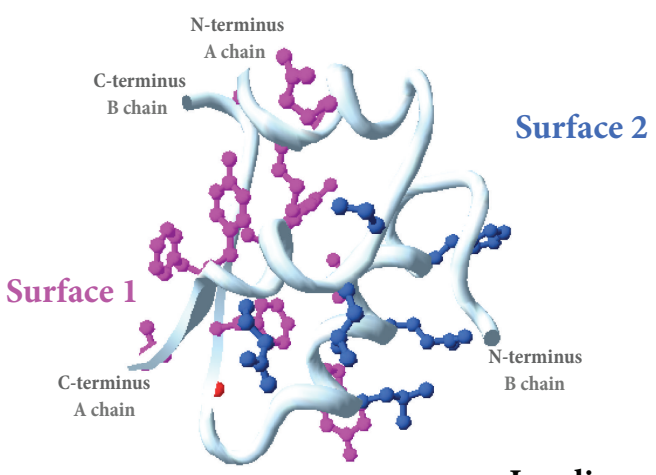

Insulin
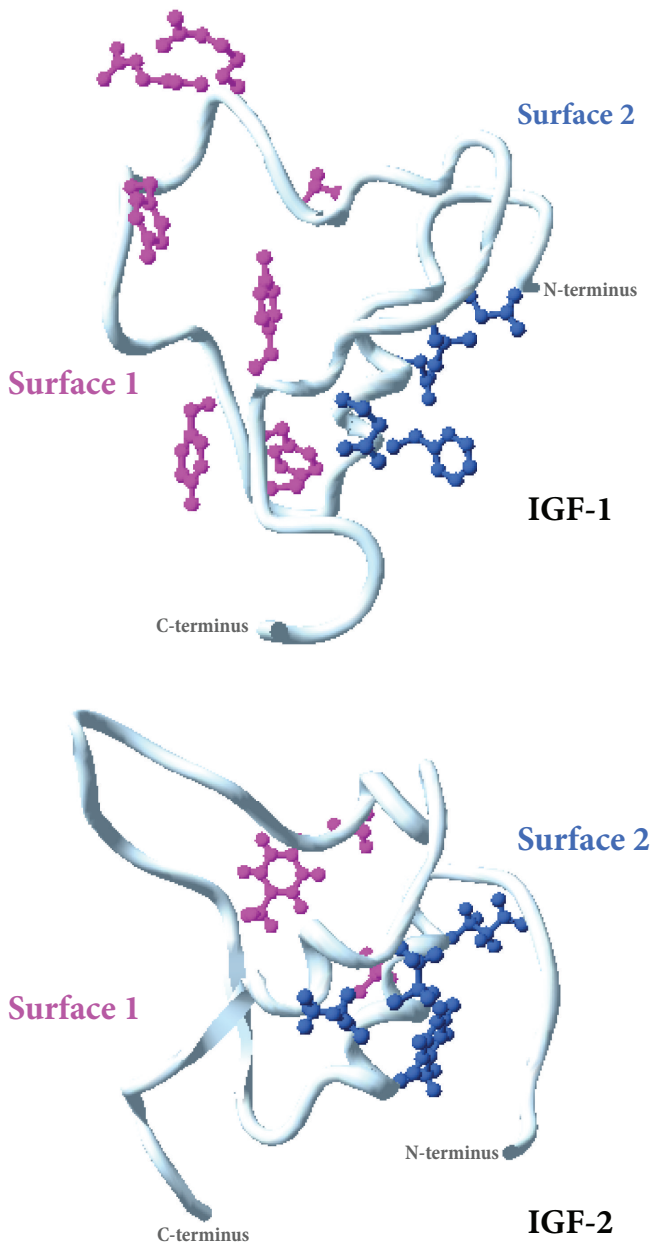

(b)

FIGURE 5: Representation of the three-dimensional structures of insulin, IGF-1, and IGF-2, and of the two binding surfaces on the ligands. Ribbon representations of the three-dimensional structures of the three ligands are shown with the insulin B chain and equivalent B domains of IGF-1 and IGF-2 coloured in red, the C domains of IGF-1 and IGF-2 in pink, the insulin A chain and A domains of IGF-1 and IGF-2 in blue, and the D domains of IGF-1 and IGF-2 in green (a). The three insulin $\alpha$ helices, one in the B chain and two in the A chain, are visible as are the equivalent structures in IGF-1 and IGF-2. The positions and orientations of the side chains of the residues implicated in interaction of the ligands with the receptors are shown on the backbone of the molecule structures which are coloured in grey (b). The side chains are shown in ball-and-stick view. The side chains of the residues located on binding Surface 1 are coloured in pink and those located on binding Surface 2 are coloured in blue. Residues ValB12, TyrB16, GlyB23, PheB24, PheB25, TyrB26, GlyA1, IleA2, ValA3, GlnA5, TyrA19, and AsnA21 of insulin are involved in Surface 1 and HisB10, GluB13, LeuB17, SerA12, LeuA13, and GluA17 in Surface 2. For IGF-1, residues Phe23, Tyr24, Tyr31, Arg36, Arg37, Val44, Tyr60, and Ala62 form Surface 1 and residues Glu9, Asp12, Phe16, Leu54, and Glu58 are thought to contribute to Surface 2. In IGF-2, residues Val14, Phe28, and Val43 are included in Surface 1 and residues Glu12, Phe19, Leu53, and Glu57 in Surface 2. 
TABLE 3: Affinities of insulin, IGF-1, and IGF-2 for homodimers and heterodimers of isoform A (IR-A) and isoform B (IR-B) of the insulin receptor and type I IGF receptor (IGF-IR).

\begin{tabular}{lcccccc}
\hline Ligand & IR-B : IR-B & IR-A : IR-A & IR-A : IR-B & IGF-IR: IGF-IR & IGF-IR:IR-B & IGF-IR:IR-A \\
\hline Insulin & $0.5 \mathrm{nM}^{\$}$ & $0.25 \mathrm{nM}$ & $0.5 \mathrm{nM}$ & $100 \mathrm{nM}$ & $80 \mathrm{nM}^{*}$ & $70 \mathrm{nM}^{*}$ \\
IGF-1 & $100 \mathrm{nM}$ & $10 \mathrm{nM}$ & $40 \mathrm{nM}$ & $0.2 \mathrm{nM}$ & $0.3 \mathrm{nM}$ & $0.4 \mathrm{nM}$ \\
IGF-2 & $10 \mathrm{nM}$ & $2 \mathrm{nM}$ & $10 \mathrm{nM}$ & $0.5 \mathrm{nM}$ & $0.5 \mathrm{nM}$ & $0.7 \mathrm{nM}$ \\
\hline
\end{tabular}

$\$$ Affinities are taken from or are estimated from the different relative affinities reported in $[92,100-102,104,310] .{ }^{*}$ The affinities reported for the hybrid between type I IGF receptor and isoform A of the insulin receptor are discrepant.

salmon) catalytic domain, and an $\sim 100$ amino acid residue carboxyl-terminal tail (C-tail, dull pink).

The structure of the extracellular domains of each receptor monomer resembles an inverted " $\mathrm{V}$ " of which the L1CR-L2 domains form one arm and the three FnIII domains form the other. In the receptor dimer, the second monomer is related to the first by a twofold rotation about the axis of the inverted "V" which results in the L1-CR-L2 arm of one monomer being packed against the three FnIII domains of the other (Figure $7(\mathrm{a})$ ).

3.4. Interaction of Insulin with the Insulin Receptor. Insulin makes contact with the insulin receptor through two distinct surfaces. Surface 1 approximates to the surface responsible for insulin dimerisation, which is known as the "classic binding surface.” It includes ValB12, TyrB16, GlyB23, PheB24, PheB25, TyrB26, GlyA1, IleA2, ValA3, GlnA5, TyrA19, and AsnA21. Surface 2 overlaps the surface on the insulin dimer responsible for hexamer formation and includes HisB10, GluB13, LeuB17, SerA12, LeuA13, and GluA17 (Figure 5(b)).

The structure of the insulin: insulin receptor complex has not been solved. The current model for insulin interaction with the insulin receptor proposes that there are two equivalent ligand binding pockets in the insulin receptor dimer. Within each pocket, there are two distinct sites of interaction with insulin $[88,89]$. The central $\beta$-sheet of the $\mathrm{L} 1$ domain from one receptor monomer and the C-terminus of the FnIII-2 insert domain ( $\alpha$-CT) from the second receptor monomer constitute one binding site, Site 1 (Figure 7(b)). The structure of the $\alpha$-CT segment has been resolved recently [84]; residues 693-710 form an $\alpha$-helical structure that is packed against the L1 domain while the remaining 21 carboxy-terminal residues are disordered. Residues at the junction between FnIII-1 and FnIII-2 domains from the second receptor monomer constitute the second binding site, Site 2. High-affinity binding involves interaction of surface 1 of an insulin molecule with Site 1 from mainly one receptor monomer and surface 2 of the insulin molecule with Site 2 from the second receptor monomer; the insulin molecule bridges the two receptor monomers. Each ligand binds the receptor with a stoichiometry of $1: 1$ at physiological concentrations. Whilst the receptor dimer has two identical Site 1Site 2 binding pockets, insulin molecules cannot occupy both pockets simultaneously. Interaction of a second ligand with the previously unoccupied binding pocket accelerates the dissociation of the first ligand which results in the observed negative-cooperativity binding mechanism. Relatively little conformational change in the receptor structure occurs after high-affinity interaction with ligand [86].

3.5. Isoform A of the Insulin Receptor. Evolution has provided mammalian insulin receptors with an additional exon, exon 11, which encodes the 12 amino acids from residues 718-729 until just three residues from the carboxyl-terminus (residue 732) of the $\alpha$ chain (Figure 6(b)). The extra amino acid residues are thought to have a disordered structure and are located just carboxy-terminal to the $\alpha$-helical region, which is packed against the L1 domain to form the insulin binding Site 1 of the receptor [86]. In mammals, the insulin receptor can be transcribed without or with exon 11 to produce isoform A or isoform B, respectively. The discovery of the two insulin receptor isoforms as part of the original cloning and sequencing of the insulin receptor mRNA [90] was regarded initially as a molecular curiosity but is now recognised to be of considerable relevance to the role of hyperinsulinaemia and diabetes in cancer risk and cancer progression and in the potential effectiveness of different IGF-targeted therapies.

The two isoforms have different tissue distributions [91]. Isoform $\mathrm{B}$ of the insulin receptor is the predominant form in classic insulin target tissues such as liver and skeletal muscle whereas isoform A tends to be expressed in nonclassic insulin target tissues. Importantly, isoform A is the predominant form of the insulin receptor expressed in the foetus and in various types of cancer including breast, colon, lung [92, 93], thyroid [94], prostate [95], and ovary [96]. The ratio of isoform $\mathrm{A}$ to isoform $\mathrm{B}$ is higher in breast cancer than in normal breast tissue [93]. In thyroid cancer, isoform $A$ is related to differentiation, being expressed at higher levels in less well-differentiated tumours [94]. Isoform A expression is not limited to cancers of epithelial origin and is the predominant isoform in some sarcomas [97] and gestational trophoblastic neoplasias [98].

3.6. Interaction of Insulin, IGF-1, and IGF-2 with Isoform $A$ of the Insulin Receptor. Subsequent to the discovery of isoform $\mathrm{A}$, it was recognised that isoforms $\mathrm{A}$ and $\mathrm{B}$ had differing affinities for insulin with isoform A having a twofold higher affinity than isoform $B$ [99]. The absence of exon 11 in isoform $\mathrm{A}$, however, produces a more promiscuous receptor with reduced specificity for insulin; isoform $A$ has increased affinities for IGF-1 and IGF-2. The affinity of isoform A of the insulin receptor for IGF-1 is about 10-fold higher than the affinity of the $\mathrm{B}$ isoform of the insulin receptor, and for 


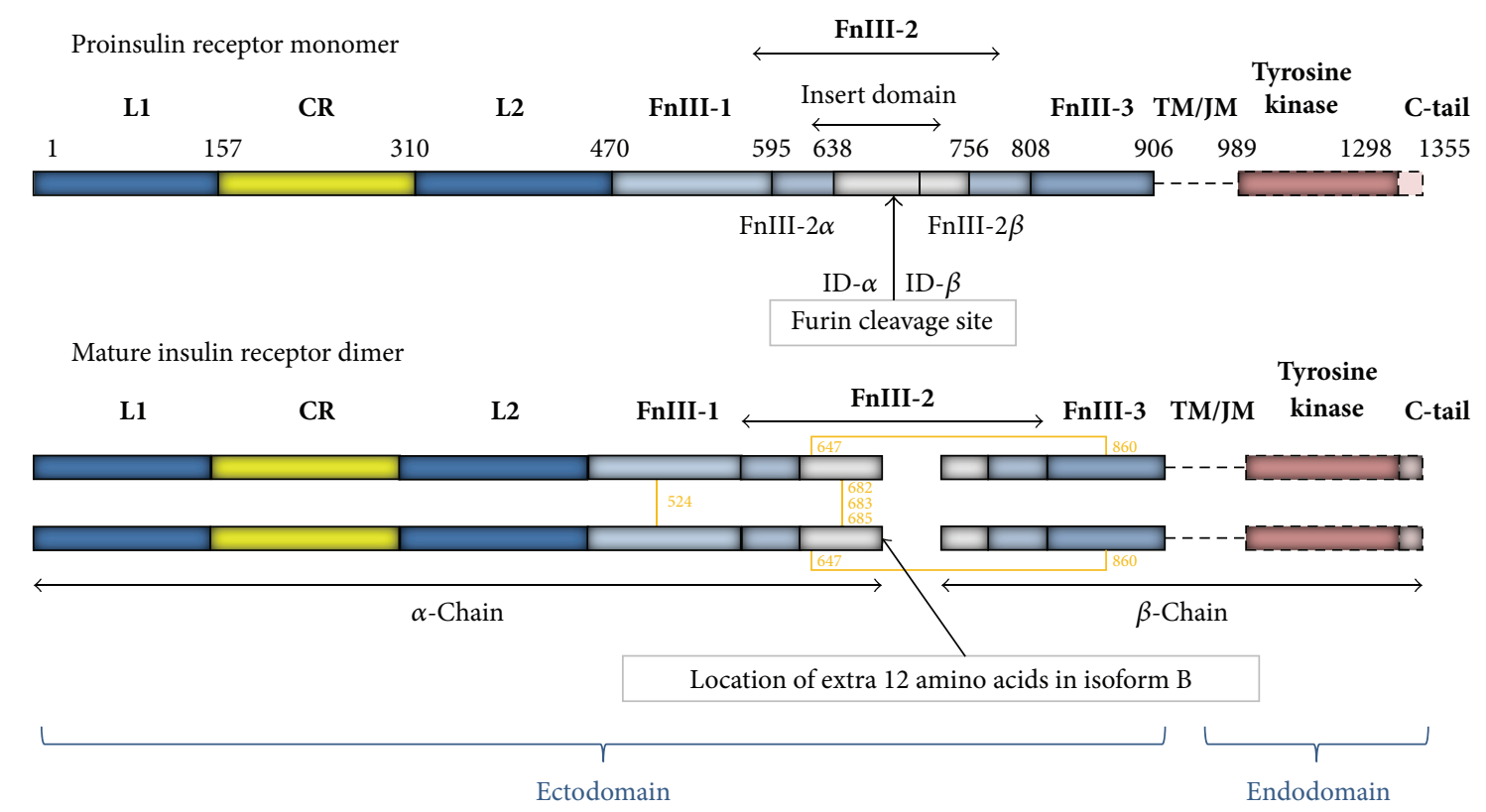

(a)

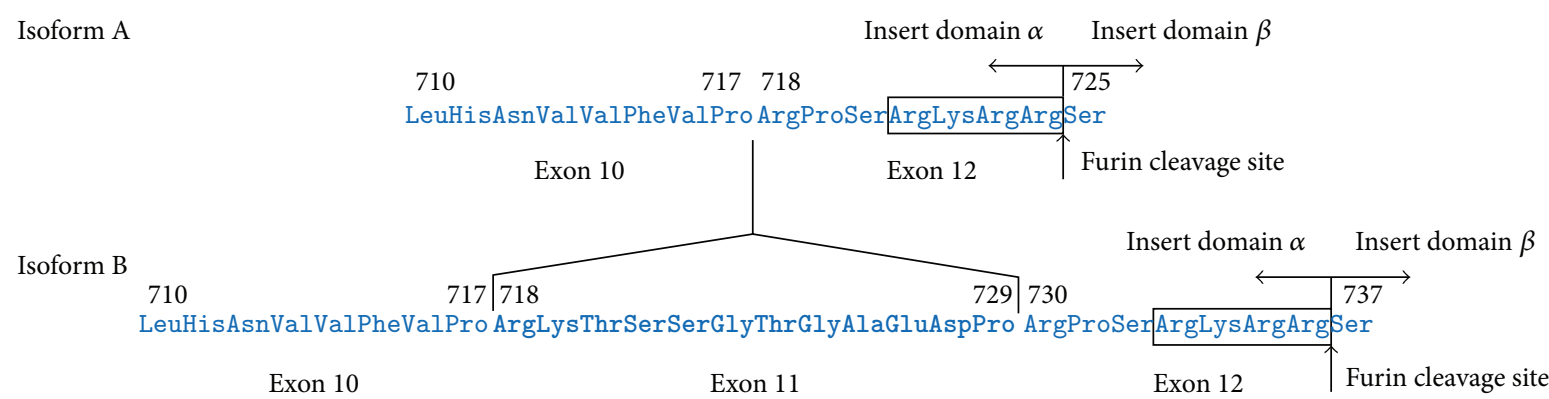

(b)

FIGURE 6: Representation of the domain structure of the human insulin and type I IGF receptors. The insulin receptor and type I IGF receptor are synthesised as single polypeptide chains that comprise several congruent, distinct domains. A linear representation of the domain structure of the proinsulin receptor isoform B after the removal of the signal peptide is shown above, a representation of the homodimer (a). From the amino-terminus, the individual domains are coloured as follows: leucine-rich repeat domain 1 (L1, blue), a cysteine-rich region (CR, yellow), a second leucine-rich repeat domain (L2, blue) followed by three fibronectin type III domains (FnIII-1, FnIII-2, and FnIII-3, different shades of pale blue). FnIII- 2 is interrupted by a $\sim 120$ residue insert domain (ID, grey) that contains the furin proteolytic cleavage site which is cleaved by a protease to create the $\alpha$ and $\beta$ chains of the receptors. The segments of the insert domain that are in the $\alpha$ and $\beta$ chains are termed ID $\alpha$ and ID $\beta$, respectively. The single helix that spans the plasma membrane (TM, dashed line) is C-terminal to the FnIII-3 domain and is followed by the intracellular domains comprising a $\sim 40$ amino acid residue intracellular juxtamembrane region (JM, dashed line), a tyrosine kinase (TK) catalytic domain, and an $\sim 60$ amino acid residue carboxyl-terminal tail. Intramonomer and intermonomer disulphide bonds are shown as ochre coloured connecting lines. The position of the furin cleavage site is indicated below the proinsulin receptor monomer and the position of the extra 12 amino acid residues present in isoform B of the insulin receptor is indicated below the depiction of the mature insulin receptor dimer. The amino acid sequences around the furin cleavage sites in isoform A and isoform B [311] of the insulin receptors are shown (b). The additional 12 residues encoded by exon 11 that are present in isoform B of the insulin receptor are shown in bold. The presence of 12 additional residues, three amino acids from the carboxy-terminus of the $\alpha$-chain, in the $\alpha$-chain insert domain impinges upon Site 1 of the insulin receptor binding pocket [84] and affects the ability of IGF-1 and IGF-2 to interact with the insulin receptor isoform B.

IGF-2 it is about 5-fold higher [100, 101]. The affinity of IGF-2 for isoform $\mathrm{A}$ of the insulin receptor approaches its affinity for type I IGF receptor (Table 3) [92, 100-102]. Although the structural basis for the increased affinities of IGF-1 and IGF2 for isoform $\mathrm{A}$ of the insulin receptor is not understood completely, it is reasonable to suppose that the removal of the
12 amino acid residues from within the ligand binding pocket adjacent to binding Site 1 of the insulin receptor provides space to accommodate the C domain of IGF-1 or IGF-2. The difference in the relative affinities of the two isoforms for IGF-1 and IGF-2 may be due to differences between the Cdomains of the two IGFs [103]. The C-domain is smaller in 
IGF-2 than in IGF-1 and may be accommodated more easily in the binding pocket of isoform $\mathrm{B}$ of the insulin receptor (Figure 5(a)).

3.7. Type I IGF Receptor. Type I IGF receptor and insulin receptor are thought to have evolved from an ancestral receptor involved probably in the regulation of both metabolism and growth. The sequences and overall structures of the two receptors remain very similar to the extent that they can form functioning heterodimeric hybrid receptors but the ligand specificity of and the signalling from the two receptors have diverged considerably. Of the three ligands, IGF-1 has the highest affinity, IGF-2 a slightly lower affinity and insulin has a much lower affinity ( 100 fold) for type I IGF receptor [104] (Table 3).

As with the insulin receptor, each type I IGF receptor monomer comprises from the amino-terminus: the first leucine-rich repeat domain (L1), the cysteine-rich region (CR), the second leucine-rich repeat domain (L2), the first fibronectin type III domain (FnIII-1), the second fibronectin type III domain (FnIII-2), the third fibronectin type III domain (FnIII-3), the transmembrane domain, the juxtamembrane domain, the tyrosine kinase domain, and the Cterminal tail region. The insert domain of $\sim 120$ residues (ID) which contains the furin recognition site is within FnIII-2, and cleavage at this site yields the $\alpha$ and $\beta$ chains of type I IGF receptor monomer.

Whereas the crystal structure of the entire ectodomain of the insulin receptor has been determined, the crystal structures of the type I IGF receptor are limited to the L1-CR-L2 domains [105] and intracellular tyrosine kinase domain [106]. Additionally, a solution structure of the ectodomain of the type I IGF receptor modelled on the insulin receptor structure has been determined by small-angle X-ray scattering [87]. Overall, the domain dispositions of the ectodomains of the type I IGF receptor are very similar to those of the insulin receptor. There are differences between the structures of the first three domains, L1-CR-L2, that may contribute to ligand specificity [107]. The first difference is in the structure of the L1 domain in the second and third $\beta$-strands of the second leucine-rich repeat. Phe39 in the second (central) $\beta$-sheet of the insulin receptor is involved in ligand binding and is a major determinant of the specificity of the receptor for insulin [108] whereas in type I IGF receptor, the equivalent residue Ser35 is not involved in ligand binding. The second difference is in the sixth module of the CR domain which is thought to govern IGF binding specificity. There are different amounts of a-helix and numbers of disulphide bonds in, and little sequence similarity between, the sixth modules of the two receptors [107]. Compared with the type I IGF receptor, the insulin receptor has a larger loop that protrudes into the ligand binding pocket (Figure $7(\mathrm{c})$ ).

3.8. Interaction of IGF-1 and IGF-2 with Their Cognate Receptor. In contrast to insulin, IGF-1, and IGF-2 exist always as monomers in solution and have no dimer- or hexamerforming surfaces. This difference raised the question of whether they interact with type I IGF receptor through two surfaces in a similar way to the interaction of insulin with the insulin receptor. The overall binding characteristics are similar to those of insulin. IGF-1 binding exhibits a curvilinear Scatchard plot indicative of the coexistence of more than one binding pocket, and binding shows negative cooperativity $[109,110]$. The main difference is that unlike insulin, there is no loss of accelerated dissociation at high concentrations of IGF-1.

Identification of the binding surfaces on IGF-1 and IGF-2 has relied on mutagenesis and cross-linking studies (Figure 5(b)). Residues equivalent to insulin's Surface 1 together with residues in the C-domain of IGF-1 that are important for binding of IGF-1 to Site I of type I IGF receptor include Phe23, Tyr24, Tyr31, Arg36, Arg37, Val44, Tyr60, and Ala62 (Figure 5(a)). Alanine scanning mutagenesis has been useful in defining a second surface which may include Glu9, Asp12, Phe16, Leu54, and Glu58 and possibly the adjacent residues Ala8 and Met59 [111]. Thus, the binding of IGF-1 to type I IGF receptor is similar to that of insulin to the insulin receptor and involves many equivalent amino acids. Residues critical for the binding of IGF- 2 to Site 1 of type I IGF receptor include Val14, Phe28, and Val43 and the second surface that engages potentially one or more of the FnIII domains is formed by Glu12, Phe19, Leu53, and Glu57 [112].

Analysis of the modelled solution structure of the ectodomain of type I IGF receptor reveals that at saturation concentrations of IGF-1, three molecules of the ligand are able to bind to the receptor. The asymmetry of the interactions led the authors to suggest that one ligand molecule binds with high affinity and bridges the two receptor monomers by interaction simultaneously with Site 1 on a first receptor monomer and Site 2 on the second receptor monomer. A further ligand molecule may bind to the available Site 2 on the first receptor monomer and a third ligand molecule to Site 1 on the second receptor monomer albeit at around 50fold lower affinity. A small conformational change in type I IGF receptor ectodomain is required to allow it to bind three IGF-1 molecules simultaneously.

Following interaction of insulin, IGF-1 or IGF-2 with a receptor and its activation by autophosphorylation, the ligand receptor complexes are internalised. The activated ligand receptor complexes continue to signal in the intracellular vesicles. Eventually, the ligand dissociates within the endosomes, the receptors are inactivated by phosphotyrosinespecific phosphatases and recycled back to the plasma membrane, and the signal is attenuated [113]. As the pathways have been elucidated, it has become apparent that the same intracellular proteins transduce the signal from all three ligands and their different receptors. A major challenge now is to understand why different responses are manifest in different cells. The "cellular context" which is the sum of all the contributions from all the signal transduction molecules present in the cell is thought to be of great import [114].

3.9. Insulin and Type I IGF Hybrid Receptors. The discovery that the insulin receptor and type I IGF receptor could form heterodimeric hybrid receptors revealed an additional level of complexity [115-117]. Heterodimers form with the same 


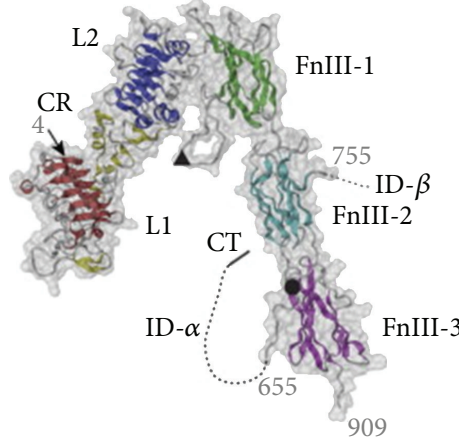

(a)

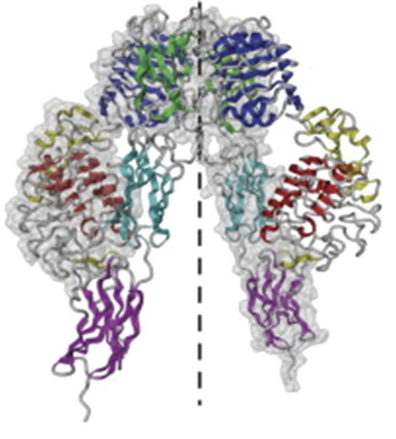

)
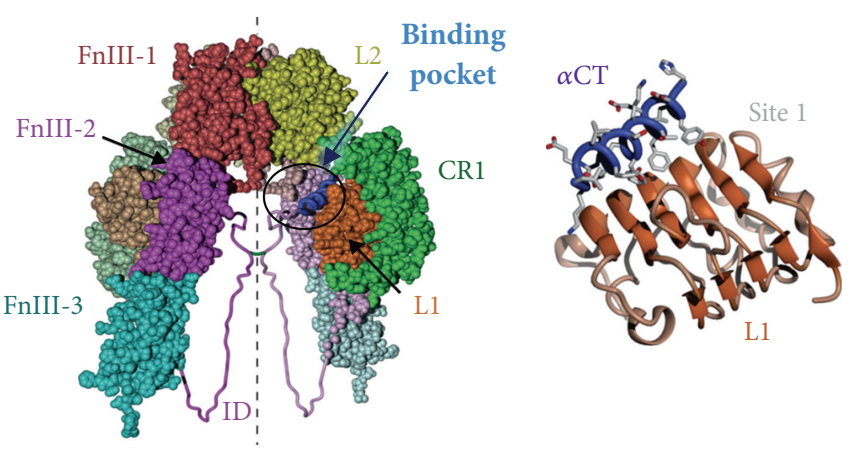

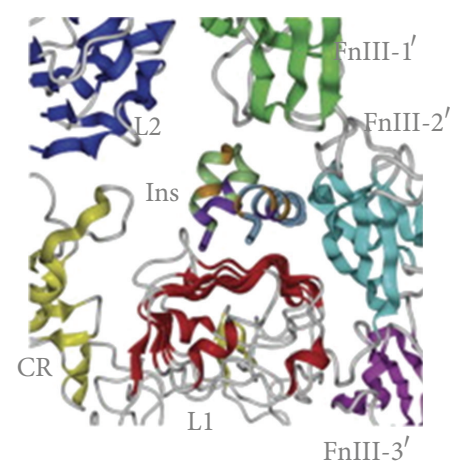

(b)

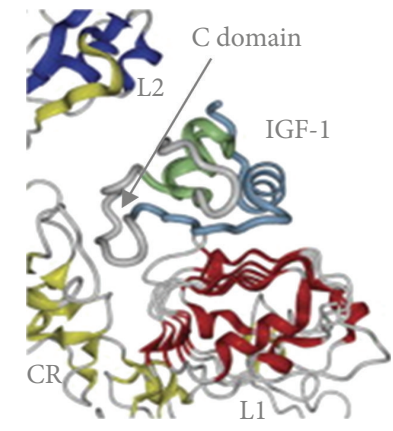

(c)

FIGURE 7: Representation of the crystal structure of the ectodomain of the insulin receptor and model for the interaction of insulin and IGF-1 with their cognate receptors. The three-dimensional structures of a monomer (LHS) and homodimer (RHS) of the insulin receptor isoform B ectodomain are shown (a). Domains are coloured: L1, red; CR, yellow; L2, blue; FnIII-1, green; FnIII-2, cyan; and FnIII-3, magenta. The observed location of the inter- $\alpha$-chain disulphide at Cys524 is indicated by a ( $\mathbf{\Delta})$ symbol, the $\alpha$ - $\beta$ chain disulphide at Cys647-Cys860 by a ( $\bullet)$ symbol. Images are taken with permission from [312]. The structures of $\alpha$-chain residues 1-3 ( $\alpha$-chain N-terminus) and 656-719 (ID- $\alpha / \mathrm{CT}$ ) and of $\beta$-chain residues 724-754 (ID- $\beta$ ) and 910-917 (C-terminus of ectodomain) were not solved. The observed termini of the regions of resolved structure within the insert domain of the $\alpha$-chain and $\beta$-chain of the ectodomain monomer are numbered. The insulin receptor ectodomain homodimer is illustrated in its apoconformation, with the twofold symmetry axis indicated by a dashed vertical line ((b), LHS) [85]. The first monomer at the front of the depiction is shown in saturated colour and the second monomer in less intense colour. The thin tubes of the insert domains (ID) indicate their speculative paths. The circled region identified by a blue arrow represents one binding pocket. The region contains the juxtaposition of the residues, derived from L1 of the first monomer and the $\alpha \mathrm{CT}$ helix of the second monomer that contribute to binding Site 1 with the residues, derived from the FnIII-1 and FnIII-2 junction of the second monomer that contribute to Site 2. The Site 1 tandem element, formed by the surface of the central $\beta$-sheet of L1 of the first insulin receptor monomer and the $\alpha \mathrm{CT}$ helix of the second insulin receptor monomer, is shown (RHS). Images are taken with permission from [86]. The proposed location of insulin bound in an insulin receptor binding pocket formed between two insulin receptor monomers with Site 1 from mainly one monomer and Site $2^{\prime}$ from the second monomer of the insulin receptor ectodomain $[85,107,312]$ is shown in (c) (LHS). Domains of the receptor are coloured as in (a). Colouring of individual $\mathrm{C} \alpha$ positions within insulin is as follows: residues forming binding Surface 1 of insulin, A1-3, A5, A19, A21, B12, and B16, are shown in purple; residues forming binding Surface 2, A12-13, A17, B13, B17, and B19, are shown in orange; the remaining A-chain residues are in light green and remaining B-chain residues in light blue. Insulin residues B22-B30 are omitted from the model [107]. The proposed location of IGF-1 bound at Site 1 of type I IGF receptor binding pocket is shown (RHS) [313]. The colouring of domains of the type I IGF receptor follows that of the insulin receptor in (a). The backbone of IGF-1 is coloured according to the corresponding colours of the A and $\mathrm{B}$ chains of insulin outlined above. The images are taken with permission from [312].

efficiency as homodimers which means that the number of hybrid receptors is determined by the level of expression of each receptor and that if one receptor is present in excess of the other, there will be relatively few homodimers of the other receptor [118].

Early studies showed that the hybrid receptors have unusual binding properties; IGF-1 is displaced by low concentrations of IGF-1 but can only be displaced by high concentrations of insulin. In comparison, insulin is displaced by low concentrations of both insulin and IGF-1, with IGF-1 being more effective. These results suggest that IGF-1 inhibits allosterically insulin binding via interaction with type I IGF receptor monomer $\alpha$-subunit in the hybrid receptor [117].

More recent analysis of the relative binding affinities and signalling capabilities of receptor heterodimers formed between either of the two insulin receptor isoforms and type I IGF receptor indicate that both hybrid receptors have a lower affinity for insulin than for either IGF-1 or IGF-2 (Table 3) 
$[101,119]$. It has been suggested that the heterodimer between isoform A of the insulin receptor and type I IGF receptor may be considered as a relatively low specificity receptor with which IGF-1 and IGF-2 interact with high affinity to activate signal transduction. Although insulin has a lower affinity than the IGFs for this hybrid receptor, it could be activated by the high insulin concentrations present in insulin-resistant individuals with hyperinsulinemia in whom serum insulin concentrations can be as high as $0.8 \mathrm{nM}[120,121]$. The high concentrations of therapeutic insulin required to reduce postprandial blood glucose in patients with diabetes mellitus type II reach $0.5 \mathrm{nM}$ which is sufficiently high also to occupy this hybrid receptor [122].

\subsection{Type II IGF Receptor and Insulin-Like Growth Factor} Binding Proteins. Type II IGF receptor is located in the plasma membrane and interacts with IGF-1 and IGF-2. Type II IGF receptor has a higher affinity for IGF-2 than IGF-1 and does not bind insulin. It is also a receptor for mannose 6 phosphate for which it contains multiple interaction domains. Type II receptor does not transduce a signal but effectively lowers the bioavailability of IGF-1 and IGF-2 because after interaction, the ligand and receptor are internalised and degraded.

IGF-1 and IGF-2 are bound to insulin-like growth factor binding proteins (IGFBPs) in the circulation [123]. IGFBP3 is the major IGFBP with which IGF-1 and IGF-2 are complexed in the serum. IGFBPs protect IGF-1 and IGF-2 from degradation whilst in the circulation and deliver them to cells. The IGFBPs help to control the action of IGF-1 and IGF-2 by increasing their half-lives. The half-life can be increased from ten minutes to 15 hours when bound to IGFBPs. Because IGFs have a higher affinity for IGFBPs than for type I IGF receptor, the IGFBPs decrease the activation of the receptors and modulate the IGF response $[124,125]$.

\section{Biological Effects and Consequences}

4.1. Metabolic Effects of Insulin. Interaction of insulin with the insulin receptor initiates the recruitment of intracellular signal transduction molecules and culminates in the activation of metabolic pathways. Activation of the receptor causes tyrosine autophosphorylation on Tyr1146, Tyr1150, and Tyr1151 [126]. The receptor tyrosine kinase is now fully active and phosphorylation of juxtamembrane and carboxylterminal residues that form binding sites for docking proteins ensues. The sequence context of the phosphorylated residues determines which protein interaction domains are able to bind to the phosphorylated receptor and dictates thereby the docking proteins that are recruited and activated [127]. These adaptor molecules are in turn phosphorylated by the active receptor kinase. Effector proteins interact with phosphorylated adaptor proteins via different protein interaction domains such as $\mathrm{SH} 3$ and PDZ domains and the signal transduction cascade is initiated.

In man, the adaptor proteins are the insulin receptor substrates, IRS-1, IRS-2, and IRS-4, and Shc. The adaptor proteins have no intrinsic catalytic activity but transmit signal from the activated receptor to effector proteins. For example, IRS-1 interacts with the activated insulin receptor via a phosphotyrosine binding domain and with the inner side of the plasma membrane via its pleckstrin homology domain. IRS-1 is then phosphorylated on multiple tyrosine, serine, and threonine residues including two tyrosine residues within YXXM motifs, Tyr612 and Tyr632. Activation of phosphatidylinositol-3 kinase (PI-3 kinase) requires interaction of both its $\mathrm{SH} 2$ domains with these phosphorylated motifs [128].

PI-3 kinase activation leads to phosphorylation of the protein kinase Akt on Thr308. Full activation of Akt requires a second phosphorylation on Ser473. Phosphorylation of Akt and hence its substrates is a key event in transmission of the insulin signal. Uptake of glucose into tissues that express GLUT4 glucose transporters, such as skeletal muscle and liver, is stimulated immediately after insulin is released into the blood stream. Insulin increases glucose transporter GLUT4 numbers at the cell surface by recruitment from an intracellular pool because activated Akt phosphorylates AS160 and TBC1D1 which are then phosphorylated by additional kinases. Phosphorylated AS160 and TBC1D1 activate small GTPases of the Rab family which are important in vesicle trafficking. GTP loading of Rab-GTPases in GLUT4positive intracellular vesicles increases interaction with Rab effectors that control GLUT4-positive vesicle transport to the plasma membrane and hence uptake of glucose from the plasma (Figure 8).

Akt phosphorylates also glycogen synthase kinase 3 (GSK-3). GSK-3 is active only in its unphosphorylated form and is thereby inactivated. Its substrate, glycogen synthase is inactivated also by phosphorylation and therefore the inactivation of GSK-3 results in an increase in active, unphosphorylated glycogen synthase. This active glycogen synthase converts glucose into glycogen, the high-molecular-weight polymeric storage form of glucose. As well as generating a major energy source, conversion of glucose to a highmolecular-weight polymer solves elegantly the osmotic problems associated with high concentrations of a low-molecularweight solute which are a major cause of tissue damage in diabetics (Figure 8).

Activated docking proteins stimulate also the transcription of insulin-regulated genes. For instance, the nucleotide exchange factor growth factor receptor-bound protein 2 (Grb2) binds the phosphorylated Tyr896 motif of IRS-1 via its SH2 domain [129]. Grb2 is then able to bind the guanine nucleotide exchange factor, son of sevenless (SOS), which in turn catalyses the replacement of bound GDP with GTP on the Ras GTPase. This protein phosphorylation cascade culminates in activation of mitogen-activated protein kinases (MAPKs), which enter the nucleus and phosphorylate nuclear transcription factors. Effects of insulin on glycolysis are mediated by increased expression of hexokinase, phosphofructokinase, and pyruvate kinase, the enzymes that control the three irreversible steps of glycolysis (Figure 8).

Insulin can stimulate nonmetabolic effects via interaction with the insulin receptor and activation of the MAPK pathway [130]. This role of insulin may be more significant in cancer cell biology than recognised previously. There is 


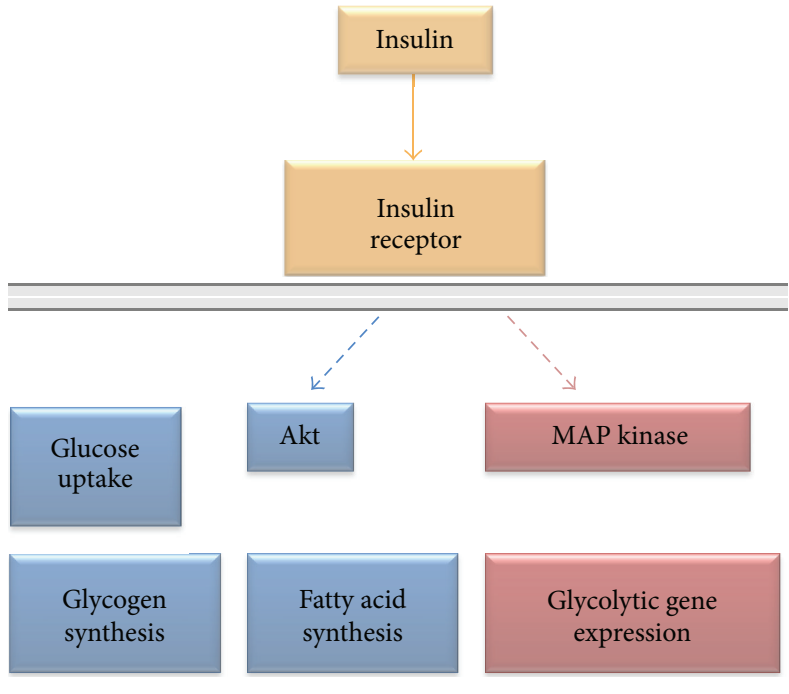

(a)

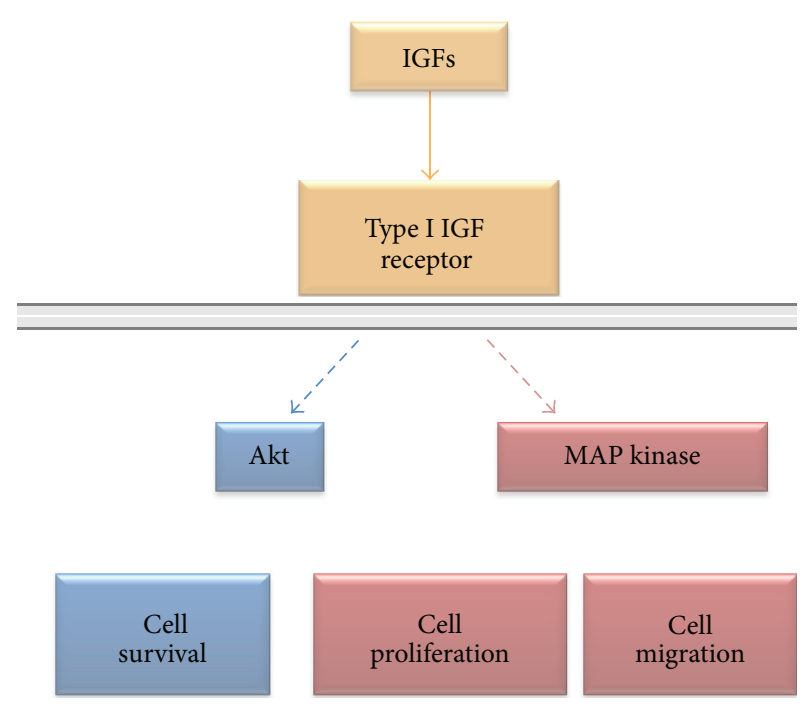

(b)

FIGURE 8: Graphic representation of the classic modes of insulin, IGF-1, and IGF-2 signal transduction. Insulin binds to the ectodomain of the insulin receptor and activates both the PI3-kinase and Akt pathway (blue) and the Ras and MAP kinase pathway (salmon pink). Activation of the Akt pathway results in translocation of GLUT4-positive intracellular vesicles to the plasma membrane and increased uptake of glucose, activation of glycogen synthase kinase 3 and the conversion of glucose to glycogen, and activation of pyruvate dehydrogenase and acetylCoA carboxylase and the conversion of glucose into the substrate for fatty acid synthesis. Activation of the MAP kinase pathway leads to increased expression of enzymes in the glycolytic pathway and preferential metabolism of glucose for energy. IGF-1 or IGF-2 (IGFs) bind to the ectodomain of type I IGF receptor and activate both the PI3-kinase and Akt pathway (blue) and the Ras and MAP kinase pathway (salmon pink). Activation of the Akt pathway results in inhibition of the Bcl-2 family of stress detection proteins and activation of GSK3 $\beta$, both of which increase cell survival. Activation of the MAP kinase pathway leads to increased expression of genes that encode proteins important in regulation of cell cycle progression and hence to increased proliferation.

evidence that the mitogenic response to insulin is more pronounced after activation of isoform $\mathrm{A}$ of the insulin receptor, which is overexpressed in some tumour cells, than after activation of isoform B of the receptor [104]. In cancer patients with insulin resistance, the consequent high levels of circulating insulin, together with overexpression of the insulin receptor by the tumour cells, stimulate significant nonmetabolic effects [100].

4.2. Biological Actions of IGF-1 and IGF-2. As for the insulin receptor, activation of type I IGF receptor occurs after ligand interaction in the extracellular domain. This interaction induces small conformational changes which lead to an increase in the intrinsic kinase activity of the receptor and autophosphorylation of Tyr1131, Tyr1135, and Tyr1136 residues in the kinase domain [131].

The classic function of both IGF-1 and IGF-2 is to stimulate growth. The major signal transduction pathways responsible is thought to be the Ras and MAPK pathway (Figure 8). After phosphorylation of IRSs or Shc, the Grb2 protein is recruited via its $\mathrm{SH} 2$ domain. Grb2 and SOS are then able to interact via an $\mathrm{SH} 3$ domain which brings SOS in close proximity to the membrane anchored Ras and reverses its autoinhibition. SOS promotes dissociation of GDP from Ras which allows GTP to bind, and after dissociation from SOS, active GTP-bound Ras phosphorylates its substrate Raf and the signal cascade is committed. Ultimately, the MAP kinase enters the nucleus to alter the expression of its target genes, and cells are driven through the cell cycle.

Activation of the protein kinase Akt by phosphorylation via the same pathway as described above for insulin is considered important in the prosurvival effect of IGFs (Figure 8). Activated Akt promotes cell survival via multiple effectors. One important pathway involves the Bcl-2 family of proteins. Akt phosphorylates $\mathrm{BAD}$ a proapoptotic member of the "stress detecting" Bcl-2 family of proteins. BAD induces apoptosis by interaction with and inhibition of the antiapoptotic Bcl-2 family members Bcl-xL and Bcl-2, which displaces them from interaction with proapoptotic proteins such as Bak and Bax. The liberated Bak and Bax are then able to aggregate and increase the porosity of mitochondria. The mitochondria release cytochrome $\mathrm{c}$ which activates caspases and induces caspase-dependent cell death. Because phosphorylated BAD does not form heterodimers with $\mathrm{Bcl}-\mathrm{xL}$ or Bcl-2, phosphorylation of $\mathrm{BAD}$ by Akt inactivates $\mathrm{BAD}$ and allows proteins like $\mathrm{Bcl}-2$ to inhibit proapoptotic proteins. Akt activates also by phosphorylation GSK3 $\beta$. GSK3 $\beta$-dependent cell survival implicates nuclear factor- $\kappa \mathrm{B}$ activation [132] and negative regulation of both intrinsic and extrinsic caspase-dependent proapoptotic pathways [133].

IGFs may also be involved in angiogenesis through induction of HIF- $1 \alpha$ and VEGF-C and by direct actions on vascular and lymphatic endothelial cells [134-139]. The effects of IGFs on invasion and metastasis include disruption of $\beta$-catenin and E-cadherin complexes which promotes cell 
detachment. IGFs promote invasion by regulating the expression of matrix metalloproteinases (MMPs) and urokinase plasminogen activator receptor system, both of which are involved in degradation of the extracellular matrix (ECM) in cancer $[140,141]$.

\subsection{Differential Insulin, IGF-1, and IGF-2 Signal Transduction} from Isoform A of the Insulin Receptor. There is evidence for subtle differences in insulin and IGF-2 signal transduction via isoform A compared to via isoform B of the insulin receptor; insulin stimulates mainly glucose uptake and IGF-2 stimulates preferentially proliferation [142]. Signals through the $\mathrm{A}$ isoform may recruit a different repertoire of proteins from signals through to the B isoform [143] and may deliver mitogenic signals in addition to metabolic signals [144-146].

Although the molecular basis of the differences in signal transduction is not understood completely, it may result from either or both of two properties: the residency time of the ligand on the insulin receptor and the ratio of affinities for the insulin and type I IGF receptors. Glu12 in IGF-2 and its equivalent Glu9 in IGF-1 are located on binding Surface 2 of the ligands and are important for high-affinity binding to the $\mathrm{A}$ isoform of the insulin receptor and type I IGF receptor. Introduction of a positive charge at this location in IGF-2 reduces affinity for both receptors and introduction of a positive charge at the equivalent position in IGF-1, Glu9Lys, reduces affinity for type I IGF receptor [147]. In insulin, the equivalent residue is HisB10 and substitution with an aspartic acid or glutamic acid acidic residue creates an analogue with a reduced "off-rate" from the insulin receptor and increased affinity for and activation of type I IGF receptor. This analogue has increased mitogenicity and increases mammary tumourigenesis in rats, supporting the contention that the kinetics of interaction of a ligand with each receptor contribute to the final biological effect stimulated by the interaction $[148,149]$.

4.4. Role of Insulin, IGF-1, and IGF-2 in Cancer. There is little evidence for the dramatic overexpression or mutation of components of the insulin and IGF signal transduction pathways in malignant cells, or for corruption by transformingviruses, that led to the identification of other oncogenes such as epidermal growth factor receptor or ErbB-2. The absence of oncogenic evidence for the importance of the IGF system in cancer delayed the realisation of its import [150-154]. There is however compelling evidence, included from animal models of tumour formation and progression, for the importance in IGFs in carcinogenesis. The question in the context of the present review is the extent to which the insulin and IGF signal transduction system is responsible for the effects of obesity and diabetes on cancer risk and progression.

4.5. Insulin and the Insulin Receptor Isoforms and Cancer Risk. The possibility that the hyperinsulinaemia in individuals who develop metabolic syndrome predisposes towards cancer implicates a direct effect of high plasma insulin concentrations. There is evidence that plasma levels of insulin or the C-peptide, which is the peptide that is cleaved from insulin during its biosynthesis, are associated with colon [155$158]$, endometrial [159], breast $[158,160]$, prostate [161] and pancreatic [162] cancers. Similarly, the hyperinsulinaemia that occurs during treatments for diabetes could be causative.

Epidemiological studies of cancer risk in diabetic patients treated with the biguanide, metformin provide support for the importance of hyperinsulinaemia in diabetes-associated cancer risk. Diabetic patients who do not take metformin to control their diabetes have a $40 \%$ higher cancer burden compared to diabetic patients who do $[23,163]$. Metformin reduces the levels of circulating insulin and decreases the levels of glucose in the blood; it is probably through these effects that metformin decreases cancer risk.

In 1990, it was found that insulin receptors are often expressed at higher levels on tumour cells than on classic insulin target cells [164]. This high expression was unexpected as the majority of cancers do not derive from the principle target organs of insulin, and cancer cells have highly effective insulin-independent glucose uptake mechanisms [165]. It is now recognised that the insulin receptor is expressed by many malignant tumours [100] including those of prostate [95], lung [166], thyroid, colon [92], and breast [164]. Studies have identified transcription factors and cofactors that regulate expression of insulin receptor in tumour cells [167-169].

The isoform of the insulin receptor present may be important in the development of cancer. The major insulin receptor isoform expressed on cancer cells is the A isoform which has a higher affinity for insulin than the B isoform and is more readily activated by circulating insulin. Isoform $\mathrm{A}$ may also provide a more mitogenic stimulus than the $\mathrm{B}$ isoform which would be associated with a higher cancer risk [170]. Another mechanism by which insulin could increase the risk of cancer in obese individuals with hyperinsulinaemia is by direct stimulation of type I IGF receptor. Although the affinity of insulin for type I IGF receptor is low, the supraphysiological concentrations of insulin present in obese people with insulin resistance and hyperinsulinaemia and in those with the metabolic syndrome are probably sufficiently high to signal through this receptor. Serum concentrations of insulin can reach $0.8 \mathrm{nM}$, at which concentration insulin would occupy and activate type I IGF receptor $[120,121]$ (Table 3).

The hyperinsulinaemia that occurs in obesity may increase cancer risk by indirect mechanisms. Hyperinsulinaemia lowers the plasma concentrations of IGFBP-1 and IGFBP-3 [171, 172] which increases free circulating IGF1. Chronic hyperglycaemia decreases IGFBP-2 to increase bioactive IGF levels [173]. High insulin concentrations in the hepatic portal circulation increase growth hormone receptor expression, thereby augmenting IGF-1 production [174]. In essence, obese individuals with hyperinsulinaemia and hyperglycemia will have higher concentrations of free circulating IGF-1 and augmented activation of the IGFdependent proliferation pathway.

Therapeutic insulin has been shown to increase cancer risk in numerous studies. Further, it has been shown that the duration of insulin treatment is associated positively with cancer incidence [175]. More recent studies have investigated 
if treatment with insulin analogues is associated with a similar or greater risk than treatment with unmodified insulin. Treatment of diabetes mellitus type 2 patients with the longacting insulin analogue, glargine, was found to be associated with an increased incidence of all cancers compared to natural therapeutic insulin in two studies [176, 177] and in pancreatic and colorectal cancer in a third study [178] whereas in a fourth study the increased risk for breast cancer was equal to unmodified insulin [179]. These conclusions were controversial and provoked extensive debate because of the implications for diabetics and pharmaceutical companies [149]. Reservations about the methodology and comparison groups have been expressed and larger studies are underway. One recent study confirmed an increased risk of breast cancer for patients given glargine, compared with those given natural insulin [180].

4.6. Insulin and the Insulin Receptor Isoforms and Cancer Progression. There has been a steady increase in the interest in the importance of insulin and the insulin receptor in cancer progression. High fasting insulin levels are associated with higher risk of colorectal adenoma recurrence [181] and with a poor breast cancer prognosis [182]. High serum insulin C-peptide levels are associated with a worse prognosis in prostate [26] and breast cancers [183]. More rapid tumour progression is associated with hyperinsulinaemia, and the dependence has been confirmed in animal models [184].

The type of insulin receptor isoform present in malignant cells may play a role in the progression of cancer as well as in cancer risk. Studies on breast cancer have shown that the ratio of isoform $\mathrm{A}$ to isoform $\mathrm{B}$ is important in determining the nature of the cancer [185]. Women with an increased ratio of isoform $\mathrm{A}$ to isoform $\mathrm{B}$ have more aggressive and rapidly progressive breast cancer [186]. The ability of the insulin receptor to form hybrids with type I IGF receptor may contribute to the effects of insulin on cancer progression. In essence, the impact of insulin on cancer risk may be large because of its capacity to deliver a more mitogenic, IGF-like signal either through isoform A of the insulin receptor or through insulin receptor: type I IGF receptor hybrids.

4.7. IGFs and Cancer Risk. Meta-analyses and recent large studies on the relationship between height and cancer risk have shown that height is a risk factor for some common cancers. The most consistent and convincing associations are for colorectal, breast, and prostate cancers [187]. Interpretation of the epidemiological data is that increased height reflects higher circulating levels of the growth stimulatory hormones particularly the IGFs during prepubertal development. The length of the long bones in the legs is a major contributor to adult height and is dependant largely on exposure to IGFs which is partly determined by genetics and partly by prenatal and childhood nutrition [188].

More direct evidence for a role for IGFs in the development of cancer was provided in 1998 when Hankinson et al. reported that the risk of breast cancer was associated with the levels of circulating IGF-1 and IGFBP-3 [189]. Notably, there was a large increased relative risk of 7.3 for developing breast cancer in premenopausal women who were in the top tertile for high serum IGF-1 concentrations and had low circulating IGFBP3 concentrations. A high ratio of IGF-1 to IGFBP3 means that more IGF-1 is bioavailable. Similar findings were reported for prostate cancer risk [190] with a 2.4-fold higher risk for men in the highest quartile of IGF-1 concentration compared to men in the lowest. The following year, an association was reported for colorectal cancer [191]. In 1999, a small increased risk of lung cancer was reported in people with elevated serum IGF-1 [192].

Thus, by the turn of the century, the prevailing view corroborated by clear evidence was that there is increased risk of common cancers in people with elevated circulating IGFs and low circulating IGFBPs, which supports earlier conclusions based on the association between height and cancer risk [193].

4.8. IGFs and Cancer Progression. Normal levels of circulating IGFs are sufficient to stimulate type I IGF receptor but tumour stroma and malignant cells can produce higher intratumour concentrations of IGFs. There are few reports of autocrine IGF-1 production but reports of autocrine IGF2 production are common. IGF-1 is expressed in colon carcinoma [194, 195] and IGF-2 is expressed in breast [196, 197], prostate [198], colorectal [199], adrenocortical [200] liver [201, 202], and thyroid [94] carcinoma cells and several types of sarcoma including osteosarcomas, myosarcomas, fibrosarcomas, and Ewing's sarcoma [203, 204]. Such high intratumour IGF concentrations enable heightened IGF signal transduction and consequent cancer cell proliferation, survival, and invasion.

Most studies on cancer progression have focussed on type I IGF receptor and the intracellular IGF signal transduction pathway. Type I IGF receptor and components of the IGF signal transduction pathways are expressed by most tumour types [152, 154, 205-207]. In some cancers, increased type I IGF receptor expression is associated with worse disease prognosis. In colorectal cancer, there is a stepwise increase in the expression of type I IGF receptor during progression from colonic adenomas towards primary colorectal adenocarcinomas and metastases [208]. For breast cancer, one study found that higher levels of type I IGF receptor were correlated with a worse prognosis for all tumours and in oestrogen receptornegative tumours [209] whereas another [210] found no prognostic value. In prostate cancer, there is a significant increase in type I IGF receptor mRNA and protein expression in primary tumours and in bone metastases, compared to benign prostatic epithelium [211, 212]. Similar associations have been reported for less common cancers including synovial sarcoma [213], melanoma [214], and gastric [215] and renal clear cell carcinomas [216]. Some studies have shown that high levels of receptor or phosphorylated receptor are associated with a poor prognosis $[166,217]$.

IGFs help metastatic cells adapt to a new environment although the mechanisms are not well defined. IGF-1 facilitates the establishment of both lung [218] and colon [219] cancer metastases in the liver. IGFs may be involved also in metastasis of prostate cancer to bone. Osteoblasts and bone 
endothelial cells produce IGFs and IGFBPs [220, 221] whilst prostate cancer cells produce uPA [222] which degrades IGFBPs and hence increases the bioavailability of IGFs [223].

4.9. Cooperation between Obesity-Associated Factors in Cancer Risk. Obesity aggregates several risk factors, some of which are particularly relevant to certain types of cancer. For example, hyperinsulinaemia, diabetes, and serum IGF levels are all independent risk factors for breast and colon cancers and may account for the increased risk associated with obesity. Hyperinsulinaemia and diabetes are associated with endometrial cancer. The associations identified may reflect the scope of the different epidemiological studies or they may reflect divergent cancer cell biology. There are clear interactions between obesity, insulin, and IGFs which compound their effects on cancer risk. In addition, steroid hormones regulate the expression of components of the IGF signal transduction pathway in some cancer cells and as a consequence can increase the cancer risk associated with hyperinsulinaemia, diabetes, and high serum IGF levels.

Hyperinsulinaemia stimulates androgen synthesis in the ovary, increases aromatisation of androgens to oestrogens, and decreases hepatic production of sex hormone-binding globulin which leads to increased bioavailable androgens and oestrogens [224, 225]. As circulating concentrations of insulin and IGF-1 rise with increasing obesity, the levels of the sex hormone-binding globulins decrease [226]. For instance, a woman with a BMI of $>30 \mathrm{~kg} / \mathrm{m}^{2}$ has half as much sex hormone-binding globulin as a woman with a BMI of $<22 \mathrm{~kg} / \mathrm{m}^{2}$ [227]. In normal or premalignant cells, the higher concentrations of, for example, bioavailable oestrogens present in obese women could augment the proliferative and anti-apoptotic effects of insulin and the IGFs with potentially oncogenic consequences.

There is some evidence that insulin resistance and high levels of IGFs, which are associated with central obesity, may play a more important role in premenopausal breast cancer while oestrogen may play a greater role in postmenopausal breast cancer $[189,228]$. Furthermore, obesity influences the type of tumour that arises. For example, basal-like or triplenegative breast tumours which do not express oestrogen and progesterone receptors or HER2 are more prevalent in obese women $[229,230]$. Interestingly, cell proliferation and survival of triple-negative breast cancer cells is IGF dependent [231].

4.10. Cooperation between Obesity-Associated Factors in Cancer Progression. The interaction between steroid hormones and the IGF signal transduction pathway plays an important role in cancer progression and has been studied mainly in breast cancer. The significance of oestrogens in progression in vivo was demonstrated by Beatson [232] but it was not clear if there was a direct effect on breast epithelial cells. This question was resolved when cultured malignant breast cells were shown to contain oestrogen receptors [233] and their proliferation was shown to be oestrogen responsive $[234,235]$. It became apparent subsequently that oestrogens control proliferation by modulating the effect of IGFs rather than by regulating the expression of genes involved in the cell cycle. The synergistic effects of oestrogens and IGFs on proliferation $[78,236]$ suggested that oestrogens might control the expression of components of the IGF signal transduction pathway. There is evidence that oestrogen increases expression of IGF-2 [237] but there is most likely an adequate supply of IGFs from the circulation and the stroma in vivo and in tissue culture medium in vitro. The main way that oestrogens potentiate the response of breast cancer cells to IGFs is probably by induction of the expression of components of the IGF signal transduction pathway [238] including type I IGF receptor [78, 239], IRS-1 [240-242], and IRS-2 [243]. Oestrogens may also regulate IGF-stimulated cell migration via increased IRS-1 and IRS-2 expressions as these are both involved in breast cancer cell migration [243].

Despite the association between IGFs and cancer progression and the androgen responsiveness of prostate cancer, there is little evidence of interaction between androgens and IGFs in an analogous way to oestrogens and IGFs in breast cancer. Androgens increase type I IGF receptor expression in prostate cancer cells [244] but few studies have investigated if androgens and the IGF signal transduction system interact to stimulate prostate cancer cell growth.

\section{Treatment Targeted to Adiposity-Induced Cancers}

Cancers that have arisen in obese or diabetic individuals will have identifiable properties that will allow them to be treated with specific therapies. These properties will reflect the forces that drove their origin and progression. We have presented evidence in this review that cancers that arise in a background of obesity and diabetes are dependent on insulin, IGFs, and their interactions with steroid hormones. Breast cancer is treated commonly with oestrogen-based endocrine therapies. More recently, the appreciation that some cancers are responsive to IGFs has led to the development of drugs that target the IGF signal transduction pathway and in some instances the insulin signal transduction pathway.

Strategies for targeting the IGF signal transduction system include antibodies to the cell surface receptors, tyrosine kinase inhibitors, siRNA [245], dominant negative constructs $[246,247]$, antibodies to the ligands [235], and IGF binding proteins.

5.1. Antibodies to Type I IGF Receptor. The component of the IGF signal pathway against which most potential drugs have been developed is type I IGF receptor. A number of humanised monoclonal antibodies specific for type I IGF receptor have been produced including figitumumab, cixutumumab, ganitumab, dalotuzumab, AVE1642, and R1507 [248-253]. They are of different subclasses but are generally long lasting with a half-life of greater than 10 days. After interaction with the ectodomain of the receptor, they promote receptor internalisation and lysosome-mediated receptor degradation. Although the antibodies do not recognise directly insulin receptors, they can bind to and inhibit the activity of hybrid receptors that are formed with either the A or B isoform of the 


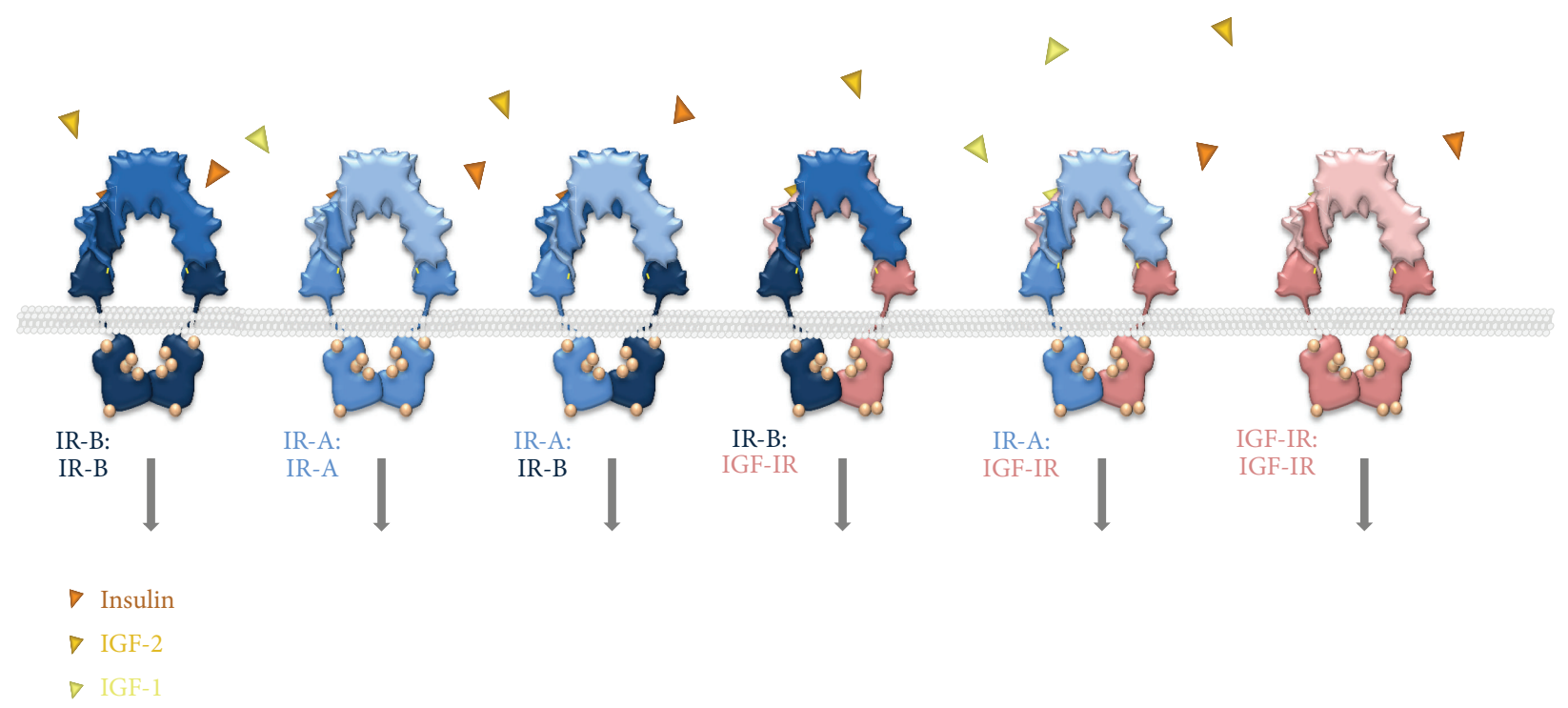

(a)

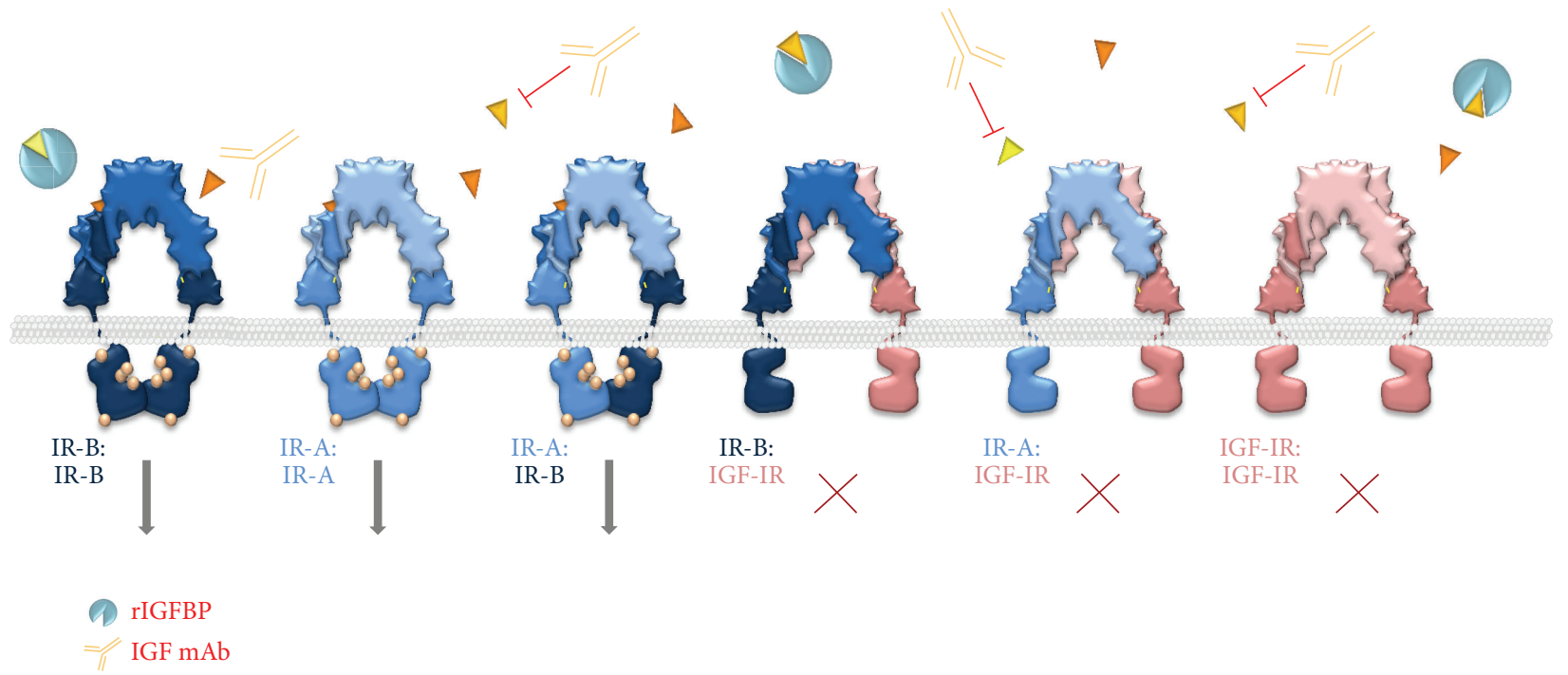

(b)

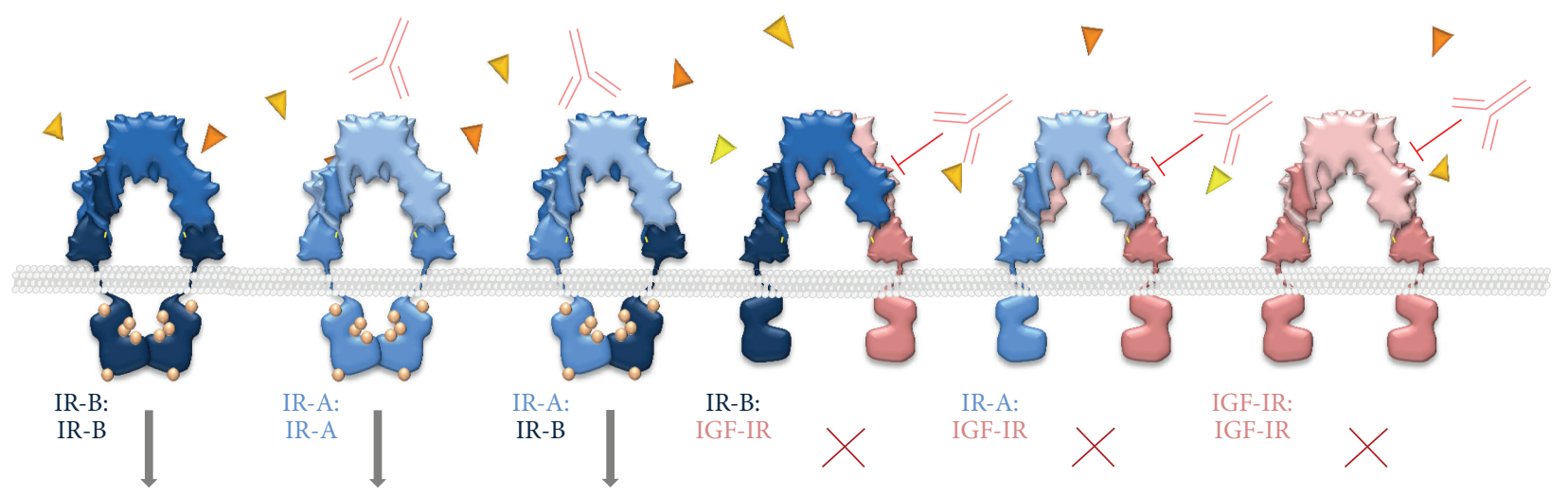

$=/ /$ Type I IGF receptor $\mathrm{mAb}$

(c)

Figure 9: Continued. 


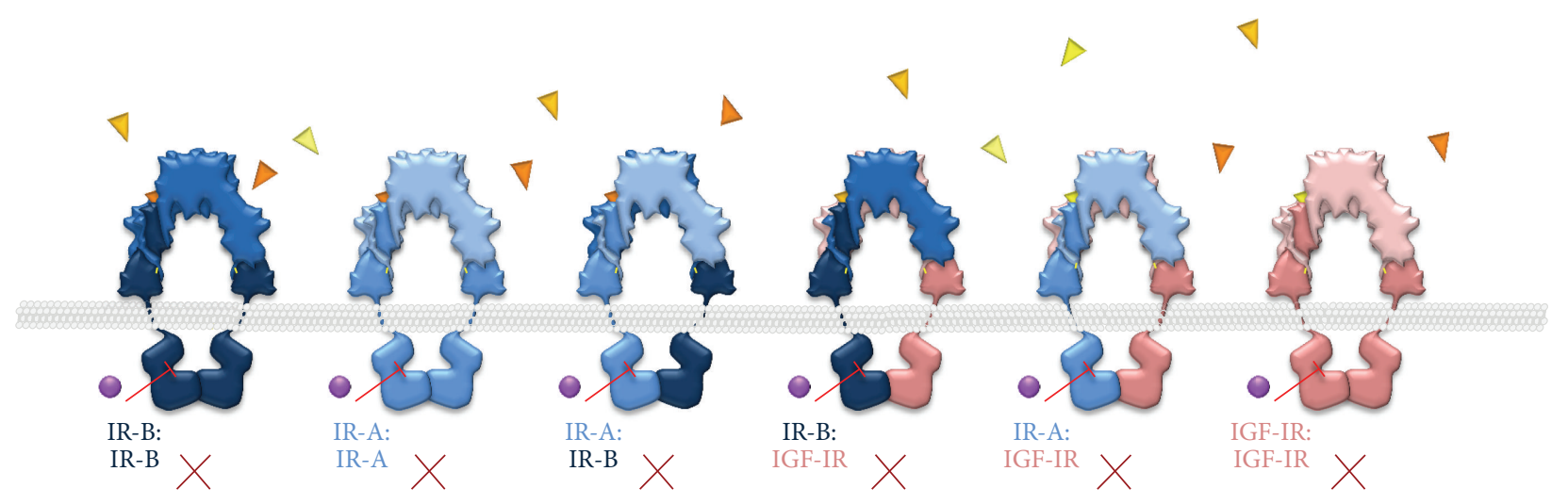

Tyrosine kinase inhibitor

(d)

FIGURE 9: Therapeutic strategies to inhibit insulin, IGF-1, and IGF-2 signal transduction. Graphic representations of the insulin receptor isoform B (IR-B, dark blue), the insulin receptor isoform A (IR-A, lighter blue), and of the type I IGF receptor (IGF-IR, pink) are shown as homodimeric or heterodimeric hybrid receptors. For each receptor monomer, the $\alpha$-chain is coloured slightly lighter than the $\beta$-chain. Bars indicate the approximate positions of the single disulphide bonds between the C647 in the $\alpha$-chain and C860 in the $\beta$-chain of each receptor monomer (yellow); the single disulphide bond between the FnIII-1 domains of each of the two $\alpha$ chains in each dimer is obscured. The extracellular ligands, insulin (orange), IGF-2 (ochre), and IGF-1 (pale yellow), are shown as triangles. The downward pointing grey arrows indicate that a signal has been transduced from a receptor dimer (a). The deep yellow spheres attached to the ectodomains of the activated receptors represent phosphorylated residues. Antibodies against IGF-1 and IGF-2 (IGF mAb; yellow), and recombinant insulin-like binding protein as an incomplete sphere (rIGFBP; light blue), are shown. Inhibition of a signal transduction molecule that is affected by one of the inhibitors is indicated by an inhibition symbol (brick red). Absence of a signal from a receptor dimer is indicated by a red cross below the receptor dimer (b). Monoclonal antibodies against IGF-1 and IGF-2 will not inhibit insulin signal transduction. Recombinant IGFBP will inhibit IGF-1 and IGF-2 but will not inhibit insulin. Antibodies specific for type I IGF receptor are shown (Type I IGF receptor mAb; deep pink) (c). Antibodies specific for the type I IGF receptor will inhibit type I IGF receptor homodimer and its hybrid receptors formed with both isoforms of the insulin receptor but will not inhibit insulin receptor homodimers or hybrids of the two isoforms of the insulin receptor. Representations of tyrosine kinase inhibitors (TKIs) that inhibit both the insulin and type I IGF receptors (tyrosine kinase inhibitor; violet) are illustrated (d). Tyrosine kinase inhibitors that affect type I IGF receptor and the insulin receptor will inhibit signal transduction via all the insulin and IGF signal transduction pathways. Tyrosine kinase inhibitors that are specific for the type I IGF receptor will inhibit the type I IGF receptor homodimer and its hybrid receptors but will not inhibit insulin receptor homodimers or hybrids of the two isoforms.

insulin receptor (Figure 9) $[153,254]$. The antibodies should have therefore activity in cells that express insulin receptors as long as type I IGF receptor is in excess.

Type I IGF receptor targeted antibodies have some undesirable side effects, notably hyperglycaemia. Blockade of type I IGF receptor in the hypothalamic pituitary axis is interpreted as a fall in circulating IGF-1 and as a consequence, growth hormone secretion is elevated. The net effect is a twofold increase in serum growth hormone concentrations, a modest increase in fasting glucose $(<20 \%)$ and an elevation in fasting insulin [248]. The induction of hyperglycaemia is thought to result from peripheral insulin-resistance associated with elevated levels of growth hormone. This side effect has resulted in the inclusion of growth hormone antagonists and glucose-lowering agents in some clinical trials.

There are upwards of 50 ongoing clinical trials of type I IGF receptor antibodies in combination with other treatments such as radiotherapy, chemotherapy, or inhibitors of other signal transduction pathways. Trials of receptor antibodies in combination with irradiation and chemotherapeutic drugs are based on the observations that type I IGF receptor causes radio- and chemoresistance in cell culture $[255,256]$ and in xenograft models by reducing apoptosis and increasing DNA replication and the repair of double-stranded breaks [257-261]. Trials have yielded mixed results with some being abandoned because of the frequency of adverse events or the low probability of achieving the endpoint of increased survival. Responses to single-agent therapy have been observed in sarcomas and adrenocortical carcinoma; prolonged periods of stable disease have been reported [251, 253, 262, 263]. Some regard these results as disappointing but others regard them as encouraging because the trials have been on unselected, heavily pretreated patients [264].

5.2. Small Molecule Inhibitors of Tyrosine Kinase Activity. The majority of the small molecule inhibitors that have been developed compete with ATP to bind to the catalytic tyrosine kinase domain of type I IGF receptor and hence inhibit its enzymatic activity: linisitinib, BMS-754807, and INSM18 [265, 266]. An exception is the picropodophyllin, AXL1717 , which is a non-ATP competitive inhibitor of the receptor kinase. The small molecule inhibitors are characterised by a short half-life which allows for easier control of their 
activity but requires frequent administration. They have the advantage compared with the therapeutic antibodies that they may be administered orally and may cross the blood brain barrier. They are generally less specific for type I IGF receptor than the antibodies, but have varying degrees of specificity for type I IGF receptor (Figure 9). For example, AXL-1717 is highly selective for type I IGF receptor whereas linisitinib inhibits the tyrosine kinases of both the insulin and type I IGF receptors. BMS-754807, is predominantly a dual type I IGF receptor and insulin receptor inhibitor which inhibits MET, TRK A, TRK B, Aurora A, and Aurora B kinases at high concentrations and INSM-18 inhibits type I IGF and insulin receptors and ErbB2 [254, 267].

Clinical trials of the tyrosine kinase inhibitors are not as advanced as trials of the inhibitory antibodies. The former are well tolerated and have shown antitumour activity in phase I dose escalation trials. They are being evaluated currently as single agents for the treatment of cancers in which the early trials showed evidence of a response, or in combination with cytotoxic drugs or inhibitors of other signal transduction pathways $[264,265]$.

5.3. Alternative Targeting Strategies. Therapeutic antibodies to the IGFs, and recombinant IGF binding proteins, are being developed to inhibit the effects of IGFs. MEDI-573 is a humanised monoclonal antibody that interacts with both IGF-1 and IGF-2. MEDI-573 prevents the IGFs binding to type I IGF and insulin receptors without affecting glucose homeostasis [268]. Cell growth of implanted malignant prostate cells is arrested in an animal model [269] and MEDI-573 has stabilised disease progression in phase I trials [254]. Recombinant IGFBP3 has been shown to lower the bioavailability of IGFs and to reduce tumour growth rate in animal models of trastuzumab-resistant breast cancer and of lung and colon cancers [270, 271].

5.4. Biomarkers of IGF Responsiveness. Stratification of patients on the basis of biomarker measurements has been shown to identify patients who are most likely to benefit from particular forms of therapy. For example, breast cancer patients are selected for hormone therapy based on oestrogen receptor or progesterone receptor status [272], and trastuzumab therapy is based on ErbB2 expression [273]. In colorectal cancer, epidermal growth factor receptor inhibitors such as cetuximab are of benefit only in patients with a nonmutated KRAS gene [274, 275].

Identification of patients who would benefit from inhibitors of the IGF signal transduction pathway is at an early stage. Studies with figitumumab have shown greater benefit in patients with high compared to those with low free IGF-1 levels in both non-small-cell lung carcinoma [276] and sarcoma [263] and a trend towards improved response in those with higher tumour type I IGF expression in non-small-cell lung carcinoma [254]. Other studies have suggested that expression of components of the IGF signal transduction pathway may help to predict responsiveness to a type I IGF receptor antibody [277] or have focussed on expression of IRS-1 or of the A isoform of the insulin receptor [204, 278]. Another approach may be to use molecular profiling to identify an IGF-responsive signature [279]. Alternatively, greater response to figitumumab was obtained in non-small-cell lung carcinomas with squamous histology which indicates that some tumour subtypes may be more responsive than others [254].

5.5. Inhibition of the Insulin Signal Transduction System. As described above, the high degree of similarity between the autophosphorylation catalytic domain of type I IGF and insulin receptors has meant that the majority of tyrosine kinase inhibitors interact with the two receptors with equivalent affinity (Figure 9). The realisation that the $\mathrm{A}$ isoform of the insulin receptor is expressed at high levels in many tumour cells has altered perceptions of this dual specificity which is viewed now by many as being advantageous.

Preclinical evidence indicates that the insulin receptor may compensate for the therapeutic inactivation of type I IGF receptor. Insulin receptor expression is increased in type I IGF receptor-null mice which allows normal growth of the animals [280] and the insulin receptor promotes resistance to inhibitory type I IGF receptor antibodies in a transgenic pancreatic and a mouse mammary tumour animal model $[267,281]$. Thus, an unforeseen benefit of the inhibitors that do not discriminate between the two receptors may be a superior clinical response.

It was expected that inhibition of the insulin receptor would lead to toxic levels of hyperglycaemia given the importance of the insulin receptor in the regulation of blood glucose. However, a recent study showed that administration of the tyrosine kinase inhibitor, BMS-536924, did not induce significant hyperglycaemia as it does not accumulate in muscle at levels sufficient to block insulin-stimulated glucose uptake [282].

Metformin, the biguanide taken by diabetes mellitus type 2 patients to lower their blood glucose levels, protects them against cancer. The exact protective mechanism is unknown and there is no evidence to suggest that metformin would be protective in nondiabetics. Nonetheless, data are encouraging and suggest that further research into biguanides and their role in cancer protection is warranted [283]. There is evidence from studies in vitro that metformin may have direct antitumour activity on tumour cells [284-287]. The demonstration that thiazolidinediones are peroxisome proliferator-activated receptor $\gamma(\operatorname{PPAR} \gamma)$ agonists suggests that they may have antiproliferative activity via repression of insulin receptor expression [288].

5.6. Steroid Hormone-Responsive Cancer. A few cancers are hormonally responsive of which the two most common are breast and prostate. Oestrogen and androgen dependence were identified as therapeutic targets for the treatment of breast and prostate cancers by oophorectomy and orchidectomy, respectively, before the molecular details of their mechanisms of action were known [232, 289]. A significant proportion of breast and prostate cancers are responsive to oestrogens and androgens, respectively; endometrial and ovarian cancers can respond to oestrogens and leukaemia 
responds to glucocorticoids. Current treatment targets either the supply of steroid hormone to the tumour cells or the interaction of the steroid hormone with its receptor.

In the context of the present review, the importance of endocrine therapy is in its value in combination with insulin- or IGF-targeted therapeutic strategies. The rationale is that because steroid hormones sensitise cancer cells to the tumour-promoting actions of insulin and IGFs, simultaneous targeting will potentiate the insulin- and IGF-suppressant effects. Present evidence indicates that this therapeutic approach is most likely to be effective in breast cancer but may have value also in endometrial and ovarian cancers [290294].

5.7. Inhibition of Steroid Synthesis. There are several different modalities of treatment designed to reduce oestrogen production. These therapies include surgical, cytotoxic chemical- or radiotherapeutic suppression of ovarian function, or inhibition of pituitary stimulation of ovarian function in pre- or perimenopausal women. Oestrogen production may be prevented by enzyme inhibition: $17 \alpha$ hydroxylase inhibitors such as abiraterone and orteronel prevent conversion of pregnenolone and progesterone into androstenedione, $5 \alpha$-reductase inhibitors such as finasteride and dutasteride prevent reduction of testosterone to the more potent dihydrotestosterone, and aromatase inhibitors such as exemestane and anastrozole prevent aromatisation of testosterone into oestradiol and of androstenedione into oestrone (Figure $4(\mathrm{~b})$ ).

In males and postmenopausal females, adipose tissue provides the major source of the enzymes $17 \beta$-hydroxysteroid dehydrogenase, which converts androstenedione into testosterone, and aromatase which converts androgens into oestrogens. It seems logical to suggest that the above therapies which target steroid synthesis might be particularly effective in the obese and many diabetic individuals who have abundant reservoirs of adipose tissue to produce the enzymes involved in steroid production.

5.8. Competitive Inhibitors of Binding of Steroids to Their Receptors. Steroid hormones are lipid-soluble and diffuse across the plasma membrane to interact with intracellular or intranuclear receptors. Responsiveness to steroid hormones is determined by the presence of steroid hormone receptors in the target cells of which there is at least one cognate receptor protein for each type of steroid hormones (Figure 4(a)). The steroid hormones bind to and activate their cognate receptors which are ligand-dependent transcription factors and thereby alter directly the expression of repertoires of hormone-responsive genes.

Antioestrogens are competitive inhibitors of oestrogen for the oestrogen receptor (Figure 4(c)). Competitive inhibitors can be partial oestrogen antagonists that do not stimulate some oestrogenic effects but do stimulate other oestrogen effects. The partial antagonist tamoxifen has been the antioestrogen used most widely. Tamoxifen is a triphenylethylene derivative that binds to the oestrogen receptor but does not induce the conformational change in the position of helix 12 relative to the ligand binding domain that is required for subsequent interaction with coactivators of transcription [295]. Tamoxifen and its metabolites have both oestrogenic and antioestrogenic activities in breast cancer cells [296, 297]. Pure oestrogen antagonists such as the steroidal antioestrogen, fulvestrant, have no oestrogen agonist activity [298]. Antiandrogens or androgen antagonists are the mainstay of systemic treatment of prostate cancer and may have a role in the treatment of some epithelial ovarian cancers. Flutamide and bicalutamide are widely used pure antiandrogens.

\subsection{Predictive Biomarkers of Responsiveness to Hormone} Therapy. Accepted predictive biomarkers of response to oestrogen-targeted therapy are the oestrogen and progesterone receptors. Other oestrogen-responsive gene products such as TFF1 have potential [299, 300]. In the context of combination therapy with insulin- or IGF-targeted drugs, measurement of important proteins in the IGF signal transduction pathway that are known to be induced by oestrogens would be apposite. Type I IGF receptor, IRS-1, IRS-2, and IGF-2 have all been shown to be induced by oestrogen in breast, and type I IGF receptor in endometrial and ovarian, cancer cells, and should be investigated as biomarkers for combination therapies.

\section{Conclusions}

Great strides have been made in understanding the pathophysiology that underlies the association between obesity and cancer risk. We have discussed the important contributions of hyperinsulinaemia, diabetes, exogenous insulins, and insulin-like growth factors and the influence of steroid hormones. The evidence for the relatively greater importance of visceral than subcutaneous obesity and of local or paracrine effects of IGFs and steroid hormones secreted by adipose tissue is overwhelming. Surgical intervention is effective and drugs to fight obesity by altered appetite or metabolism are available albeit with significant side effects. As obesity is preventable and reversible, the most effective cancer prevention strategy should be successful encouragement of a healthy lifestyle to control weight.

The effects of obesity and diabetes on cancer progression are mediated by the same pathways as cancer risk. This review has focused on insulin, insulin-like growth factors, and how their effects may be enhanced by steroid hormones. Conventional therapies have been used to target steroid hormone action for many years, and new therapies are being evaluated. Novel drugs that target the IGF signal transduction pathway, and in some cases the insulin signal transduction pathway in addition, have been developed and are in clinical evaluation. It is opportune that the availability of drugs which are predicted to be effective in cancers that arise in a background of obesity, hyperinsulinaemia, and diabetes has coincided with the onset of the obesity-associated cancer epidemic. 
It is fortuitous also that the onset of epic morbidity induced by altered hormonal balance and homeostasis disruption has been paralleled by enormous advances in our appreciation of the molecular mechanisms that underlie the interactions of insulin and IGFs with their receptors and their subsequent actions. Formerly, the distinctions between insulin, IGF-1, and IGF-2 and the biological effects that they stimulated via their cognate receptors were clear. We appreciate now that there is considerable redundancy and cross-interaction and that the same signal transduction proteins are activated by all three ligands. In malignant cells, high local IGF-2 concentrations, isoform A of the insulin receptor and hybrid receptors contribute to the significant insulin- and IGF-dependency. The ability of the malignant cells to respond to endogenous hyperinsulinaemia or to therapeutically induced hyperinsulinaemia or to the high local concentrations of IGF-1 and IGF-2 secreted from visceral adipose tissue in the case of endometrial and oesophageal cells or from mammary adipose tissue in the case of breast cells will be influenced by increased expression of isoform A of the insulin receptor and the type I IGF receptor. The biological response to the ligand is determined by the target cell as much or more than by which of the three ligands interacting with which receptor. The response of the target cell is dictated by the spectrum of proteins expressed within the cell which is programmed during differentiation. Thus, an endometrial, oesophageal, or breast cell will respond differently to the hormonal message of hyperinsulinaemia than will a liver or skeletal muscle cell; a mitogenic or cell survival signal will be transduced instead of glucose uptake and glycogenesis.

Increased knowledge about the underlying reasons for the increased risk associated with obesity, the metabolic syndrome, and diabetes should alert clinicians to the possibility that cancers that arise in obese or diabetic individuals are more likely to be driven by the aforementioned. As drugs improve and knowledge about effective biomarkers increases, appropriate and effective stratification of patients will become a reality. Surgeons and oncologists should be made aware of the likely pathways that drive the progression of cancers that arise in the obese, and in those with diabetes mellitus type 2 , to ensure that they request appropriate tests and prescribe appropriate therapies.

\section{Acknowledgments}

The authors thank the Breast Cancer Campaign and Cancer Research UK for their support of our work in some of the topics covered in this review. They are grateful to their colleagues for invaluable discussions and for their important contributions to this review.

\section{References}

[1] H. Pijl, "Obesity: evolution of a symptom of affluence," The Netherlands Journal of Medicine, vol. 69, no. 4, pp. 159-166, 2011.

[2] A. G. Renehan, I. Soerjomataram, M. Tyson et al., "Incident cancer burden attributable to excess body mass index in 30
European countries,' International Journal of Cancer, vol. 126, no. 3, pp. 692-702, 2010.

[3] F. G. Banting, C. H. Best, J. B. Collip, W. R. Campbell, and A. A. Fletcher, "Pancreatic extracts in the treatment of diabetes mellitus," Canadian Medical Association Journal, vol. 12, no. 3, pp. 141-146, 1922.

[4] H. Bays, L. Mandarino, and R. A. DeFronzo, "Role of the adipocyte, free fatty acids, and ectopic fat in pathogenesis of type 2 diabetes mellitus: peroxisomal proliferator-activated receptor agonists provide a rational therapeutic approach," Journal of Clinical Endocrinology and Metabolism, vol. 89, no. 2, pp. 463-478, 2004.

[5] M. Snel, J. T. Jonker, J. Schoones et al., "Ectopic fat and insulin resistance: pathophysiology and effect of diet and lifestyle Interventions," International Journal of Endocrinology, vol. 2012, Article ID 983814, 18 pages, 2012.

[6] M. H. Shanik, Y. Xu, J. Skrha, R. Dankner, Y. Zick, and J. Roth, "Insulin resistance and hyperinsulinemia: is hyperinsulinemia the cart or the horse?" Diabetes Care, vol. 31, 2, pp. S262-S268, 2008.

[7] A. Gupta and V. Gupta, "Metabolic syndrome: what are the risks for humans?" Bioscience Trends, vol. 4, no. 5, pp. 204-212, 2010.

[8] Z. A. Ma, Z. Zhao, and J. Turk, "Mitochondrial dysfunction and beta-cell failure in type 2 diabetes mellitus," Experimental Diabetes Research, vol. 2012, Article ID 703538, 11 pages, 2012.

[9] V. Poitout, "Glucolipotoxicity of the pancreatic $\beta$-cell: myth or reality?" Biochemical Society Transactions, vol. 36, no. 5, pp. 901904, 2008.

[10] V. Poitout and R. P. Robertson, "Glucolipotoxicity: fuel excess and $\beta$-cell dysfunction," Endocrine Reviews, vol. 29, no. 3, pp. 351-366, 2008.

[11] J. C. Mbanya and K. Ramiaya, Diabetes Mellitus, 2006.

[12] T. Kuzuya, S. Nakagawa, J. Satoh et al., "Report of the Committee on the classification and diagnostic criteria of diabetes mellitus," Diabetes Research and Clinical Practice, vol. 55, no. 1, pp. 65-85, 2002.

[13] T. Salvatore and D. Giugliano, "Pharmacokinetic-pharmacodynamic relationships of acarbose," Clinical Pharmacokinetics, vol. 30, no. 2, pp. 94-106, 1996.

[14] J. K. DiStefano and R. M. Watanabe, "Pharmacogenetics of Anti-diabetes drugs," Pharmaceuticals, vol. 3, no. 8, pp. 26102646, 2010.

[15] M. K. Piya, A. A. Tahrani, and A. H. Barnett, "Emerging treatment options for type 2 diabetes," British Journal of Clinical Pharmacology, vol. 70, no. 5, pp. 631-644, 2010.

[16] J. Unger, "Insulin initiation and intensification in patients with T2DM for the primary care physician," Diabetes, Metabolic Syndrome and Obesity, vol. 4, pp. 253-261, 2011.

[17] A. P. Polednak, "Estimating the number of U.S. incident cancers attributable to obesity and the impact on temporal trends in incidence rates for obesity-related cancers," Cancer Detection and Prevention, vol. 32, no. 3, pp. 190-199, 2008.

[18] T. D. Adams, A. M. Stroup, R. E. Gress et al., "Cancer incidence and mortality after gastric bypass surgery," Obesity, vol. 17, no. 4, pp. 796-802, 2009.

[19] A. G. Renehan, M. Tyson, M. Egger, R. F. Heller, and M. Zwahlen, "Body-mass index and incidence of cancer: a systematic review and meta-analysis of prospective observational studies," The Lancet, vol. 371, no. 9612, pp. 569-578, 2008.

[20] D. M. Parkin and L. Boyd, "Cancers attributable to overweight and obesity in the UK in 2010," British Journal of Cancer, vol. 105, Supplemnt 2, pp. S34-S37, 2011. 
[21] A. Bergstrom, P. Pisani, V. Tenet, A. Wolk, and H. O. Adami, "Overweight as an avoidable cause of cancer in Europe," International Journal of Cancer, vol. 91, no. 3, pp. 421-430, 2001.

[22] P. Vigneri, F. Frasca, L. Sciacca, G. Pandini, and R. Vigneri, "Diabetes and cancer," Endocrine-Related Cancer, vol. 16, no. 4, pp. 1103-1123, 2009.

[23] E. Giovannucci, D. M. Harlan, M. C. Archer et al., "Diabetes and cancer: a consensus report," CA Cancer Journal for Clinicians, vol. 60, no. 4, pp. 207-221, 2010.

[24] B. Arcidiacono, S. Iiritano, A. Nocera et al., "Insulin resistance and cancer risk: an overview of the pathogenetic mechanisms," Experimental Diabetes Research, vol. 2012, Article ID 789174, 2012.

[25] W. Huang, H. Ren, Q. Ben, Q. Cai, W. Zhu, and Z. Li, "Risk of esophageal cancer in diabetes mellitus: a meta-analysis of observational studies," Cancer Causes Control, vol. 23, no. 2, pp. 263-272, 2012.

[26] J. Ma, H. Li, E. Giovannucci et al., "Prediagnostic body-mass index, plasma C-peptide concentration, and prostate cancerspecific mortality in men with prostate cancer: a long-term survival analysis," The Lancet Oncology, vol. 9, no. 11, pp. 10391047, 2008.

[27] D. L. Roberts, C. Dive, and A. G. Renehan, "Biological mechanisms linking obesity and cancer risk: new perspectives," Annual Review of Medicine, vol. 61, pp. 301-316, 2010.

[28] C. J. Balentine, J. Enriquez, W. Fisher et al., "Intra-abdominal fat predicts survival in pancreatic cancer," Journal of Gastrointestinal Surgery, vol. 14, no. 11, pp. 1832-1837, 2010.

[29] J. J. Dignam, B. N. Polite, G. Yothers et al., "Body mass index and outcomes in patients who receive adjuvant chemotherapy for colon cancer," Journal of the National Cancer Institute, vol. 98, no. 22, pp. 1647-1654, 2006.

[30] J. A. Meyerhardt, P. J. Catalano, D. G. Haller et al., "Influence of body mass index on outcomes and treatment-related toxicity in patients with colon carcinoma," Cancer, vol. 98, no. 3, pp. 484495, 2003.

[31] F. A. Sinicrope, N. R. Foster, D. J. Sargent, M. J. O'Connell, and C. Rankin, "Obesity is an independent prognostic variable in colon cancer survivors," Clinical Cancer Research, vol. 16, no. 6, pp. 1884-1893, 2010.

[32] V. E. von Gruenigen, C. Tian, H. Frasure, S. Waggoner, H. Keys, and R. R. Barakat, "Treatment effects, disease recurrence, and survival in obese women with early endometrial carcinoma: a Gynecologic Oncology Group Study," Cancer, vol. 107, no. 12, pp. 2786-2791, 2006.

[33] V. M. Chia, P. A. Newcomb, A. Trentham-Dietz, and J. M. Hampton, "Obesity, diabetes, and other factors in relation to survival after endometrial cancer diagnosis," International Journal of Gynecological Cancer, vol. 17, no. 2, pp. 441-446, 2007.

[34] H. S. Yang, C. Yoon, S. K. Myung, and S. M. Park, "Effect of obesity on survival of women with epithelial ovarian cancer: a systematic review and meta-analysis of observational studies," International Journal of Gynecological Cancer, vol. 21, no. 9, pp. 1525-1532, 2011.

[35] A. McTiernan, M. Irwin, and V. Vongruenigen, "Weight, physical activity, diet, and prognosis in breast and gynecologic cancers," Journal of Clinical Oncology, vol. 28, no. 26, pp. 40744080, 2010.

[36] C. L. Rock and W. Demark-Wahnefried, "Nutrition and survival after the diagnosis of breast cancer: a review of the evidence," Journal of Clinical Oncology, vol. 20, no. 15, pp. 3302-3316, 2002.
[37] M. Ewertz, M. B. Jensen, K. Á. Gunnarsdóttir et al., "Effect of obesity on prognosis after early-stage breast cancer," Journal of Clinical Oncology, vol. 29, no. 1, pp. 25-31, 2011.

[38] J. P. Pierce, M. L. Stefanick, S. W. Flatt et al., "Greater survival after breast cancer in physically active women with high vegetable-fruit intake regardless of obesity," Journal of Clinical Oncology, vol. 25, no. 17, pp. 2345-2351, 2007.

[39] B. Sternfeld, E. Weltzien, C. P. Quesenberry et al., "Physical activity and risk of recurrence and mortality in breast cancer survivorsfindings from the LACE study," Cancer Epidemiology Biomarkers and Prevention, vol. 18, no. 1, pp. 87-95, 2009.

[40] C. H. Saely, K. Geiger, and H. Drexel, "Brown versus white adipose tissue: a mini-review," Gerontology, vol. 58, no. 1, pp. 15-23, 2012.

[41] W. Shen, Z. Wang, M. Punyanita et al., "Adipose tissue quantification by imaging methods: a proposed classification," Obesity Research, vol. 11, no. 1, pp. 5-16, 2003.

[42] W. F. Ferris and N. J. Crowther, "Once fat was fat and that was that: our changing perspectives on adipose tissue," Cardiovascular Journal of Africa, vol. 22, no. 3, pp. 147-154, 2011.

[43] P. Trayhurn and J. H. Beattie, "Physiological role of adipose tissue: white adipose tissue as an endocrine and secretory organ," Proceedings of the Nutrition Society, vol. 60, no. 3, pp. 329-339, 2001.

[44] M. Korsic, K. Fister, D. Ivankovic, and J. Jelcic, "Visceral obesity," Lijecnicki Vjesnik, vol. 133, no. 7-8, pp. 284-287, 2011.

[45] B. L. Wajchenberg, "Subcutaneous and visceral adipose tissue: their relation to the metabolic syndrome," Endocrine Reviews, vol. 21, no. 6, pp. 697-738, 2000.

[46] T. Pischon, H. Boeing, K. Hoffmann et al., "General and abdominal adiposity and risk of death in Europe," The New England Journal of Medicine, vol. 359, no. 20, pp. 2105-2120, 2008.

[47] T. McLaughlin, C. Lamendola, A. Liu, and F. Abbasi, "Preferential fat deposition in subcutaneous versus visceral depots is associated with insulin sensitivity," The Journal of Clinical Endocrinology and Metabolism, vol. 96, no. 11, pp. E1756-E1760, 2011.

[48] J. P. Després, I. Lemieux, J. Bergeron et al., "Abdominal obesity and the metabolic syndrome: contribution to global cardiometabolic risk," Arteriosclerosis, Thrombosis, and Vascular Biology, vol. 28, no. 6, pp. 1039-1049, 2008.

[49] S. L. Doyle, C. L. Donohoe, J. Lysaght, and J. V. Reynolds, "Visceral obesity, metabolic syndrome, insulin resistance and cancer," Proceedings of the Nutrition Society, vol. 71, no. 1, pp. 181-189, 2012.

[50] R. W. Taylor, A. M. Grant, S. M. Williams, and A. Goulding, "Sex differences in regional body fat distribution from pre- to postpuberty," Obesity, vol. 18, no. 7, pp. 1410-1416, 2010.

[51] M. J. Toth, A. Tchernof, C. K. Sites, and E. T. Poehlman, "Menopause-related changes in body fat distribution," Annals of the New York Academy of Sciences, vol. 904, pp. 502-506, 2000.

[52] H. Su, L. Jiang, C. Carter-Su, and L. Rui, "Glucose enhances leptin signaling through modulation of AMPK activity," PLoS One, vol. 7, no. 2, article e31636, 2012.

[53] D. L. Morris and L. Rui, "Recent advances in understanding leptin signaling and leptin resistance," American Journal of Physiology, Endocrinology and Metabolism, vol. 297, no. 6, pp. E1247-E1259, 2009.

[54] R. C. Frederich, A. Hamann, S. Anderson, B. Lollmann, B. B. Lowell, and J. S. Flier, "Leptin levels reflect body lipid content 
in mice: evidence for diet-induced resistance to leptin action," Nature Medicine, vol. 1, no. 12, pp. 1311-1314, 1995.

[55] P. Stattin, R. Palmqvist, S. Söderberg et al., "Plasma leptin and colorectal cancer risk: a prospective study in Northern Sweden.," Oncology Reports, vol. 10, no. 6, pp. 2015-2021, 2003.

[56] E. Petridou, M. Belechri, N. Dessypris et al., "Leptin and body mass index in relation to endometrial cancer risk," Annals of Nutrition and Metabolism, vol. 46, no. 3-4, pp. 147-151, 2002.

[57] D. C. Chen, Y. F. Chung, Y. T. Yeh et al., "Serum adiponectin and leptin levels in Taiwanese breast cancer patients," Cancer Letters, vol. 237, no. 1, pp. 109-114, 2006.

[58] M. R. Hoda, S. J. Keely, L. S. Bertelsen, W. G. Junger, D. Dharmasena, and K. E. Barrett, "Leptin acts as a mitogenic and antiapoptotic factor for colonic cancer cells," British Journal of Surgery, vol. 94, no. 3, pp. 346-354, 2007.

[59] M. R. Hoda and G. Popken, "Mitogenic and anti-apoptotic actions of adipocyte-derived hormone leptin in prostate cancer cells," BJU International, vol. 102, no. 3, pp. 383-388, 2008.

[60] N. K. Saxena, L. Taliaferro-Smith, B. B. Knight et al., "Bidirectional crosstalk between leptin and insulin-like growth factor-I signaling promotes invasion and migration of breast cancer cells via transactivation of epidermal growth factor receptor," Cancer Research, vol. 68, no. 23, pp. 9712-9722, 2008.

[61] A. Shehzad, W. Iqbal, O. Shehzad, and Y. S. Lee, "Adiponectin: regulation of its production and its role in human diseases," Hormones-International Journal of Endocrinology and Metabolism, vol. 11, no. 1, pp. 8-20, 2012.

[62] C. Mantzoros, E. Petridou, N. Dessypris et al., "Adiponectin and breast cancer risk," The Journal of Clinical Endocrinology and Metabolism, vol. 89, no. 3, pp. 1102-1107, 2004.

[63] P. T. Soliman, D. Wu, G. Tortolero-Luna et al., "Association between adiponectin, insulin resistance, and endometrial cancer," Cancer, vol. 106, no. 11, pp. 2376-2381, 2006.

[64] E. K. Wei, E. Giovannucci, C. S. Fuchs, W. C. Willett, and C. S. Mantzoros, "Low plasma adiponectin levels and risk of colorectal cancer in men: a prospective study," Journal of the National Cancer Institute, vol. 97, no. 22, pp. 1688-1694, 2005.

[65] S. Goktas, I. Y. Mahmut, K. Caglar, A. Sonmez, S. Kilic, and S. Bedir, "Prostate cancer and adiponectin," Urology, vol. 65, no. 6, pp. 1168-1172, 2005.

[66] L. de Sevilla, S. A. McCune, and M. E. White, "Insulin-like growth factor mRNA expression in tissue of lean and obese male SHFF/Mcc-fa(cp) rats," Comparative Biochemistry and Physiology B, vol. 109, no. 2-3, pp. 371-382, 1994.

[67] C. K. Wolverton, M. J. Azain, J. Y. Duffy, M. E. White, and T. G. Ramsay, "Influence of somatotropin on lipid metabolism and IGF gene expression in porcine adipose tissue," American Journal of Physiology, Endocrinology and Metabolism, vol. 263, no. 4, pp. E637-E645, 1992.

[68] P. C. Owens, K. L. Gatford, P. E. Walton, W. Morley, and R. G. Campbel, "The relationship between endogenous insulin-like growth factors and growth in pigs," Journal of Animal Science, vol. 77, no. 8, pp. 2098-2103, 1999.

[69] C. L. Donohoe, S. L. Doyle, S. McGarrigle et al., "Role of the insulin-like growth factor 1 axis and visceral adiposity in oesophageal adenocarcinoma," British Journal of Surgery, vol. 99, no. 3, pp. 387-396, 2012.

[70] P. Marin, H. Kvist, G. Lindstedt, L. Sjistrim, and P. Bjirntorp, "Low concentrations of insulin-like growth factor-I in abdominal obesity," International Journal of Obesity and Related Metabolic Disorders, vol. 17, no. 2, pp. 83-89, 1993.
[71] E. R. Simpson, C. Clyne, G. Rubin et al., "Aromatase-a brief overview," Annual Review of Physiology, vol. 64, pp. 93-127, 2002.

[72] K. Subbaramaiah, L. R. Howe, P. Bhardwaj et al., "Obesity is associated with inflammation and elevated aromatase expression in the mouse mammary gland," Cancer Prevention Research, vol. 4, no. 3, pp. 329-346, 2011.

[73] A. L. Chand, H. Thorne, E. R. Simpson, and C. D. Clyne, "Aromatase expression is increased in BRCA1 mutation carriers," BMC Cancer, vol. 9, article no. 148, 2009.

[74] C. A. Lamar, J. F. Dorgan, C. Longcope, F. Z. Stanczyk, R. T. Falk, and H. E. Stephenson, "Serum sex hormones and breast cancer risk factors in postmenopausal women," Cancer Epidemiology Biomarkers and Prevention, vol. 12, no. 4, pp. 380-383, 2003.

[75] F. E. B. May and B. R. Westley, "Cloning of estrogen-regulated messenger RNA sequences from human breast cancer cells," Cancer Research, vol. 46, no. 12, pp. 6034-6040, 1986.

[76] B. R. Westley and F. E. B. May, "Oestrogen regulates cathepsin D mRNA levels in oestrogen responsive human breast cancer cells," Nucleic Acids Research, vol. 15, no. 9, pp. 3773-3786, 1987.

[77] F. E. B. May and B. R. Westley, "Identification and characterization of estrogen-regulated RNAs in human breast cancer cells," Journal of Biological Chemistry, vol. 263, no. 26, pp. 12901-12908, 1988.

[78] A. J. Stewart, M. D. Johnson, F. E. B. May, and B. R. Westley, "Role of insulin-like growth factors and the type I insulin-like growth factor receptor in the estrogen-stimulated proliferation of human breast cancer cells," Journal of Biological Chemistry, vol. 265, no. 34, pp. 21172-21178, 1990.

[79] W. D. Salmon Jr. and W. H. Daughaday, "A hormonally controlled serum factor which stimulates sulfate incorporation by cartilage in vitro," The Journal of Laboratory and Clinical Medicine, vol. 49, no. 6, pp. 825-836, 1957.

[80] F. C. Nielsen, "The molecular and cellular biology of insulinlike growth factor II," Cytokine and Growth Factor Reviews, vol. 4, no. 3, pp. 257-290, 1992.

[81] S. Rainier, L. A. Johnson, C. J. Dobry, A. J. Ping, P. E. Grundy, and A. P. Feinberg, "Relaxation of imprinted genes in human cancer," Nature, vol. 362, no. 6422, pp. 747-749, 1993.

[82] P. Jelinic and P. Shaw, "Loss of imprinting and cancer," Journal of Pathology, vol. 211, no. 3, pp. 261-268, 2007.

[83] O. Ogawa, M. R. Eccles, J. Szeto et al., "Relaxation of insulin-like growth factor II gene imprinting implicated in Wilms' tumour," Nature, vol. 362, no. 6422, pp. 749-751, 1993.

[84] B. J. Smith, K. Huang, G. Kong et al., "Structural resolution of a tandem hormone-binding element in the insulin receptor and its implications for design of peptide agonists," Proceedings of the National Academy of Sciences of the United States of America, vol. 107, no. 15, pp. 6771-6776, 2010.

[85] N. M. McKern, M. C. Lawrence, V. A. Streltsov et al., "Structure of the insulin receptor ectodomain reveals a folded-over conformation," Nature, vol. 443, no. 7108, pp. 218-221, 2006.

[86] C. W. Ward and M. C. Lawrence, "Similar but different: ligandinduced activation of the insulin and epidermal growth factor receptor families," Current Opinion in Structural Biology, vol. 22, no. 3, pp. 360-366, 2012.

[87] A. E. Whitten, B. J. Smith, J. G. Menting et al., "Solution structure of ectodomains of the insulin receptor family: the ectodomain of the type 1 insulin-like growth factor receptor displays asymmetry of ligand binding accompanied by limited conformational change," Journal of Molecular Biology, vol. 394, no. 5, pp. 878-892, 2009. 
[88] C. W. Ward and M. C. Lawrence, "Ligand-induced activation of the insulin receptor: a multi-step process involving structural changes in both the ligand and the receptor," Bioessays, vol. 31, no. 4, pp. 422-434, 2009.

[89] L. Whittaker, C. Hao, W. Fu, and J. Whittaker, "High-affinity insulin binding: insulin interacts with two receptor ligand binding sites," Biochemistry, vol. 47, no. 48, pp. 12900-12909, 2008.

[90] A. Ullrich, J. R. Bell, and E. Y. Chen, "Human insulin receptor and its relationship to the tyrosine kinase family of oncogenes," Nature, vol. 313, no. 6005, pp. 756-761, 1985.

[91] D. E. Moller, A. Yokota, J. F. Caro, and J. S. Flier, “Tissue-specific expression of two alternatively spliced insulin receptor mRNAs in man," Molecular Endocrinology, vol. 3, no. 8, pp. 1263-1269, 1989.

[92] F. Frasca, G. Pandini, P. Scalia et al., "Insulin receptor isoform A, a newly recognized, high-affinity insulin- like growth factor II receptor in fetal and cancer cells," Molecular and Cellular Biology, vol. 19, no. 5, pp. 3278-3288, 1999.

[93] L. Sciacca, A. Costantino, G. Pandini et al., "Insulin receptor activation by IGF-II in breast cancers: evidence for a new autocrine/paracrine mechanism," Oncogene, vol. 18, no. 15, pp. 2471-2479, 1999.

[94] V. Vella, L. Sciacca, G. Pandini et al., "The IGF system in thyroid cancer: new concepts," Molecular Pathology, vol. 54, no. 3, pp. 121-124, 2001.

[95] M. E. Cox, M. E. Gleave, M. Zakikhani et al., "Insulin receptor expression by human prostate cancers," Prostate, vol. 69, no. 1, pp. 33-40, 2009.

[96] K. R. Kalli, O. I. Falowo, L. K. Bale, M. A. Zschunke, P. C. Roche, and C. A. Conover, "Functional insulin receptors on human epithelial ovarian carcinoma cells: implications for IGFII mitogenic signaling," Endocrinology, vol. 143, no. 9, pp. 32593267, 2002.

[97] Y. Li, Q. Chang, B. P. Rubin et al., "Insulin receptor activation in solitary fibrous tumours," Journal of Pathology, vol. 211, no. 5, pp. 550-554, 2007.

[98] A. Altieri, S. Franceschi, J. Ferlay, J. Smith, and C. La Vecchia, "Epidemiology and aetiology of gestational trophoblastic diseases," The Lancet Oncology, vol. 4, no. 11, pp. 670-678, 2003.

[99] L. Mosthaf, K. Grako, T. J. Dull, L. Coussens, A. Ullrich, and D. A. McClain, "Functionally distinct insulin receptors generated by tissue-specific alternative splicing," EMBO Journal, vol. 9, no. 8, pp. 2409-2413, 1990.

[100] A. Belfiore and R. Malaguarnera, "Insulin receptor and cancer," Endocrine-Related Cancer, vol. 18, no. 4, pp. R125-R147, 2011.

[101] S. Benyoucef, K. H. Surinya, D. Hadaschik, and K. Siddle, "Characterization of insulin/IGF hybrid receptors: contributions of the insulin receptor L2 and Fn1 domains and the alternatively spliced exon 11 sequence to ligand binding and receptor activation," Biochemical Journal, vol. 403, no. 3, pp. 603-613, 2007.

[102] Y. Yamaguchi, J. S. Flier, H. B. B. J. Ransil, and D. E. Moller, "Ligand-binding properties of the two isoforms of the human insulin receptor," Endocrinology, vol. 132, no. 3, pp. 1132-1138, 1993.

[103] A. Denley, G. V. Brierley, J. M. Carroll et al., "Differential activation of insulin receptor isoforms by insulin-like growth factors is determined by the C domain," Endocrinology, vol. 147, no. 2, pp. 1029-1036, 2006.
[104] G. Pandini, F. Frasca, R. Mineo, L. Sciacca, R. Vigneri, and A. Belfiore, "Insulin/insulin-like growth factor I hybrid receptors have different biological characteristics depending on the insulin receptor isoform involved," Journal of Biological Chemistry, vol. 277, no. 42, pp. 39684-39695, 2002.

[105] T. P. J. Garrett, N. M. McKern, M. Lou et al., "Crystal structure of the first three domains of the type-1 insulin-like growth factor receptor," Nature, vol. 394, no. 6691, pp. 395-399, 1998.

[106] J. Wu, W. Li, B. P. Craddock et al., "Small-molecule inhibition and activation-loop trans-phosphorylation of the IGF1 receptor," EMBO Journal, vol. 27, no. 14, pp. 1985-1994, 2008.

[107] M. Lou, T. P. J. Garrett, N. M. McKern et al., "The first three domains of the insulin receptor differ structurally from the insulin-like growth factor 1 receptor in the regions governing ligand specificity," Proceedings of the National Academy of Sciences of the United States of America, vol. 103, no. 33, pp. 12429-12434, 2006.

[108] T. Kjeldsen, F. C. Wiberg, and A. S. Andersen, "Chimeric receptors indicate that phenylalanine 39 is a major contributor to insulin specificity of the insulin receptor," Journal of Biological Chemistry, vol. 269, no. 52, pp. 32942-32946, 1994.

[109] C. T. Christoffersen, K. E. Bornfeldt, C. M. Rotella et al., "Negative cooperativity in the insulin-like growth factor-I receptor and a chimeric IGF-I/insulin receptor," Endocrinology, vol. 135, no. 1, pp. 472-475, 1994.

[110] K. H. Surinya, B. E. Forbes, F. Occhiodoro et al., "An investigation of the ligand binding properties and negative cooperativity of soluble insulin-like growth factor receptors," Journal of Biological Chemistry, vol. 283, no. 9, pp. 5355-5363, 2008.

[111] L. Gauguin, C. Delaine, C. L. Alvino et al., "Alanine scanning of a putative receptor binding surface of insulin-like growth factorI," Journal of Biological Chemistry, vol. 283, no. 30, pp. 2082120829, 2008.

[112] C. L. Alvino, K. A. McNeil, S. C. Ong et al., "A novel approach to identify two distinct receptor binding surfaces of insulin-like growth factor II," Journal of Biological Chemistry, vol. 284, no. 12, pp. 7656-7664, 2009.

[113] K. Siddle, "Signalling by insulin and IGF receptors: supporting acts and new players," Journal of Molecular Endocrinology, vol. 47, no. 1, pp. R1-R10, 2011.

[114] K. Siddle, "Molecular basis of signaling specificity of insulin and IGF receptors: neglected corners and recent advances," Frontiers in Endocrinology, vol. 3, article 34, 2012.

[115] M. A. Soos and K. Siddle, "Immunological relationships between receptors for insulin and insulin-like growth factor I. Evidence for structural heterogeneity of insulin-like growth factor I receptors involving hybrids with insulin receptors," Biochemical Journal, vol. 263, no. 2, pp. 553-563, 1989.

[116] M. A. Soos, B. T. Nave, and K. Siddle, "Immunological studies of type I IGF receptors and insulin receptors: characterisation of hybrid and atypical receptor subtypes," Advances in Experimental Medicine and Biology, vol. 343, pp. 145-157, 1993.

[117] M. A. Soos, C. E. Field, and K. Siddle, "Purified hybrid insulin/ insulin-like growth factor-I receptors bind insulin-like growth factor-I, but not insulin, with high affinity," Biochemical Journal, vol. 290, no. 2, pp. 419-426, 1993.

[118] E. M. Bailyes, B. T. Nave, M. A. Soos, S. R. Orr, A. C. Hayward, and K. Siddle, "Insulin receptor/IGF-I receptor hybrids are widely distributed in mammalian tissues: quantification of individual receptor species by selective immunoprecipitation and immunoblotting," Biochemical Journal, vol. 327, no. 1, pp. 209-215, 1997. 
[119] R. Slaaby, L. Schäffer, I. Lautrup-Larsen et al., "Hybrid receptors formed by insulin receptor (IR) and insulin-like growth factor i receptor (IGF-IR) have low insulin and high IGF-1 affinity irrespective of the IR splice variant," Journal of Biological Chemistry, vol. 281, no. 36, pp. 25869-25874, 2006.

[120] C. Weyer, T. Funahashi, S. Tanaka et al., "Hypoadiponectinemia in obesity and type 2 diabetes: close association with insulin resistance and hyperinsulinemia," Journal of Clinical Endocrinology and Metabolism, vol. 86, no. 5, pp. 1930-1935, 2001.

[121] M. A. Abdul-Ghani, M. Matsuda, B. Balas, and R. A. DeFronzo, "Insulin resistance and insulin secretory dysfunction are independent predictors of worsening of glucose tolerance during each stage of type 2 diabetes development," Diabetes Care, vol. 24, no. 1, pp. 89-94, 2001.

[122] J. A. Mayfield and R. D. White, "Insulin therapy for type 2 diabetes: rescue, augmentation, and replacement of beta-cell function," American Family Physician, vol. 70, no. 3, pp. 489500, 2004.

[123] V. Hwa, Y. Oh, and R. G. Rosenfeld, "The insulin-like growth factor-binding protein (IGFBP) superfamily," Endocrine Reviews, vol. 20, no. 6, pp. 761-787, 1999.

[124] D. R. Clemmons, W. Busby, J. B. Clarke, A. Parker, C. Duan, and T. J. Nam, "Modifications of insulin-like growth factor binding proteins and their role in controlling IGF actions," Endocrine Journal, vol. 45, supplement, pp. S1-S8, 1998.

[125] D. R. Clemmons, "Role of insulin-like growth factor binding proteins in controlling IGF actions," Molecular and Cellular Endocrinology, vol. 140, no. 1-2, pp. 19-24, 1998.

[126] M. F. White, S. E. Shoelson, H. Keutmann, and C. R. Kahn, "A cascade of tyrosine autophosphorylation in the $\beta$-subunit activates the phosphotransferase of the insulin receptor," Journal of Biological Chemistry, vol. 263, no. 6, pp. 2969-2980, 1988.

[127] B. A. Liu, K. Jablonowski, E. E. Shah, B. W. Engelmann, R. B. Jones, and P. D. Nash, "SH2 domains recognize contextual peptide sequence information to determine selectivity," Molecular and Cellular Proteomics, vol. 9, no. 11, pp. 2391-2404, 2010.

[128] T. Rordorf-Nikolic, D. J. Van Horn, D. Chen, M. F. White, and J. M. Backer, "Regulation of phosphatidylinositol 3'-kinase by tyrosyl phosphoproteins. Full activation requires occupancy of both SH2 domains in the $85-\mathrm{kDa}$ regulatory subunit," Journal of Biological Chemistry, vol. 270, no. 8, pp. 3662-3666, 1995.

[129] A. M. Valverde, C. Mur, S. Pons et al., "Association of insulin receptor substrate 1 (IRS-1) Y895 with Grb-2 mediates the insulin signaling involved in IRS-1-deficient brown adipocyte mitogenesis," Molecular and Cellular Biology, vol. 21, no. 7, pp. 2269-2280, 2001.

[130] C. M. Taniguchi, B. Emanuelli, and C. R. Kahn, "Critical nodes in signalling pathways: insights into insulin action," Nature Reviews Molecular Cell Biology, vol. 7, no. 2, pp. 85-96, 2006.

[131] C. Hernandez-Sanchez, V. Blakesley, T. Kalebic, L. Helman, and D. LeRoith, "The role of the tyrosine kinase domain of the insulin-like growth factor- I receptor in intracellular signaling, cellular proliferation, and tumorigenesis," Journal of Biological Chemistry, vol. 270, no. 49, pp. 29176-29181, 1995.

[132] A. V. Ougolkov, N. D. Bone, M. E. Fernandez-Zapico, N. E. Kay, and D. D. Billadeau, "Inhibition of glycogen synthase kinase3 activity leads to epigenetic silencing of nuclear factor $\kappa \mathrm{B}$ target genes and induction of apoptosis in chronic lymphocytic leukemia B cells," Blood, vol. 110, no. 2, pp. 735-742, 2007.

[133] M. Sun, G. Meares, L. Song, and R. S. Jope, "XIAP associates with GSK3 and inhibits the promotion of intrinsic apoptotic signaling by GSK3," Cellular Signalling, vol. 21, no. 12, pp. 18571865, 2009.

[134] D. Feldser, F. Agani, N. V. Iyer, B. Pak, G. Ferreira, and G. L. Semenza, "Reciprocal positive regulation of hypoxia-inducible factor $1 \alpha$ and insulin-like growth factor 2," Cancer Research, vol. 59, no. 16, pp. 3915-3918, 1999.

[135] R. Fukuda, K. Hirota, F. Fan, Y. D. Jung, L. M. Ellis, and G. L. Semenza, "Insulin-like growth factor 1 induces hypoxiainducible factor 1-mediated vascular endothelial growth factor expression, which is dependent on MAP kinase and phosphatidylinositol 3-kinase signaling in colon cancer cells," Journal of Biological Chemistry, vol. 277, no. 41, pp. 38205-38211, 2002.

[136] S. Shigematsu, K. Yamauchi, K. Nakajima, S. Iijima, T. Aizawa, and K. Hashizume, "IGF-1 regulates migration and angiogenesis of human endothelial cells," Endocrine Journal, vol. 46, supplement, pp. S59-S62, 1999.

[137] O. H. Lee, S. K. Bae, M. H. Bae et al., "Identification of angiogenic properties of insulin like growth factor II in in vitro angiogenesis models," British Journal of Cancer, vol. 82, no. 2, pp. 385-391, 2000.

[138] Y. Tang, D. Zhang, L. Fallavollita, and P. Brodt, "Vascular endothelial growth factor $\mathrm{C}$ expression and lymph node metastasis are regulated by the type I insulin-like growth factor receptor," Cancer Research, vol. 63, no. 6, pp. 1166-1171, 2003.

[139] M. Bjorndahl, R. Cao, L. J. Nissen et al., "Insulin-like growth factors 1 and 2 induce lymphangiogenesis in vivo," Proceedings of the National Academy of Sciences of the United States of America, vol. 102, no. 43, pp. 15593-15598, 2005.

[140] S. E. Dunn, J. V. Torres, N. Nihei, and J. C. Barrett, “The insulin-like growth factor-1 elevates urokinase-type plasminogen activator-1 in human breast cancer cells: a new avenue for breast cancer therapy," Molecular Carcinogenesis, vol. 27, no. 1, pp. 10$17,2000$.

[141] T. W. Bauer, W. Liu, F. Fan et al., "Targeting of urokinase plasminogen activator receptor in human pancreatic carcinoma cells inhibits c-Met- and insulin-like growth factor-I receptormediated migration and invasion and orthotopic tumor growth in mice," Cancer Research, vol. 65, no. 17, pp. 7775-7781, 2005.

[142] L. Sciacca, R. Mineo, G. Pandini, A. Murabito, R. Vigneri, and A. Belfiore, "In IGF-I receptor-deficient leiomyosarcoma cells autocrine IGF-II induces cell invasion and protection from apoptosis via the insulin receptor isoform A," Oncogene, vol. 21, no. 54, pp. 8240-8250, 2002.

[143] A. Morcavallo, M. Gaspari, G. Pandini et al., "Research resource: new and diverse substrates for the insulin receptor isoform a revealed by quantitative proteomics after stimulation with IGFII or insulin," Molecular Endocrinology, vol. 25, no. 8, pp. 14561468, 2011.

[144] A. Morrione, B. Valentinis, S. Q. Xu et al., "Insulin-like growth factor II stimulates cell proliferation through the insulin receptor," Proceedings of the National Academy of Sciences of the United States of America, vol. 94, no. 8, pp. 3777-3782, 1997.

[145] R. Sharon, G. Pillemer, D. Ish-Shalom et al., "Insulin dependence of murine T-cell lymphoma. II. Insulin-deficient diabetic mice and mice fed low-energy diet develop resistance to lymphoma growth," International Journal of Cancer, vol. 53, no. 5, pp. 843-849, 1993.

[146] B. Gliozzo, C. K. Sung, P. Scalia et al., "Insulin-stimulated cell growth in insulin receptor substrate-1-deficient ZR-75-1 cells is mediated by a phosphatidylinositol-3-kinase-independent 
pathway," Journal of Cellular Biochemistry, vol. 70, no. 2, pp. 268-280, 1998.

[147] C. L. Alvino, S. C. Ong, K. A. McNeil et al., "Understanding the mechanism of insulin and insulin-like growth factor (IGF) receptor activation by IGF-II," PLoS One, vol. 6, no. 11, article e27488, 2011.

[148] K. Drejer, "The bioactivity of insulin analogues from in vitro receptor binding to in vivo glucose uptake," Diabetes/Metabolism Reviews, vol. 8, no. 3, pp. 259-285, 1992.

[149] S. C. Gough, C. Belda-Iniesta, C. Poole et al., "Insulin therapy in diabetes and cancer risk: current understanding and implications for future study: proceedings of the meeting of a European Insulin Safety Consensus Panel, convened and sponsored by Novo Nordisk, held Tuesday October 5, 2010 at The Radisson Edwardian Heathrow Hotel, Hayes, Middlesex, UK," Advances in Therapy, vol. 285, supplement 5, pp. 1-18, 2011.

[150] A. A. Samani, S. Yakar, D. LeRoith, and P. Brodt, “The role of the IGF system in cancer growth and metastasis: overview and recent insights," Endocrine Reviews, vol. 28, no. 1, pp. 20-47, 2007.

[151] M. M. Chitnis, J. S. P. Yuen, A. S. Protheroe, M. Pollak, and V. M. Macaulay, "The type 1 insulin-like growth factor receptor pathway," Clinical Cancer Research, vol. 14, no. 20, pp. 63646370, 2008.

[152] M. Pollak, "The insulin and insulin-like growth factor receptor family in neoplasia: an update," Nature Reviews Cancer, vol. 12, no. 3, pp. 159-169, 2012.

[153] M. Pollak, "The insulin receptor/insulin-like growth factor receptor family as a therapeutic target in oncology," Clinical Cancer Research, vol. 18, no. 1, pp. 40-50, 2012.

[154] B. R. Westley and F. E. B. May, "Insulin-like growth factors: the unrecognised oncogenes," British Journal of Cancer, vol. 72, no. 5, pp. 1065-1066, 1995.

[155] E. Giovannucci, "Insulin, insulin-like growth factors and colon cancer: a review of the evidence," Journal of Nutrition, vol. 131, no. 11, 2001.

[156] E. K. Wei, J. Ma, M. N. Pollak et al., "C-peptide, insulinlike growth factor binding protein-1, glycosylated hemoglobin, and the risk of distal colorectal adenoma in women," Cancer Epidemiology Biomarkers and Prevention, vol. 15, no. 4, pp. 750755, 2006.

[157] J. Ma, E. Giovannucci, M. Pollak et al., "A prospective study of plasma C-peptide and colorectal cancer risk in men," Journal of the National Cancer Institute, vol. 96, no. 7, pp. 546-553, 2004.

[158] P. Pisani, "Hyper-insulinaemia and cancer, meta-analyses of epidemiological studies," Archives of Physiology and Biochemistry, vol. 114, no. 1, pp. 63-70, 2008.

[159] A. Lukanova, A. Zeleniuch-Jacquotte, E. Lundin et al., "Prediagnostic levels of C-peptide, IGF-I, IGFBP -1, -2 and -3 and risk of endometrial cancer," International Journal of Cancer, vol. 108, no. 2, pp. 262-268, 2004.

[160] G. C. Kabat, M. Kim, B. J. Caan et al., "Repeated measures of serum glucose and insulin in relation to postmenopausal breast cancer," International Journal of Cancer, vol. 125, no. 11, pp. 2704-2710, 2009.

[161] D. Albanes, S. J. Weinstein, M. E. Wright et al., "Serum insulin, glucose, indices of insulin resistance, and risk of prostate cancer," Journal of the National Cancer Institute, vol. 101, no. 18, pp. 1272-1279, 2009.

[162] R. Z. Stolzenberg-Solomon, B. I. Graubard, S. Chari et al., "Insulin, glucose, insulin resistance, and pancreatic cancer in male smokers," Journal of the American Medical Association, vol. 294, no. 22, pp. 2872-2878, 2005.

[163] G. Libby, L. A. Donnelly, P. T. Donnan, D. R. Alessi, A. D. Morris, and J. M. M. Evans, "New users of metformin are at low risk of incident cancer: a cohort study among people with type 2 diabetes," Diabetes Care, vol. 32, no. 9, pp. 1620-1625, 2009.

[164] V. Papa, V. Pezzino, A. Costantino et al., "Elevated insulin receptor content in human breast cancer," Journal of Clinical Investigation, vol. 86, no. 5, pp. 1503-1510, 1990.

[165] M. G. V. Heiden, L. C. Cantley, and C. B. Thompson, "Understanding the warburg effect: the metabolic requirements of cell proliferation," Science, vol. 324, no. 5930, pp. 1029-1033, 2009.

[166] J. S. Kim, E. S. Kim, D. Liu et al., "Prognostic impact of insulin receptor expression on survival of patients with nonsmall cell lung cancer," Cancer, vol. 118, no. 9, pp. 2454-2465, 2011.

[167] D. Foti, R. Iuliano, E. Chiefari, and A. Brunetti, "A nucleoprotein complex containing Sp1, C/EBP $\beta$, and HMGI-Y controls human insulin receptor gene transcription," Molecular and Cellular Biology, vol. 23, no. 8, pp. 2720-2732, 2003.

[168] F. Paonessa, D. Foti, V. Costa et al., "Activator protein-2 overexpression accounts for increased insulin receptor expression in human breast cancer," Cancer Research, vol. 66, no. 10, pp. 5085-5093, 2006.

[169] S. Kolb, R. Fritsch, D. Saur, M. Reichert, R. M. Schmid, and G. Schneider, "HMGA1 controls transcription of insulin receptor to regulate cyclin D1 translation in pancreatic cancer cells," Cancer Research, vol. 67, no. 10, pp. 4679-4686, 2007.

[170] A. Belfiore, F. Frasca, G. Pandini, L. Sciacca, and R. Vigneri, "Insulin receptor isoforms and insulin receptor/insulin-like growth factor receptor hybrids in physiology and disease," Endocrine Reviews, vol. 30, no. 6, pp. 586-623, 2009.

[171] D. L. Russell-Jones, A. M. Umpleby, F. Shojaee-Moradie et al., "The effect of an intravenous infusion of IGF-I and insulin on IGFBP-1, IGFBP-3, acid labile subunit, free and bound IGF-I, catecholamines and potassium in normal volunteers during an amino acid and glucose clamp," Clinical Endocrinology, vol. 47, no. 6, pp. 685-691, 1997.

[172] J. Frystyk, "Free insulin-like growth factors-measurements and relationships to growth hormone secretion and glucose homeostasis," Growth Hormone and IGF Research, vol. 14, no. 5, pp. 337-375, 2004.

[173] M. S. Sandhu, D. B. Dunger, and E. L. Giovannucci, "Insulin, insulin-like growth factor-I (IGF-I), IGF binding proteins, their biologic interactions, and colorectal cancer," Journal of the National Cancer Institute, vol. 94, no. 13, pp. 972-980, 2002.

[174] R. C. Baxter, J. M. Bryson, and J. R. Turtle, "Somatogenic receptors of rat liver: regulation by insulin," Endocrinology, vol. 107, no. 4, pp. 1176-1181, 1980.

[175] Y. X. Yang, S. Hennessy, and J. D. Lewis, "Insulin therapy and colorectal cancer risk among type 2 diabetes mellitus patients," Gastroenterology, vol. 127, no. 4, pp. 1044-1050, 2004.

[176] C. J. Currie, C. D. Poole, and E. A. M. Gale, "The influence of glucose-lowering therapies on cancer risk in type 2 diabetes," Diabetologia, vol. 52, no. 9, pp. 1766-1777, 2009.

[177] L. G. Hemkens, U. Grouven, R. Bender et al., "Risk of malignancies in patients with diabetes treated with human insulin or insulin analogues: a cohort study," Diabetologia, vol. 52, no. 9, pp. 1732-1744, 2009.

[178] J. M. Jonasson, R. Ljung, M. Talbäck, B. Haglund, S. Gudbjörnsdòttir, and G. Steineck, "Insulin glargine use and short-term incidence of malignancies-a population-based 
follow-up study in Sweden," Diabetologia, vol. 52, no. 9, pp. 1745-1754, 2009.

[179] H. M. Colhoun, "Use of insulin glargine and cancer incidence in Scotland: a study from the Scottish Diabetes Research Network Epidemiology Group," Diabetologia, vol. 52, no. 9, pp. 1755-1765, 2009.

[180] R. Ruiter, L. E. Visser, M. P. van Herk-Sukel et al., "Risk of cancer in patients on insulin glargine and other insulin analogues in comparison with those on human insulin: results from a large population-based follow-up study," Diabetologia, vol. 55, no. 1 , pp. 51-62, 2012.

[181] A. Flood, V. Mai, R. Pfeiffer et al., "Elevated serum concentrations of insulin and glucose increase risk of recurrent colorectal adenomas," Gastroenterology, vol. 133, no. 5, pp. 1423-1429, 2007.

[182] P. J. Goodwin, M. Ennis, K. I. Pritchard et al., "Fasting insulin and outcome in early-stage breast cancer: results of a prospective cohort study," Journal of Clinical Oncology, vol. 20, no. 1, pp. 42-51, 2002.

[183] M. L. Irwin, C. Duggan, C. Y. Wang et al., "Fasting C-peptide levels and death resulting from all causes and breast cancer: the health, eating, activity, and lifestyle study," Journal of Clinical Oncology, vol. 29, no. 1, pp. 47-53, 2011.

[184] R. Novosyadlyy, D. E. Lann, A. Vijayakumar et al., "Insulinmediated acceleration of breast cancer development and progression in a nonobese model of type 2 diabetes," Cancer Research, vol. 70, no. 2, pp. 741-751, 2010.

[185] J. Huang, C. Morehouse, B. W. Higgs et al., "Altered expression of insulin receptor isoforms in breast cancer," PLoS One, vol. 6, no. 10, article e26177, 2011.

[186] S. K. Singh, C. Brito, Q. W. Tan, M. De Lean et al., "Differential expression and signaling activation of insulin receptor isoforms A and B: a link between breast cancer and diabetes," Growth Factors, vol. 29, no. 6, pp. 278-289, 2011.

[187] D. Gunnell, M. Okasha, G. D. Smith, S. E. Oliver, J. Sandhu, J. M. Holly et al., "Height, leg length, and cancer risk: a systematic review," Epidemiologic Reviews, vol. 23, no. 2, pp. 313-342, 2001.

[188] J. M. Ketelslegers, D. Maiter, M. Maes, L. E. Underwood, and J. P. Thissen, "Nutritional regulation of insulin-like growth factor-I," Metabolism, vol. 44, no. 4, pp. 50-57, 1995.

[189] S. E. Hankinson, W. C. Willett, G. A. Colditz et al., "Circulating concentrations of insulin-like growth factor-I and risk of breast cancer," The Lancet, vol. 351, no. 9113, pp. 1393-1396, 1998.

[190] J. M. Chan, M. J. Stampfer, E. Giovannucci et al., "Plasma insulin-like growth factor-I and prostate cancer risk: a prospective study," Science, vol. 279, no. 5350, pp. 563-566, 1998.

[191] J. Ma, M. N. Pollak, E. Giovannucci et al., "Prospective study of colorectal cancer risk in men and plasma levels of insulin-like growth factor (IGF)-I and IGF-binding protein-3," Journal of the National Cancer Institute, vol. 91, no. 7, pp. 620-625, 1999.

[192] H. Yu, M. R. Spitz, J. Mistry, J. Gu, W. K. Hong, and X. Wu, "Plasma levels of insulin-like growth factor-I and lung cancer risk: a case-control analysis," Journal of the National Cancer Institute, vol. 91, no. 2, pp. 151-156, 1999.

[193] W. Chen, S. Wang, T. Tian et al., "Phenotypes and genotypes of insulin-like growth factor 1, IGF-binding protein-3 and cancer risk: evidence from 96 studies," European Journal of Human Genetics, vol. 17, no. 12, pp. 1668-1675, 2009.

[194] N. P. Michell, M. J. S. Langman, and M. C. Eggo, "Insulinlike growth factors and their binding proteins in human colonocytes: preferential degradation of insulin-like growth factor binding protein 2 in colonic cancers," British Journal of Cancer, vol. 76, no. 1, pp. 60-66, 1997.
[195] S. A. Bustin, S. Dorudi, S. M. Phillips, R. M. Feakins, and P. J. Jenkins, "Local expression of insulin-like growth factor-I affects angiogenesis in colorectal cancer," Tumor Biology, vol. 23, no. 3, pp. 130-138, 2002.

[196] C. Giani, A. Pinchera, A. Rasmussen et al., "Stromal IGF-II messenger RNA in breast cancer: relationship with progesterone receptor expressed by malignant epithelial cells," Journal of Endocrinological Investigation, vol. 21, no. 3, pp. 160-165, 1998.

[197] A. A. Rasmussen and K. J. Cullen, "Paracrine/autocrine regulation of breast cancer by the insulin-like growth factors," Breast Cancer Research and Treatment, vol. 47, no. 3, pp. 219-233, 1998.

[198] M. K. Tennant, J. B. Thrasher, P. A. Twomey, R. H. Drivdahl, R. S. Birnbaum, and S. R. Plymate, "Protein and messenger ribonucleic acid (mRNA) for the type 1 insulin- like growth factor (IGF) receptor is decreased and IGF-II mRNA is increased in human prostate carcinoma compared to benign prostate epithelium," Journal of Clinical Endocrinology and Metabolism, vol. 81, no. 10, pp. 3774-3782, 1996.

[199] A. Vrieling, D. W. Voskuil, A. Bosma et al., "Expression of insulin-like growth factor system components in colorectal tissue and its relation with serum IGF levels," Growth Hormone and IGF Research, vol. 19, no. 2, pp. 126-135, 2009.

[200] C. Gicquel, X. Bertagna, V. Gaston et al., "Molecular markers and long-term recurrences in a large cohort of patients with sporadic adrenocortical tumors," Cancer Research, vol. 61, no. 18, pp. 6762-6767, 2001.

[201] E. Cariani, C. Lasserre, D. Seurin et al., "Differential expression of insulin-like growth factor II mRNA in human primary liver cancers, benign liver tumors, and liver cirrhosis," Cancer Research, vol. 48, no. 23, pp. 6844-6849, 1988.

[202] K. Breuhahn, S. Vreden, R. Haddad et al., "Molecular profiling of human hepatocellular carcinoma defines mutually exclusive interferon regulation and insulin-like growth factor II overexpression," Cancer Research, vol. 64, no. 17, pp. 6058-6064, 2004.

[203] K. Scotlandi, M. C. Manara, M. Serra et al., "Expression of insulin-like growth factor system components in Ewing's sarcoma and their association with survival," European Journal of Cancer, vol. 47, no. 8, pp. 1258-1266, 2011.

[204] C. Garofalo, M. C. Manara, G. Nicoletti et al., "Efficacy of and resistance to anti-IGF-1R therapies in Ewing's sarcoma is dependent on insulin receptor signaling," Oncogene, vol. 30, no. 24, pp. 2730-2740, 2011.

[205] M. Pollak, "Insulin and insulin-like growth factor signalling in neoplasia," Nature Reviews Cancer, vol. 8, no. 12, pp. 915-928, 2008.

[206] E. J. Gallagher and D. LeRoith, "The proliferating role of insulin and insulin-like growth factors in cancer," Trends in Endocrinology and Metabolism, vol. 21, no. 10, pp. 610-618, 2010.

[207] E. J. Gallagher and D. LeRoith, "Minireview: IGF, insulin, and cancer," Endocrinology, vol. 152, no. 7, pp. 2546-2551, 2011.

[208] A. Hakam, T. J. Yeatman, L. Lu et al., "Expression of insulin-like growth factor-1 receptor in human colorectal cancer," Human Pathology, vol. 30, no. 10, pp. 1128-1133, 1999.

[209] M. J. Railo, K. von Smitten, and F. Pekonen, "The prognostic value of insulin-like growth factor-I in breast cancer patients. Results of a follow-up study on 126 patients," European Journal of Cancer A, vol. 30, no. 3, pp. 307-311, 1994.

[210] C. Shimizu, T. Hasegawa, Y. Tani et al., "Expression of insulinlike growth factor 1 receptor in primary breast cancer: immunohistochemical analysis," Human Pathology, vol. 35, no. 12, pp. 1537-1542, 2004. 
[211] G. O. Hellawell, G. D. H. Turner, D. R. Davies, R. Poulsom, S. F. Brewster, and V. M. Macaulay, "Expression of the type 1 insulinlike growth factor receptor is up-regulated in primary prostate cancer and commonly persists in metastatic disease," Cancer Research, vol. 62, no. 10, pp. 2942-2950, 2002.

[212] B. W. Turney, G. D. H. Turner, S. F. Brewster, and V. M. MacAulay, "Serial analysis of resected prostate cancer suggests up-regulation of type 1 IGF receptor with disease progression," British Journal of Urology International, vol. 107, no. 9, pp. 14881499, 2011.

[213] Y. Xie, B. Skytting, G. Nilsson, B. Brodin, and O. Larsson, "Expression of insulin-like growth factor-1 receptor in synovial sarcoma: association with an aggressive phenotype," Cancer Research, vol. 59, no. 15, pp. 3588-3591, 1999.

[214] C. All-Ericsson, L. Girnita, S. Seregard, A. Bartolazzi, M. J. Jager, and O. Larsson, "Insulin-like growth factor-1 receptor in uveal melanoma: a predictor for metastatic disease and a potential therapeutic target," Investigative Ophthalmology and Visual Science, vol. 43, no. 1, pp. 1-8, 2002.

[215] Y. Jiang, L. Wang, W. Gong et al., "A high expression level of insulin-like growth factor I receptor is associated with increased expression of transcription factor Sp1 and regional lymph node metastasis of human gastric cancer," Clinical and Experimental Metastasis, vol. 21, no. 8, pp. 755-764, 2005.

[216] A. S. Parker, J. C. Cheville, C. A. Janney, and J. R. Cerhan, "High expression levels of insulin-like growth factor-I receptor predict poor survival among women with clear-cell renal cell carcinomas," Human Pathology, vol. 33, no. 8, pp. 801-805, 2002.

[217] J. H. Law, G. Habibi, K. Hu et al., "Phosphorylated insulin-like growth factor-I/insulin receptor is present in all breast cancer subtypes and is related to poor survival," Cancer Research, vol. 68, no. 24, pp. 10238-10246, 2008.

[218] P. Brodt, L. Fallavollita, A. M. Khatib, A. A. Samani, and D. Zhang, "Cooperative regulation of the invasive and metastatic phenotypes by different domains of the type I insulin-like growth factor receptor $\beta$ subunit," The Journal of Biological Chemistry, vol. 276, no. 36, pp. 33608-33615, 2001.

[219] Y. Wu, S. Yakar, L. Zhao, L. Hennighausen, and D. LeRoith, "Circulating insulin-like growth factor-I levels regulate colon cancer growth and metastasis," Cancer Research, vol. 62, no. 4, pp. 1030-1035, 2002.

[220] Y. Chen, H. Shu, C. Ji et al., "Insulin-like growth factor binding proteins localize to discrete cell culture compartments in periosteal and osteoblast cultures from fetal rat bone," Journal of Cellular Biochemistry, vol. 71, no. 3, pp. 351-362, 1998.

[221] G. Fiorelli, C. Orlando, S. Benvenuti et al., "Characterization, regulation, and function of specific cell membrane receptors for insulin-like growth factor I on bone endothelial cells," Journal of Bone and Mineral Research, vol. 9, no. 3, pp. 329-337, 1994.

[222] M. Koutsilieris and C. Polychronakos, "Proteinolytic activity against IGF-binding proteins involved in the paracrine interactions between prostate adenocarcinoma cells and osteoblasts," Anticancer Research, vol. 12, no. 3, pp. 905-910, 1992.

[223] K. S. Koeneman, F. Yeung, and L. W. Chung, "Osteomimetic properties of cancer cells: a hypothesis supporting the predilection of prostate cancer metastasis and growth in the bone environment," ProstateProstate, vol. 39, no. 4, pp. 246-261, 1999.

[224] E. E. Calle and R. Kaaks, "Overweight, obesity and cancer: epidemiological evidence and proposed mechanisms," Nature Reviews Cancer, vol. 4, no. 8, pp. 579-591, 2004.

[225] J. P. Baillargeon and J. E. Nestler, "Commentary: polycystic ovary syndrome: a syndrome of ovarian hypersensitivity to insulin?" Journal of Clinical Endocrinology and Metabolism, vol. 91, no. 1, pp. 22-24, 2006.

[226] M. Pugeat, J. C. Crave, M. Elmidani et al., "Pathophysiology of sex hormone binding globulin (SHBG): relation to insulin," Journal of Steroid Biochemistry and Molecular Biology, vol. 40, no. 4-6, pp. 841-849, 1991.

[227] A. McTiernan, K. B. Rajan, S. S. Tworoger et al., "Adiposity and sex hormones in postmenopausal breast cancer survivors," Journal of Clinical Oncology, vol. 21, no. 10, pp. 1961-1966, 2003.

[228] M. Harvie, L. Hooper, and A. H. Howell, "Central obesity and breast cancer risk: a systematic review," Obesity Reviews, vol. 4, no. 3, pp. 157-173, 2003.

[229] R. C. Millikan, B. Newman, C. K. Tse et al., "Epidemiology of basal-like breast cancer," Breast Cancer Research and Treatment, vol. 109, no. 1, pp. 123-139, 2008.

[230] L. Vona-Davis, D. P. Rose, H. Hazard et al., "Triple-negative breast cancer and obesity in a rural appalachian population," Cancer Epidemiology Biomarkers and Prevention, vol. 17, no. 12, pp. 3319-3324, 2008.

[231] Z. Davison, G. E. de Blacquière, B. R. Westley, and F. E. B. May, "Insulin-like growth factor-dependent proliferation and survival of triple-negative breast cancer cells: implications for therapy," Neoplasia, vol. 13, no. 6, pp. 504-515, 2011.

[232] G. Beatson, "On the treatment of inoperable cases of carcinoma of the mamma: suggestions for a new method of treatment with illustrative cases," The Lancet, vol. 148, no. 3803, pp. 162-165, 1896.

[233] S. C. Brooks, E. R. Locke, and H. D. Soule, "Estrogen receptor in a human cell line (MCF 7) from breast carcinoma," The Journal of Biological Chemistry, vol. 248, no. 17, pp. 6251-6253, 1973.

[234] M. Lippman, G. Bolan, and K. Huff, “The effects of estrogens and antiestrogens on hormone responsive human breast cancer in long term tissue culture," Cancer Research, vol. 36, no. 12, pp. 4595-4601, 1976.

[235] M. E. Lippman and G. Bolan, "Oestrogen responsive human breast cancer in long term tissue culture," Nature, vol. 256, no. 5518, pp. 592-593, 1975.

[236] T. Thorsen, H. Lahooti, M. Rasmussen, and A. Aakvaag, "Oestradiol treatment increases the sensitivity of MCF-7 cells for the growth stimulatory effect of IGF-I," Journal of Steroid Biochemistry and Molecular Biology, vol. 41, no. 3-8, pp. 537540, 1992.

[237] B. R. Westley, S. J. Clayton, M. R. Daws, C. A. Molloy, and F. E. B. May, "Interactions between the oestrogen and insulinlike growth factor signalling pathways in the control of breast epithelial cell proliferation," Biochemical Society Symposium, vol. 63, pp. 35-44, 1998.

[238] A. V. Lee, X. Cui, and S. Oesterreich, "Cross-talk among estrogen receptor, epidermal growth factor, and insulin-like growth factor signaling in breast cancer," Clinical Cancer Research, vol. 7, no. 12, supplement, pp. 4429s-4435s, 2001.

[239] M. R. Daws, B. R. Westley, and F. E. B. May, "Paradoxical effects of overexpression of the type I insulin-like growth factor (IGF) receptor on the responsiveness of human breast cancer cells to IGFs and estradiol," Endocrinology, vol. 137, no. 4, pp. 1177-1186, 1996.

[240] C. A. Molloy, F. E. B. May, and B. R. Westley, "Insulin receptor substrate-1 expression is regulated by estrogen in the MCF7 human breast cancer cell line," The Journal of Biological Chemistry, vol. 275, no. 17, pp. 12565-12571, 2000. 
[241] L. Mauro, M. Salerno, M. L. Panno et al., "Estradiol increases IRS-1 gene expression and insulin signaling in breast cancer cells," Biochemical and Biophysical Research Communications, vol. 288, no. 3, pp. 685-689, 2001.

[242] J. G. Jackson, M. F. White, and D. Yee, "Insulin receptor substrate-1 is the predominant signaling molecule activated by insulin-like growth factor-I, insulin, and interleukin- 4 in estrogen receptor-positive human breast cancer cells," The Journal of Biological Chemistry, vol. 273, no. 16, pp. 9994-10003, 1998.

[243] G. E. de Blaquière, F. E. B. May, and B. R. Westley, "Increased expression of both insulin receptor substrates 1 and 2 confers increased sensitivity to IGF-1 stimulated cell migration," Endocrine-Related Cancer, vol. 16, no. 2, pp. 635-647, 2009.

[244] G. Pandini, R. Mineo, F. Frasca et al., "Androgens up-regulate the insulin-like growth factor-I receptor in prostate cancer cells," Cancer Research, vol. 65, no. 5, pp. 1849-1857, 2005.

[245] M. A. Rochester, J. Riedemann, G. O. Hellawell, S. F. Brewster, and V. M. Macaulay, "Silencing of the IGF1R gene enhances sensitivity to DNA-damaging agents in both PTEN wild-type and mutant human prostate cancer," Cancer Gene Therapy, vol. 12, no. 1, pp. 90-100, 2005.

[246] S. E. Dunn, M. Ehrlich, N. J. H. Sharp et al., "A dominant negative mutant of the insulin-like growth factor-I receptor inhibits the adhesion, invasion, and metastasis of breast cancer," Cancer Research, vol. 58, no. 15, pp. 3353-3361, 1998.

[247] J. L. Burgaud, M. Resnicoff, and R. Baserga, "Mutant IGF-I receptors as dominant negatives for growth and transformation," Biochemical and Biophysical Research Communications, vol. 214, no. 2, pp. 475-481, 1995.

[248] A. Gualberto, "Figitumumab (CP-751,871) for cancer therapy," Expert Opinion on Biological Therapy, vol. 10, no. 4, pp. 575-585, 2010.

[249] E. K. Rowinsky, J. D. Schwartz, N. Zojwalla et al., "Blockade of insulin-like growth factor type-1 receptor with cixutumumab (IMC-A12): a novel approach to treatment for multiple cancers," Current Drug Targets, vol. 12, no. 14, pp. 2016-2033, 2011.

[250] W. D. Tap, G. Demetri, P. Barnette et al., "Phase II study of ganitumab, a fully human anti-type-1 insulin-like growth factor receptor antibody, in patients with metastatic ewing family tumors or desmoplastic small round cell tumors," Journal of Clinical Oncology, vol. 30, no. 15, pp. 1849-1856, 2012.

[251] M. Scartozzi, M. Bianconi, E. MacCaroni, R. Giampieri, R. Berardi, and S. Cascinu, "Dalotuzumab, a recombinant humanized mab targeted against IGFR1 for the treatment of cancer," Current Opinion in Molecular Therapeutics, vol. 12, no. 3, pp. 361-371, 2010.

[252] P. Moreau, F. Cavallo, X. Leleu et al., "Phase I study of the antiinsulin-like growth factor 1 receptor (IGF-1R) monoclonal antibody, AVE1642, as single agent and in combination with bortezomib in patients with relapsed multiple myeloma," Leukemia, vol. 25, no. 5, pp. 872-874, 2011.

[253] R. Kurzrock, A. Patnaik, J. Aisner et al., "A phase I study of weekly R1507, a human monoclonal antibody insulin-like growth factor-I receptor antagonist, in patients with advanced solid tumors," Clinical Cancer Research, vol. 16, no. 8, pp. 24582465, 2010.

[254] J. Gao, Y. S. Chang, B. Jallal, and J. Viner, "Targeting the insulinlike growth factor axis for the development of novel therapeutics in oncology," Cancer Research, vol. 72, no. 1, pp. 3-12, 2012.

[255] B. C. Turner, B. G. Haffty, L. Narayanan et al., "Insulinlike growth factor-I receptor overexpression mediates cellular radioresistance and local breast cancer recurrence after lumpectomy and radiation," Cancer Research, vol. 57, no. 15, pp. 30793083, 1997.

[256] J. L. Gooch, C. L. van den Berg, and D. Yee, "Insulin-like growth factor (IGF)-I rescues breast cancer cells from chemotherapyinduced cell death-proliferative and anti-apoptotic effects," Breast Cancer Research and Treatment, vol. 56, no. 1, pp. 1-10, 1999.

[257] G. W. Allen, C. Saba, E. A. Armstrong et al., "Insulin-like growth factor-I receptor signaling blockade combined with radiation," Cancer Research, vol. 67, no. 3, pp. 1155-1162, 2007.

[258] T. Iwasa, I. Okamoto, M. Suzuki et al., "Inhibition of insulinlike growth factor 1 receptor by CP-751,871 radiosensitizes nonsmall cell lung cancer cells," Clinical Cancer Research, vol. 15, no. 16, pp. 5117-5125, 2009.

[259] E. Buck, A. Eyzaguirre, M. Rosenfeld-Franklin et al., "Feedback mechanisms promote cooperativity for small molecule inhibitors of epidermal and insulin-like growth factor receptors," Cancer Research, vol. 68, no. 20, pp. 8322-8332, 2008.

[260] A. K. Chakraborty, K. Liang, and M. P. DiGiovanna, "Cotargeting insulin-like growth factor I receptor and HER2: dramatic effects of HER2 inhibitors on nonoverexpressing breast cancer," Cancer Research, vol. 68, no. 5, pp. 1538-1545, 2008.

[261] J. S. P. Yuen and V. M. Macaulay, "Targeting the type 1 insulinlike growth factor receptor as a treatment for cancer," Expert Opinion on Therapeutic Targets, vol. 12, no. 5, pp. 589-603, 2008.

[262] A. W. Tolcher, J. Sarantopoulos, A. Patnaik et al., "Phase I, pharmacokinetic, and pharmacodynamic study of AMG 479, a fully human monoclonal antibody to insulin-like growth factor receptor 1," Journal of Clinical Oncology, vol. 27, no. 34, pp. 58005807, 2009.

[263] D. Olmos, A. S. Martins, R. L. Jones, S. Alam, M. Scurr, and I. R. Judson, "Targeting the insulin-like growth factor 1 receptor in Ewing's sarcoma: reality and expectations," Sarcoma, vol. 2011, Article ID 402508, 13 pages, 2011.

[264] M. Scartozzi, M. Bianconi, E. Maccaroni et al., "State of the art and future perspectives for the use of insulin-like growth factor receptor 1 (IGF-1R) targeted treatment strategies in solid tumors," Discovery Medicine, vol. 11, no. 57, pp. 144-153, 2011.

[265] E. Buck and M. Mulvihill, "Small molecule inhibitors of the IGF-1R/IR axis for the treatment of cancer," Expert Opinion on Investigational Drugs, vol. 20, no. 5, pp. 605-621, 2011.

[266] J. M. Carboni, M. Wittman, Z. Yang et al., "BMS-754807, a small molecule inhibitor of insulin-like growth factor-1R/IR," Molecular Cancer Therapeutics, vol. 8, no. 12, pp. 3341-3349, 2009.

[267] E. Buck, P. C. Gokhale, S. Koujak et al., "Compensatory insulin receptor (IR) activation on inhibition of insulin-like growth factor-1 receptor (IGF-1R): rationale for cotargeting IGF-1R and IR in cancer," Molecular Cancer Therapeutics, vol. 9, no. 10, pp. 2652-2664, 2010.

[268] J. Gao, J. W. Chesebrough, S. A. Cartlidge et al., "Dual IGFI/II-neutralizing antibody MEDI-573 potently inhibits IGF signaling and tumor growth," Cancer Research, vol. 71, no. 3, pp. 1029-1040, 2011.

[269] M. Goya, S. Miyamoto, K. Nagai et al., "Growth inhibition of human prostate cancer cells in human adult bone implanted into nonobese diabetic/severe combined immunodeficient mice by a ligand-specific antibody to human insulinlike growth factors," Cancer Research, vol. 64, no. 17, pp. 62526258, 2004. 
[270] N. Alami, V. Page, Q. Yu et al., "Recombinant human insulinlike growth factor-binding protein 3 inhibits tumor growth and targets the Akt pathway in lung and colon cancer models," Growth Hormone and IGF Research, vol. 18, no. 6, pp. 487-496, 2008.

[271] L. Jerome, N. Alami, S. Belanger et al., "Recombinant human insulin-like growth factor binding protein 3 inhibits growth of human epidermal growth factor receptor-2-overexpressing breast tumors and potentiates herceptin activity in vivo," Cancer Research, vol. 66, no. 14, pp. 7245-7252, 2006.

[272] D. P. Edwards, G. C. Chamness, and W. L. McGuire, "Estrogen and progesterone receptor in breast cancer," Biochimica et Biophysica Acta, vol. 560, no. 4, pp. 457-486, 1979.

[273] C. A. Hudis, "Trastuzumab-mechanism of action and use in clinical practice," The New England Journal of Medicine, vol. 357, no. 1, pp. 39-51, 2007.

[274] E. van Cutsem, C. H. Köhne, E. Hitre et al., "Cetuximab and chemotherapy as initial treatment for metastatic colorectal cancer," The New England Journal of Medicine, vol. 360, no. 14, pp. 1408-1417, 2009.

[275] A. Lièvre, J. B. Bachet, D. Le Corre et al., "KRAS mutation status is predictive of response to cetuximab therapy in colorectal cancer," Cancer Research, vol. 66, no. 8, pp. 3992-3995, 2006.

[276] A. Gualberto, M. L. Hixon, D. D. Karp et al., "Pre-treatment levels of circulating free IGF-1 identify NSCLC patients who derive clinical benefit from figitumumab," British Journal of Cancer, vol. 104, no. 1, pp. 68-74, 2011.

[277] J. Zha, C. O’Brien, H. Savage et al., "Molecular predictors of response to a humanized anti-insulin-like growth factor-I receptor monoclonal antibody in breast and colorectal cancer," Molecular Cancer Therapeutics, vol. 8, no. 8, pp. 2110-2121, 2009.

[278] R. Baserga, "The insulin receptor substrate-1: a biomarker for cancer?" Experimental Cell Research, vol. 315, no. 5, pp. 727-732, 2009.

[279] C. J. Creighton, A. Casa, Z. Lazard et al., "Insulin-like growth factor-I activates gene transcription programs strongly associated with poor breast cancer prognosis," Journal of Clinical Oncology, vol. 26, no. 25, pp. 4078-4085, 2008.

[280] A. Louvi, D. Accili, and A. Efstratiadis, "Growth-promoting interaction of IGF-II with the insulin receptor during mouse embryonic development," Developmental Biology, vol. 189, no. 1, pp. 33-48, 1997.

[281] D. B. Ulanet, D. L. Ludwig, C. R. Kahn, and D. Hanahan, "Insulin receptor functionally enhances multistage tumor progression and conveys intrinsic resistance to IGF-1R targeted therapy," Proceedings of the National Academy of Sciences of the United States of America, vol. 107, no. 24, pp. 10791-10798, 2010.

[282] C. J. Dool, H. Mashhedi, M. Zakikhani et al., "IGF1/insulin receptor kinase inhibition by BMS-536924 is better tolerated than alloxan-induced hypoinsulinemia and more effective than metformin in the treatment of experimental insulin-responsive breast cancer," Endocrine-Related Cancer, vol. 18, no. 6, pp. 699709, 2011.

[283] M. Pollak, "Metformin and other biguanides in oncology: advancing the research agenda," Cancer Prevention Research, vol. 3, no. 9, pp. 1060-1065, 2010.

[284] A. Vazquez-Martin, C. Oliveras-Ferraros, and J. A. Menendez, "The antidiabetic drug metformin suppresses HER2 (erbB-2) oncoprotein overexpression via inhibition of the mTOR effector p70S6K1 in human breast carcinoma cells," Cell Cycle, vol. 8, no. 1, pp. 88-96, 2009.
[285] S. Cufí, A. Vazquez-Martin, C. Oliveras-Ferraros, B. MartinCastillo, J. Joven, and J. A. Menendez, "Metformin against TGF $\beta$-induced epithelial-to-mesenchymal transition (EMT): from cancer stem cells to aging-associated fibrosis," Cell Cycle, vol. 9, no. 22, pp. 4461-4468, 2010.

[286] D. Whitaker-Menezes, U. E. Martinez-Outschoorn, N. Flomenberg et al., "Hyperactivation of oxidative mitochondrial metabolism in epithelial cancer cells in situ visualizing the therapeutic effects of metformin in tumor tissue," Cell Cycle, vol. 10, no. 23, pp. 4047-4064, 2011.

[287] R. J. O. Dowling, S. Niraula, V. Stambolic, and P. J. Goodwin, "Metformin in cancer: translational challenges," Journal of Molecular Endocrinology, vol. 48, no. 3, pp. R31-R43, 2012.

[288] V. Costa, D. Foti, F. Paonessa et al., "The insulin receptor: a new anticancer target for peroxisome proliferator-activated receptor- $\gamma(\operatorname{PPAR} \gamma)$ and thiazolidinedione-PPAR $\gamma$ agonists," Endocrine-Related Cancer, vol. 15, no. 1, pp. 325-335, 2008.

[289] C. Huggins and C. V. Hodges, "Studies on prostatic cancer. I. The effect of castration, of estrogen and of androgen injection on serum phosphatases in metastatic carcinoma of the prostate," Cancer Research, vol. 1, pp. 293-297, 1941.

[290] S. C. J. P. Gielen, E. E. Hanekamp, L. J. Blok, F. J. Huikeshoven, and C. W. Burger, "Steroid-modulated proliferation of human endometrial carcinoma cell lines: any role for insulin-like growth factor signaling?" Journal of the Society for Gynecologic Investigation, vol. 12, no. 1, pp. 58-64, 2005.

[291] D. Kleinman, M. Karas, C. T. Roberts et al., "Modulation of insulin-like growth factor I (IGF-I) receptors and membraneassociated IGF-binding proteins in endometrial cancer cells by estradiol," Endocrinology, vol. 136, no. 6, pp. 2531-2537, 1995.

[292] J. Wimalasena, D. Meehan, R. Dostal, J. S. Foster, M. Cameron, and M. Smith, "Growth factors interact with estradiol and gonadotropins in the regulation of ovarian cancer cell growth and growth factor receptors," Oncology Research, vol. 5, no. 8, pp. 325-337, 1993.

[293] R. F. Krywicki, J. A. Figueroa, J. G. Jackson et al., "Regulation of insulin-like growth factor binding proteins in ovarian cancer cells by oestrogen," European Journal of Cancer A, vol. 29, no. 14, pp. 2015-2019, 1993.

[294] G. Walker, K. MacLeod, A. R. W. Williams, D. A. Cameron, J. F. Smyth, and S. P. Langdon, "Insulin-like growth factor binding proteins IGFBP3, IGFBP4, and IGFBP5 predict endocrine responsiveness in patients with ovarian cancer," Clinical Cancer Research, vol. 13, no. 5, pp. 1438-1444, 2007.

[295] A. M. Brzozowski, A. C. W. Pike, Z. Dauter et al., "Molecular basis of agonism and antagonism in the oestrogen receptor," Nature, vol. 389, no. 6652, pp. 753-758, 1997.

[296] F. E. B. May and B. R. Westley, "Effects of tamoxifen and 4hydroxytamoxifen on the pNR-1 and pNR-2 estrogen-regulated RNAs in human breast cancer cells," The Journal of Biological Chemistry, vol. 262, no. 33, pp. 15894-15899, 1987.

[297] M. D. Johnson, B. R. Westley, and F. E. B. May, "Oestrogenic activity of tamoxifen and its metabolites on gene regulation and cell proliferation in MCF-7 breast cancer cells," British Journal of Cancer, vol. 59, no. 5, pp. 727-738, 1989.

[298] S. Dauvois, R. White, and M. G. Parker, "The antiestrogen ICI 182780 disrupts estrogen receptor nucleocytoplasmic shuttling," Journal of Cell Science, vol. 106, no. 4, pp. 1377-1388, 1993.

[299] F. E. B. May and B. R. Westley, "Trefoil proteins: their role in normal and malignant cells," Journal of Pathology, vol. 183, no. 1, pp. 4-7, 1997. 
[300] B. R. Westley and F. E. May, "Identification of steroid hormoneregulated genes in breast cancer," Methods in molecular medicine., vol. 120, pp. 363-388, 2006.

[301] S. C. Larsson, N. Orsini, K. Brismar, and A. Wolk, "Diabetes mellitus and risk of bladder cancer: a meta-analysis," Diabetologia, vol. 49, no. 12, pp. 2819-2823, 2006.

[302] S. C. Larsson, C. S. Mantzoros, and A. Wolk, "Diabetes mellitus and risk of breast cancer: a meta-analysis," International Journal of Cancer, vol. 121, no. 4, pp. 856-862, 2007.

[303] H. Yuhara, C. Steinmaus, S. E. Cohen, D. A. Corley, Y. Tei, and P. A. Buffler, "Is diabetes mellitus an independent risk factor for colon cancer and rectal cancer?" American Journal of Gastroenterology, vol. 106, no. 11, pp. 1911-1921, 2011.

[304] E. Friberg, N. Orsini, C. S. Mantzoros, and A. Wolk, "Diabetes mellitus and risk of endometrial cancer: a meta-analysis," Diabetologia, vol. 50, no. 7, pp. 1365-1374, 2007.

[305] W. Jing, G. Jin, X. Zhou et al., "Diabetes mellitus and increased risk of cholangiocarcinoma: a meta-analysis," European Journal of Cancer Prevention, vol. 21, no. 1, pp. 24-31, 2012.

[306] H. B. El-Serag, H. Hampel, and F. Javadi, "The association between diabetes and hepatocellular carcinoma: a systematic review of epidemiologic evidence," Clinical Gastroenterology and Hepatology, vol. 4, no. 3, pp. 369-380, 2006.

[307] C. Chao and J. H. Page, "Type 2 diabetes mellitus and risk of non-hodgkin lymphoma: a systematic review and metaanalysis," American Journal of Epidemiology, vol. 168, no. 5, pp. 471-480, 2008.

[308] R. Huxley, A. Ansary-Moghaddam, A. B. de González, F. Barzi, and M. Woodward, "Type-II diabetes and pancreatic cancer: a meta-analysis of 36 studies," British Journal of Cancer, vol. 92, no. 11, pp. 2076-2083, 2005.

[309] S. C. Larsson and A. Wolk, "Diabetes mellitus and incidence of kidney cancer: a meta-analysis of cohort studies," Diabetologia, vol. 54, no. 5, pp. 1013-1018, 2011.

[310] G. Pandini, R. Vigneri, A. Costantino et al., "Insulin and insulinlike growth factor-I (IGF-I) receptor overexpression in breast cancers leads to insulin/IGF-I hybrid receptor overexpression: evidence for a second mechanism of IGF-I signaling," Clinical Cancer Research, vol. 5, no. 7, pp. 1935-1944, 1999.

[311] J. Bass, C. Turck, M. Rouard, and D. F. Steiner, "Furin-mediated processing in the early secretory pathway: sequential cleavage and degradation of misfolded insulin receptors," Proceedings of the National Academy of Sciences of the United States of America, vol. 97, no. 22, pp. 11905-11909, 2000.

[312] M. C. Lawrence, N. M. McKern, and C. W. Ward, "Insulin receptor structure and its implications for the IGF-1 receptor," Current Opinion in Structural Biology, vol. 17, no. 6, pp. 699-705, 2007.

[313] V. C. Epa and C. W. Ward, "Model for the complex between the insulin-like growth factor I and its receptor: towards designing antagonists for the IGF-1 receptor," Protein Engineering, Design and Selection, vol. 19, no. 8, pp. 377-384, 2006. 


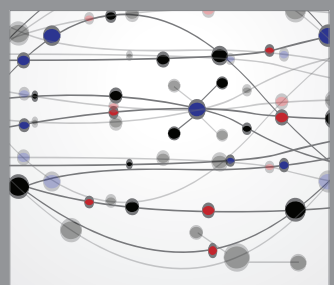

The Scientific World Journal
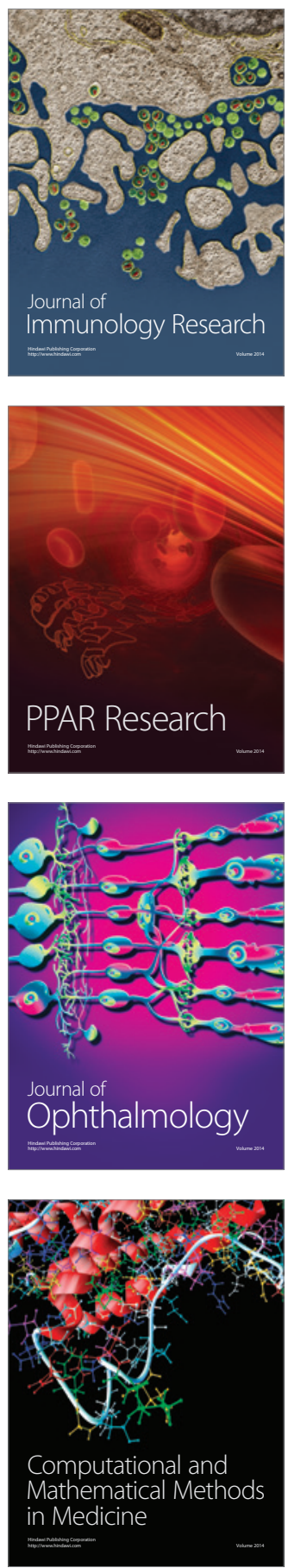

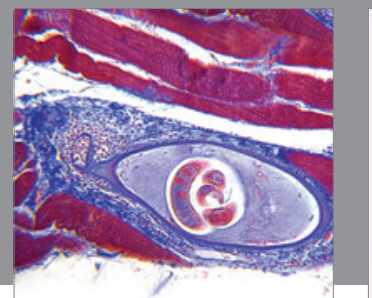

Gastroenterology

Research and Practice
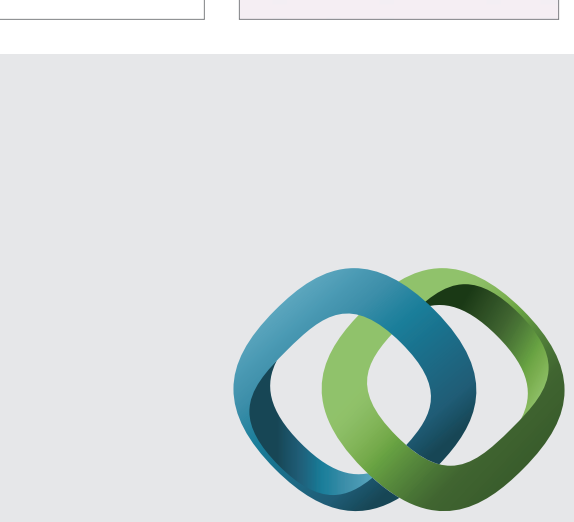

\section{Hindawi}

Submit your manuscripts at

http://www.hindawi.com
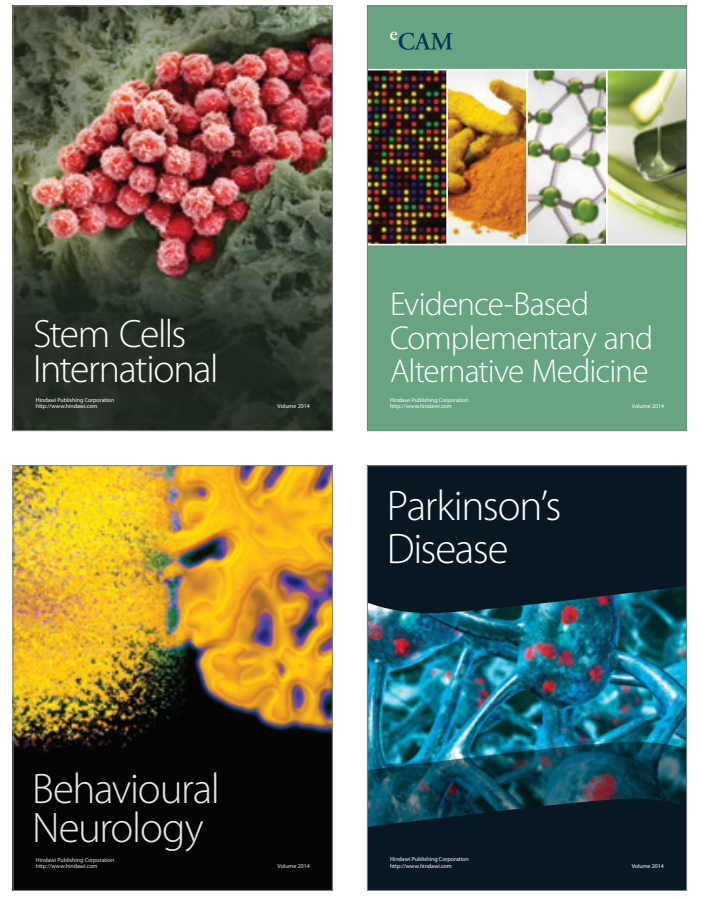
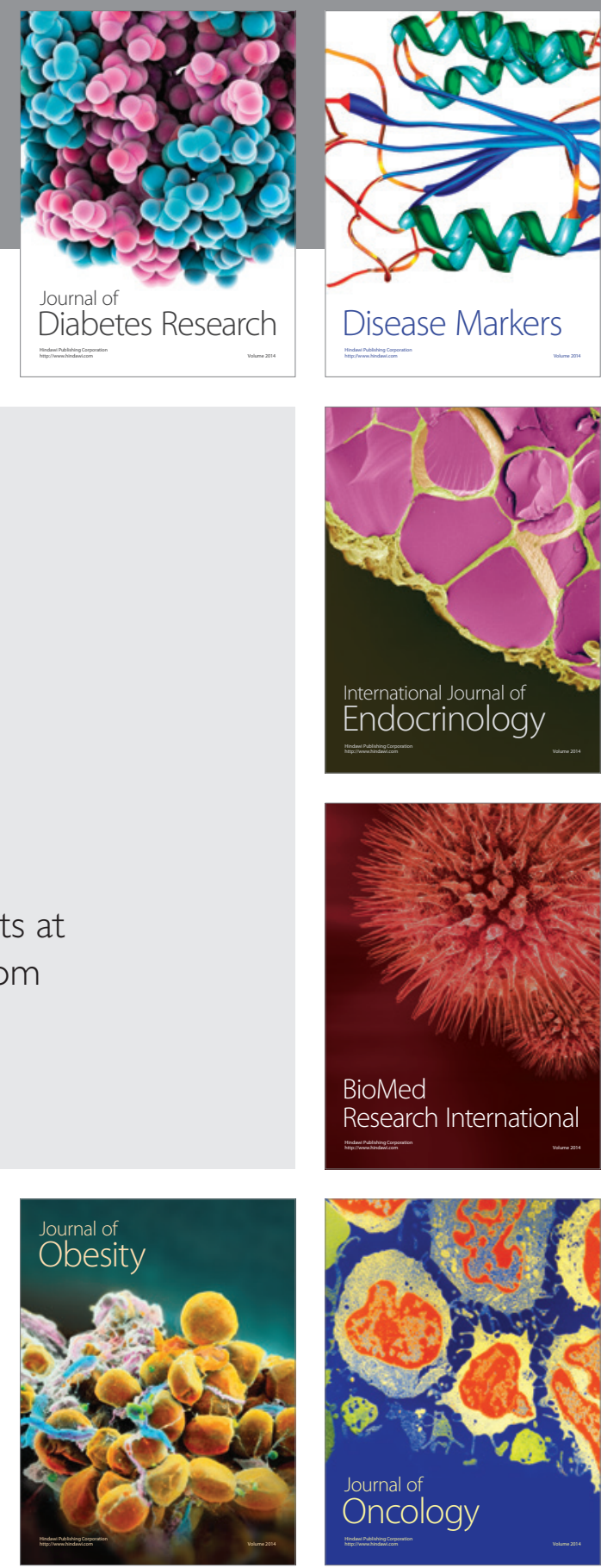

Disease Markers
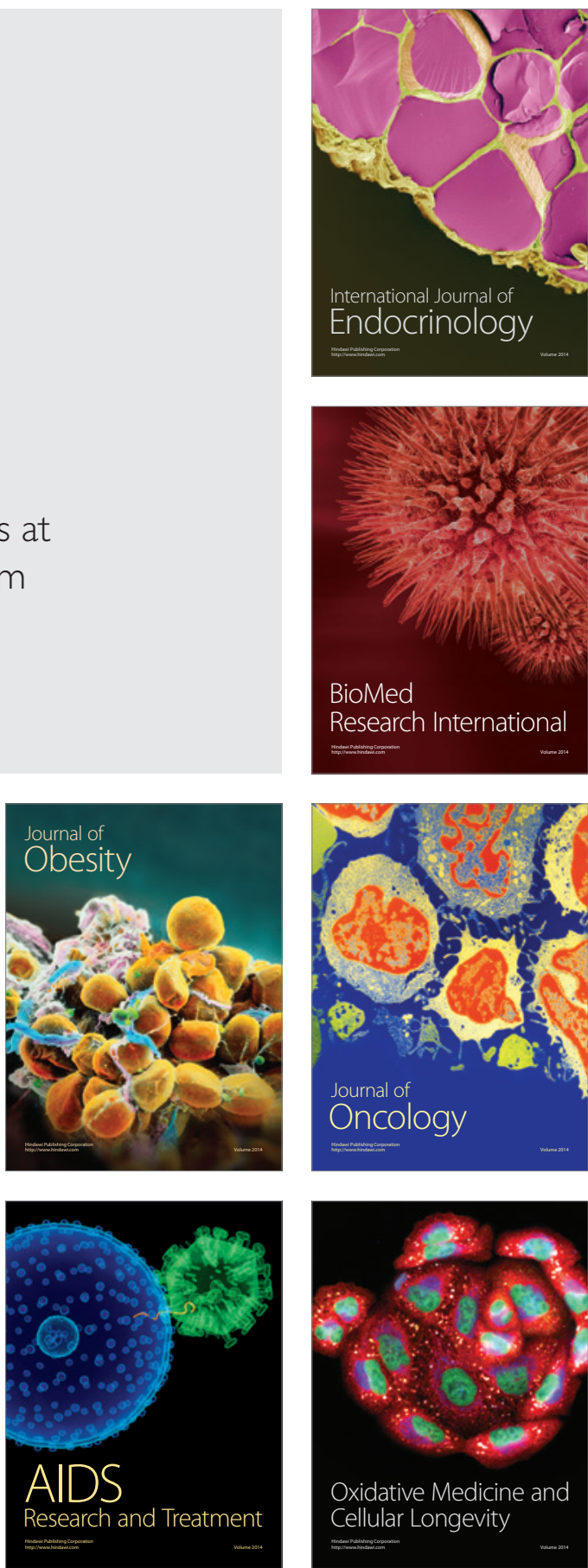